LBNL-51813

\title{
INTERCOMPARISON OF NUMERICAL SIMULATION CODES FOR GeOlogic Disposal of CO2
}

\author{
Karsten Pruess ${ }^{1}$, Julio Garcíal, Tony Kovscek ${ }^{2}$, Curt Oldenburgl, \\ Jonny Rutqvist ${ }^{1}$, Carl Steefel ${ }^{3}$, Tianfu Xu ${ }^{1}$
}

\footnotetext{
${ }^{1}$ Lawrence Berkeley National Laboratory (LBNL), Berkeley, CA 94720, U.S.A.

2 Stanford University, Stanford, CA 94305, U.S.A.

3 Lawrence Livermore National Laboratory (LLNL), Livermore, CA 94550, U.S.A.
}

December 2002

This work was supported as part of the GeoSeq project by the National Energy Technology Laboratory (NETL) of the U.S. Department of Energy under Contract No. DE-AC03-76SF00098. 


\begin{abstract}
Numerical simulation codes were exercised on a suite of eight test problems that address $\mathrm{CO} 2$ disposal into geologic storage reservoirs, including depleted oil and gas reservoirs, and brine aquifers. Processes investigated include single- and multi-phase flow, gas diffusion, partitioning of $\mathrm{CO} 2$ into aqueous and oil phases, chemical interactions of $\mathrm{CO} 2$ with aqueous fluids and rock minerals, and mechanical changes due to changes in fluid pressures. Representation of fluid properties was also examined. In most cases results obtained from different simulation codes were in satisfactory agreement, providing confidence in the ability of current numerical simulation approaches to handle the physical and chemical processes that would be induced by $\mathrm{CO} 2$ disposal in geologic reservoirs. Some discrepancies were also identified and can be traced to differences in fluid property correlations, and space and time discretization.
\end{abstract}




\section{EXECUTIVE SUMMARY}

Mathematical models and numerical simulation codes are playing an important role in evaluating the feasibility of geologic disposal of greenhouse gases, and they will be necessary tools for designing and operating future disposal systems. In order to serve these functions, simulation codes must be tested to demonstrate that they can adequately represent the physical and chemical processes that would be induced by injection of $\mathrm{CO} 2$ and other gases into geologic formations.

The present code intercomparison study aimed at such testing and demonstration. The study was initiated and designed by LBNL in the framework of the GeoSeq project. The overall approach was as follows. In a first step, we designed a number of test problems that would probe major issues relating to geologic disposal of greenhouse gases. Actual field applications will involve threedimensional flows in media with multi-scale hydrologic and chemical heterogeneity, and coupled processes involving fluid dynamics, chemical reactions, mechanical deformation, and thermal effects. It was considered that establishing confidence in the capabilities of numerical simulators would be an iterative process, proceeding from simple to complex. Accordingly, the test problems posed for the present study were intentionally designed to be simplified prototypes of actual field problems.

The main issues addressed in this work are as follows. Do we understand the fundamental physical and chemical processes that would play a role in geologic disposal of greenhouse gases? Do we have valid mathematical models for them? Can currently available numerical simulators obtain reliable and accurate numerical solutions for conditions and parameters of practical interest?

As to the actual execution of the study, the initiators decided that worldwide participation would be sought, and that participants would work with their own funding and using codes available to them. It was hoped that the study would provide a win-win opportunity where all participants could benefit by testing and comparing their codes, learn from one another, and identify areas where additional research and improvements in simulation capabilities would be needed. The initiators of the study could not offer funding support to prospective participants, but were hoping that the potential benefits to be obtained from participation would be sufficient inducement to attract a sizable number of participants.

The approach outlined above was implemented and proved successful. The intercomparison study was started by sending a solicitation to participate to approximately 150 organizations worldwide. Additional solicitation was made at technical conferences, such as the First National Conference on 
Carbon Sequestration which was held in May 2001 in Washington, DC. At that meeting we also presented an overview of the proposed study in hopes of attracting additional participants. A set of eight proposed test problems were posted on the Internet (http://www-esd.lbl.gov/GEOSEQ/). Our efforts resulted in participation of ten research groups from six countries. Communication among participants was done by e-mail and through a workshop that was held in Berkeley in October 2001. The workshop provided a forum for clarifying some of the technical issues in the test problems, presenting and intercomparing first preliminary results, and arriving at a consensus for detailed specifications of the results that were to be submitted.

The proposers of the individual test problems served as coordinators, who handled the collection of results and communication with submitting organizations. The problem coordinators then produced writeups with presentation and intercomparison of results for their respective test problems, which were collated and merged by LBNL into the present final report of the project.

The eight problems posed in the study address processes that would be induced by $\mathrm{CO} 2$ injection into depleted gas reservoirs, saline formations, and oil reservoirs. Before we give brief problem-byproblem summaries of the individual test problems, we first attempt a brief overall summary of outcomes and lessons learned. Important observations are:

1. A considerable number of numerical simulation codes is capable of simulating, in realistic, quantitative detail, the important flow and transport processes that would accompany geologic sequestration.

2. Agreement between results from different groups and different codes ranges from fair to good.

3. All codes attempt to represent fluid properties and thermodynamic data in a realistic fashion, but there are some considerable disagreements between fluid parameters in different codes.

4. Agreement between simulations of fluid flow and transport, and hydromechanical and geochemical effects, ranged from fair to good. Where discrepancies persisted they were usually traced to differences in fluid property descriptions. 
5. The hydro-mechanical test problem was solved by only one code. The interplay of hydrology and geomechanics plays an important role in the integrity of potential geologic disposal sites, and capabilities for modeling such processes need to be strengthened.

6. Code developers should also aim for a more accurate description of fluid properties, including PVT data, as well as transport and caloric properties, using up-to-date experimental data.

7. Although further improvements in fluid property descriptions are important, it is recognized that in actual practice it would be uncertainties in the conceptual model at a given site that would most strongly affect simulation results.

8. The problems investigated here were simplified prototypes of field problems. Further modeling studies should be undertaken on problems that approach the full realism and complexity of actual field problems, to more fully establish the usefulness and credibility of numerical simulation codes for geologic sequestration.

Problems 1 and 2 examined interdiffusion and mixing of $\mathrm{CO} 2$ and $\mathrm{CH} 4$, as affected by highly nonlinear fluid property dependencies on temperature, pressure, and composition. Results were submitted by four groups, using four different simulation codes. Agreement for fluid property estimations ranged from fair to good. Agreement between flow simulations ranged from fair to good also, which is attributed to considerable disagreement in some fluid parameters. Code developers should aim for a more accurate description of fluid properties, including PVT data, as well as transport and caloric properties.

Problems 3 and 4 involve introduction of $\mathrm{CO} 2$ into a single-phase saline formation. Both problems probe similar aspects of thermodynamic and transport properties of brine-CO2 mixtures, including mutual solubility of brine and $\mathrm{CO} 2$. While fluid properties used in different codes are generally in good agreement, within a few percentage points, there are also occasional disagreements in excess of $50 \%$. Problem 3 studies CO2 injection into a saline formation from a vertical well in onedimensional radial flow geometry. This represents the basic prototype of a $\mathrm{CO} 2$ disposal problem. Predictions from different codes for fluid pressures and advancement of the $\mathrm{CO} 2$ injection front generally show satisfactory agreement, with existing differences largely attributable to fluid property data. 
Problem 4 represents a prototype of the basic leakage problem. The problem simulates the extremely non-linear processes whereby $\mathrm{CO} 2$ lost from storage would be migrating up a fault zone. A similar evaluation as for Problem 3 applies, i.e., agreement between different codes is generally satisfactory.

Problem 5 examines chemical interactions between rock minerals and an aqueous phase with high $\mathrm{CO} 2$ partial pressure. There was satisfactory agreement between three different codes in the predictions of mineral dissolution and precipitation, and aqueous phase chemistry.

The hydromechanical Problem 6 was solved by only one group, in spite of considerable efforts on the part of the organizers to attract additional solutions. Few existing codes seem capable of simulating these practically very important processes.

Problem 7 was the most complex of the flow problems, representing a simplified model of the Sleipner Vest CO2 injection site in the Norwegian sector of the North Sea. The problem involves $\mathrm{CO} 2$ injection into a 2-D model of alternating sand-shale layers. Predictions for shape and growth of the $\mathrm{CO} 2$ injection plume showed good agreement between different codes.

Problem 8 addressed $\mathrm{CO} 2$ injection into a multi-component oil reservoir. The flow geometry is very simple, a single 1-D tube, but very complex fluid phase behavior must be accurately represented. Agreements between four participating groups and "exact" results obtained from a semi-analytical solution is from fair to good. In this problem, there is a strong interaction between fluid phase behavior and effects from finite space discretization. Accurate solution requires very fine discretization that may not be practical for 3-D field problems.

Overall it can be stated that numerical simulation capabilities are available now that can describe the complex non-linear processes that would be induced by $\mathrm{CO} 2$ injection into various types of potential disposal reservoirs. In general agreement between different simulators was satisfactory. In the process of the study a number of bugs were identified and remedied in different codes. There is considerable scatter in the representation of fluid properties, such as densities, viscosities, and partitioning of components among phases. This is an area that needs more work and close interplay with experimental data.

Future development and demonstration of simulation codes should be directed towards a more comprehensive description of processes in more realistic settings. It will also be necessary to go beyond "paper problems," and to conduct field tests of proposed disposal schemes. Carefully 
controlled and monitored field experiments integrated with modeling are required on a range of space and time scales, to build a bridge towards practical disposal systems that would generate very large subsurface plumes of $\mathrm{CO} 2$.

This work was supported as part of the GeoSeq project by the National Energy Technology Laboratory (NETL) of the U.S. Department of Energy under Contract No. DE-AC03-76SF00098. 


\section{TABLE OF CONTENTS}

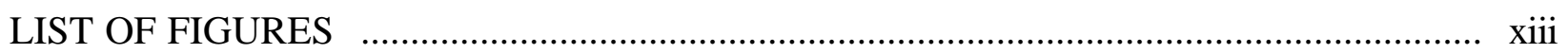

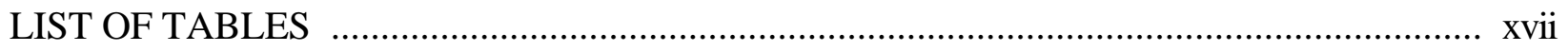

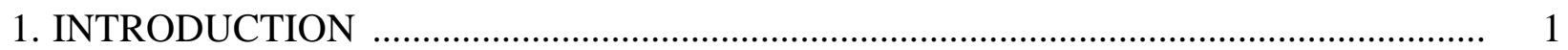

2. CO2 DISPOSAL IN DEPLETED GAS RESERVOIRS ………………………............... 4

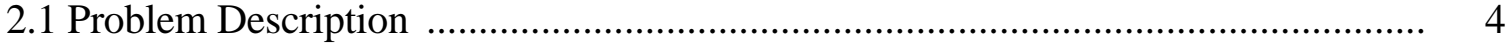

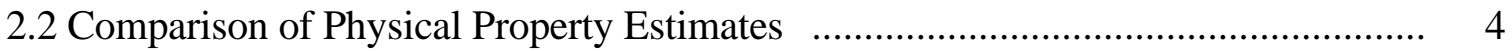

2.3 Results for Problem 1. Mixing of Stably Stratified Gases ........................................ 5

2.4 Results for Problem 2. Advective-Diffusive Mixing due to

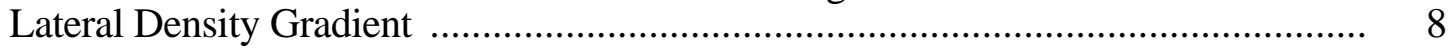

2.5 Discussion and Conclusions ............................................................................ 9

3. PROBLEM 3. RADIAL FLOW FROM A CO2 INJECTION WELL .............................. 10

3.1 Problem Description ........................................................................... 10

3.2 Results Without Salinity ........................................................................... 10

3.3 Results With Salinity $\quad$........................................................................... 18

4. PROBLEM 4. CO2 DISCHARGE ALONG A FAULT ZONE ......................................... 23

4.1 Problem Description .................................................................................. 23

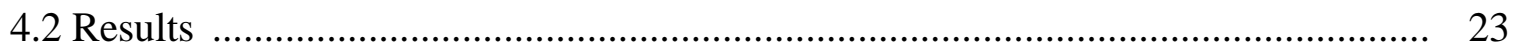

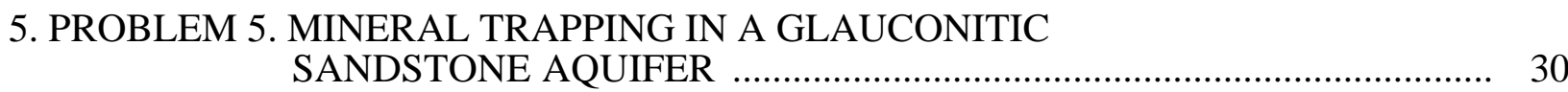

5.1 Problem Description .............................................................................. 30

5.2 Results and Discussion ............................................................................ 32

6. PROBLEM 6. HYDROMECHANICAL RESPONSES DURING CO2 INJECTION INTO AN AQUIFER-CAPROCK SYSTEM ....................... 38

6.1 Problem Description .................................................................................. 38

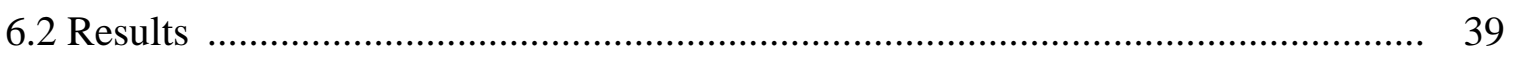

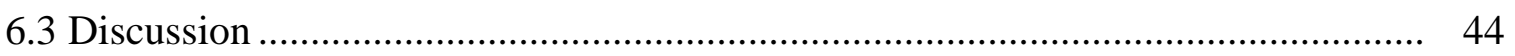

7. PROBLEM 7: CO2 INJECTION INTO A 2-D LAYERED

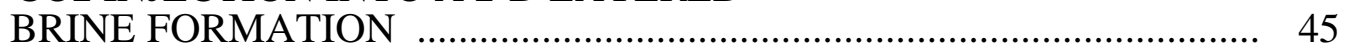

7.1 Introduction and General Description .............................................................. 45

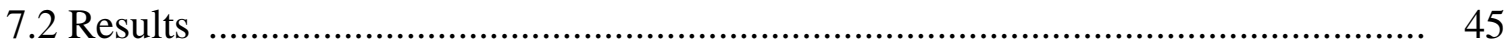

8. PROBLEM 8. CO2-OIL DISPLACEMENT AND PHASE BEHAVIOR …………........... 53

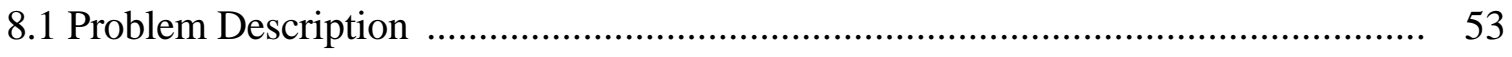


8.2 Results

9. CONCLUDING REMARKS _............................................................................. 59

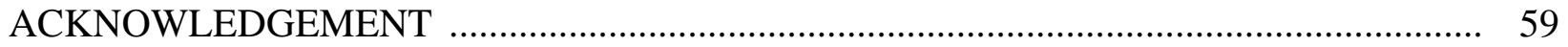

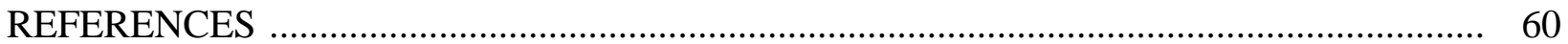

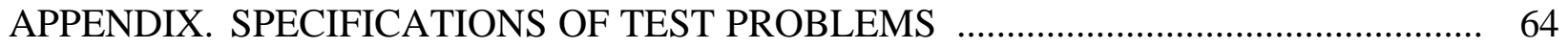

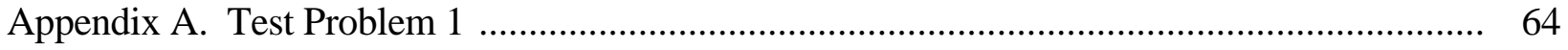

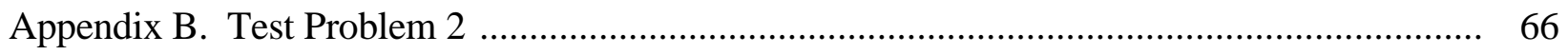

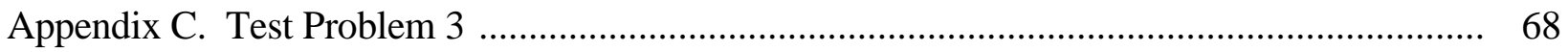

Appendix D. Test Problem 4................................................................................. 70

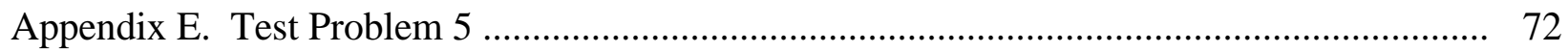

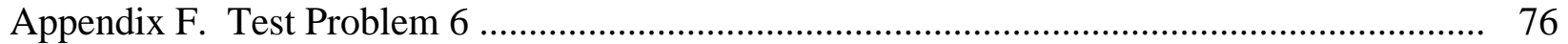

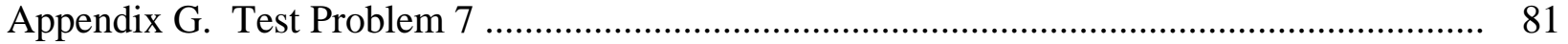

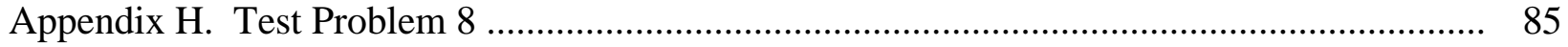




\section{LIST OF FIGURES}

Figure 2.1 Schematic of test problems 1 and 2 ...................................................... 5

Figure 2.2 Mole fraction of $\mathrm{CO} 2$ in gas (a) and pressure (b) as a function of elevation $\mathrm{Z}$ for problem 1 at $\mathrm{t}=0,10$, and 100 yrs ......................................... 7

Figure 2.3 Two-dimensional density field (a) and horizontal profiles of $\mathrm{x}_{\mathrm{g}}{ }^{\mathrm{CO} 2}$

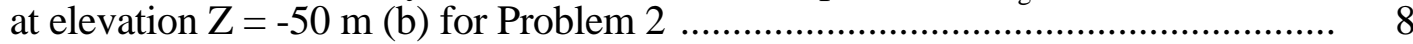

Figure 3.1 Simulated gas saturation front (no salinity, results from LBNL group) .............. 12

Figure 3.2 Simulated pressures as a function of the similarity variable

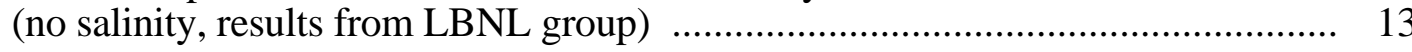

Figure 3.3 Simulated gas saturation as a function of similarity variable (no salinity, results from LBNL group)

Figure 3.4 Simulated dissolved $\mathrm{CO}_{2}$ mass fraction as a function of similarity variable (no salinity, results from LBNL group)

Figure 3.5 Simulated pressures in Problem 3 (no salinity)

Figure 3.6 Simulated gas saturations in Problem 3 (no salinity)

Figure 3.7 Simulated mass fractions of $\mathrm{CO} 2$ dissolved in the aqueous phase in Problem 3 (no salinity)

Figure 3.8 Properties of pure fluids and aqueous phase at $\mathrm{T}=45^{\mathrm{O}} \mathrm{C}$

Figure 3.9 Dissolved CO2 mass fraction in aqueous phase at $\mathrm{T}=45^{\circ} \mathrm{C}$ (no salinity)

Figure 3.10 Simulated pressures in Problem 3 (15 weight \% salinity)

Figure 3.11 Simulated gas saturations in Problem 3 (15 weight \% salinity)

Figure 3.12 Simulated mass fractions of $\mathrm{CO} 2$ dissolved in the aqueous phase in Problem 3 (15 weight \% salinity)

Figure 3.13 Simulated solid saturations in Problem 3 (15 weight \% salinity)

Figure 3.14 Properties of aqueous fluids at $\mathrm{T}=45^{\circ} \mathrm{C}$ (15 weight $\%$ salinity)

Figure 3.15 Dissolved $\mathrm{CO} 2$ mass fraction in aqueous phase at $\mathrm{T}=45^{\circ} \mathrm{C}$ (15 weight \% salinity)

Figure 4.1 Schematic of the fault zone model (a) and applied boundary conditions (b)

Figure 4.2 Gas saturations for $\mathrm{CO} 2$ migrating up a fault zone at times of $10^{7}$ seconds (top) and $2 \times 10^{7}$ seconds (bottom) 
Figure 4.3 Mass fractions of CO2 dissolved in the liquid (aqueous) phase at times of $10^{7}$ seconds (top) and $2 \times 10^{7}$ seconds (bottom)

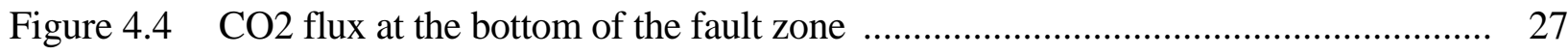

Figure $4.5 \quad \mathrm{CO} 2$ flux at the top of the fault zone ..................................................... 28

Figure 4.6 Water flux at the top of the fault zone .................................................... 28

Figure 5.1 $\mathrm{pH}$ evolution in glauconitic sandstone with $\mathrm{CO}_{2}$ injected at 260 bar $\ldots \ldots \ldots \ldots \ldots \ldots . . . . . . .32$

Figure 5.2 Evolution of aqueous oxygen concentration ................................................. 33

Figure 5.3 Cumulative $\mathrm{CO}_{2}$ sequestration in glauconitic sandstone

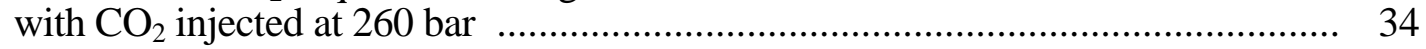

Figure 5.4 Evolution of mineral abundances in glauconitic sandstone

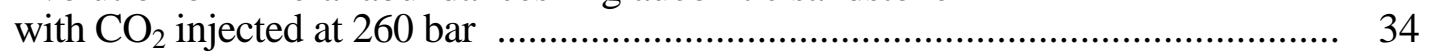

Figure 6.1 One-dimensional model of Test Problem 6 in a general three-dimensional aquifer-caprock system ......................................................................... 38

Figure 6.2 Calculated fluid pressure using the TOUGH-FLAC simulator .......................... 40

Figure 6.3 Calculated effective mean stress using the TOUGH-FLAC simulator ................. 41

Figure 6.4 Calculated CO2 mass flux through the upper part of the caprock (1200 meters)

Figure 6.5 Calculated CO2 gas saturation at various times during 30-year injection of $\mathrm{CO} 2$

Figure 6.6 Calculated CO2 gas saturation after 30 and 100 years

Figure 6.7 Calculated $\mathrm{CO} 2$ gas saturation at 30 years for a pure hydraulic calculation $(\mathrm{H})$ and a coupled hydromechanical (HM) calculation

Figure 6.8 Calculated permeability profile at various times

Figure 7.1 Supercritical $\mathrm{CO}_{2}$ phase saturation as a function of time in Problem 7 ............... 46

Figure 7.2 Pressure distribution after two years of $\mathrm{CO}_{2}$ injection ................................. 47

Figure 7.3 Time histories of total $\mathrm{CO}_{2}$ for the various sands within the formation .............. 48

Figure 7.4 Vertical profiles of $\mathrm{CO}_{2}$ phase saturation at a horizontal distance of 10 meters from the injection well

Figure 7.5 Pressure distributions at a horizontal distance of 10 meters from the injection well

Figure 7.6 Vertical profiles of $\mathrm{CO}_{2}$ phase saturations after 1 year of injection at various horizontal distances from the injection well 
Figure 7.7 Vertical profiles of $\mathrm{CO}_{2}$ phase saturations after 2 years of injection at various horizontal distances from the injection well

Figure 7.8 Density and viscosity of the supercritical $\mathrm{CO}_{2}$ phase at $37^{\circ} \mathrm{C}$ as a function of pressure used by the various codes applied to Problem 7

Figure 8.1 Comparison of simulation results at $11 \mathrm{MPa}$, case (1) .................................... 56

Figure 8.2 Comparison of simulation results at $12 \mathrm{MPa}$, case (2) ...................................... 57

Figure 8.3 Solution route in composition space. Analytical solution (broken line) and FD 100 simulation results .................................................................... 58

Figure D.1 Schematic of the fault zone model (a) and applied boundary conditions (b) ......... 70

Figure F.1 Geometry of vertical column for hydromechanical test problem ……................... 78

Figure G.1 Schematic representation of geometry for $\mathrm{CO} 2$ injection in Utsira Formation ....... 82 


\section{LIST OF TABLES}

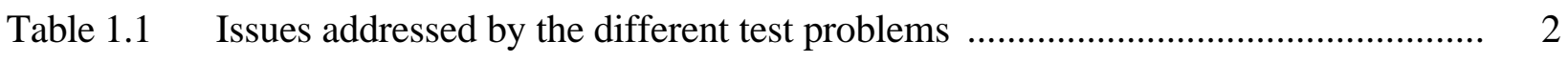

Table 2.1 Properties of $\mathrm{CO}_{2}-\mathrm{CH}_{4}$ gas mixtures and aqueous solubility

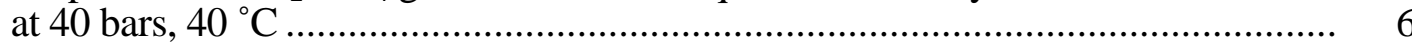

Table 2.2 Properties of $\mathrm{CO}_{2}-\mathrm{CH}_{4}$ gas mixtures and aqueous solubility at 100 bars, $40{ }^{\circ} \mathrm{C}$

Table $3.1 \quad$ Reported Results ............................................................................. 11

Table 4.1 Simulated CO2 inventories (metric tonnes) per $1 \mathrm{~m}$ thickness of the fault zone in gas and liquid phases after $10^{7}$ and $2 \times 10^{7}$ seconds

Table 7.1 Comparison of $\mathrm{CO}_{2}$ mass balances (in units of $\mathrm{kg}$ ) and "sequestration efficiency" after 2 years of injection

Table C.1 Hydrogeologic parameters

Table C.2 Initial conditions and injection specifications

Table E.1 List of initial mineral volume fractions, potential secondary mineral phases, and their kinetic properties

Table F.1 Rock properties .............................................................................. 79

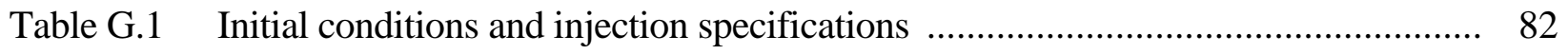

Table G.2 Hydrogeologic parameters …............................................................ 84 
xviii 


\section{Introduction}

Geologic sequestration of $\mathrm{CO} 2$ can be accomplished by separating $\mathrm{CO} 2$ from flue gases and subsequently injecting it into a variety of storage reservoirs, including brine aquifers, producing or depleted oil and gas reservoirs, and coalbeds. Injection of greenhouse gases into such formations will give rise to complex coupled processes of fluid flow, mechanical and chemical changes, and heat transfer. Mathematical models and numerical simulation tools will play an important role in evaluating the feasibility of $\mathrm{CO} 2$ storage in subsurface reservoirs, in designing and analyzing field tests, and in designing and operating geologic $\mathrm{CO} 2$ disposal systems. In order to establish credibility for numerical simulators as practical engineering tools, it is necessary to demonstrate that they can model accurately and reliably the important physical and chemical processes that are induced by injection of $\mathrm{CO} 2$ into potential disposal reservoirs. This can be accomplished by running simulators on a series of test problems that engage the processes, fluid properties, and geologic features of interest. Code intercomparison studies have been successfully used as a means for establishing confidence in simulation tools in related technical fields such as petroleum engineering (Firoozabadi and Thomas, 1989) and geothermal reservoir engineering (Stanford, 1980), and in nuclear waste management (Larsson, 1992; Chapman et al., 1994; Jing et al., 1995; Stephansson et al., 1996).

Depending on the storage reservoir of interest and the composition of the waste gas stream (pure $\mathrm{CO} 2$ vs. mixtures of $\mathrm{CO} 2$ with other gases), injection of $\mathrm{CO} 2$ in geologic formations may give rise to a number of physical and chemical phenomena, such as miscible or immiscible displacement of native fluids, dissolution of injected fluids into reservoir fluids, changes in effective stress with associated porosity and permeability change and the possibility of inducing seismic activity, chemical interactions between fluids and solids, and nonisothermal effects. Key issues arising in process simulation include (1) thermodynamics of sub- and supercritical CO2, and PVT properties of mixtures of $\mathrm{CO} 2$ with other fluids, including (saline) water, oil, and natural gas; (2) fluid mechanics of single and multi-phase flow when $\mathrm{CO} 2$ is injected into aquifers, oil reservoirs, and natural gas reservoirs; (3) coupled hydro-chemical effects due to interactions between $\mathrm{CO} 2$, reservoir fluids, and primary mineral assemblages; and (4) coupled hydro-mechanical effects, such as porosity and permeability change due to increased fluid pressures from $\mathrm{CO} 2$ injection. Additional topics that need to be addressed include space and time discretization and their impacts on the solution of the underlying mathematical model, and the dependence of processes and parameters on space and time scale.

We report here on the results of a code intercomparison study whose purpose was to evaluate key processes in $\mathrm{CO} 2$ geologic disposal and to test the capabilities of numerical simulators 
to model these processes. The present study was initiated and coordinated by Lawrence Berkeley National Laboratory (Pruess et al., 2000, 2001). It was decided to include only brine formation, oil, and gas reservoir problems, for which well-developed simulation capabilities are available. Coalbed methane simulators are the subject of a separate study (Law et al., 2002). A set of eight simulation problems was adopted. The issues addressed by these problems are summarized in Table 1.1. Detailed problem specifications are given in the appendix; they include formation properties, initial and boundary conditions, and sinks and sources. (The appendices are reproduced essentially unchanged from the original report, Pruess et al., 2000, except that some typographical errors were corrected and references updated.) No prescriptions were given for fluid properties to be used, nor were there any specifications of space discretization (gridding) and time stepping. The choice of

Table 1.1 Issues addressed by the different test problems

\begin{tabular}{|l|c|c|c|c|c|}
\hline $\begin{array}{c}\text { property/process } \\
\text { storage reservoir }\end{array}$ & PVT data & fluid flow & $\begin{array}{c}\text { transport } \\
\text { (diffusion, } \\
\text { dispersion) }\end{array}$ & $\begin{array}{c}\text { chemical } \\
\text { reactions }\end{array}$ & $\begin{array}{c}\text { mechanical } \\
\text { couplings }\end{array}$ \\
\hline \hline brine aquifer & $3,4,7$ & $3,4,6,7$ & & 5 & 6 \\
\hline oil & 8 & 8 & 8 & & \\
\hline gas & 1,2 & 1,2 & 1,2 & & \\
\hline coalbed & & & & & \\
\hline
\end{tabular}

these parameters was left to the participants, and was to be evaluated as part of the intercomparison of simulation results. The test problems studied and reported here should be considered an initial set specifically designed to address basic processes in different potential disposal reservoirs. Accordingly, problem specifications were kept relatively simple. Most problems are for 1-D homogeneous media, although a heterogeneous 2-D problem was included also. Problems with more complex and realistic features, such as 3-D heterogeneous flows systems, will be addressed in future studies.

Participation in the code intercomparison study was solicited through mailings, personal contacts, and the Internet (http://www-esd.lbl.gov/GEOSEQ/code/index.html). All participants worked with their own funding, and used codes available to them. Participants were free to choose any subset of problems they wanted to tackle. Reporting requirements had been included as part of the original problem specifications (see appendix), and were further refined during a two-day workshop that was held at the Lawrence Berkeley National Laboratory in October, 2001. The proposers of each of the test problems served as coordinators and communicated with the various participating groups in obtaining and collating results. 
Results were submitted by ten groups from six countries, as follows.

- Lawrence Berkeley National Laboratory (LBNL), U.S.A., using the TOUGH2/ECO2, TOUGHREACT and TOUGH-FLAC codes;

- University of Stuttgart, Germany, using the MUFTE_UG code;

- CSIRO Petroleum, Australia, using an in-house version of TOUGH2/ECO2;

- Institut Français du Pétrole (IFP), France, using the SIMUSCOPP code;

- Stanford University, U.S.A., using an unnamed research code;

- Alberta Research Council (ARC), Canada, using the GEM code of the Computer Modeling Group (CMG) of Calgary, Alberta;

- Los Alamos National Laboratory (LANL), U.S.A., using the FLOTRAN and ECLIPSE 300 codes;

- Lawrence Livermore National Laboratory (LLNL), U.S.A., using the NUFT code;

- Industrial Research Limited (IRL), New Zealand, using an in-house version of TOUGH2 and the CHEM-TOUGH code;

- $\quad$ Pacific Northwest National Laboratory (PNNL), U.S.A., using the STOMP code.

We now proceed through a problem-by-problem presentation and discussion of results, that had previously only been summarized in abbreviated form (Pruess et al., 2002). In the presentation we include those data that most clearly highlight areas of agreement as well as disagreement between different codes. A separate report is available with a more detailed presentation of the results obtained by LBNL for the saline aquifer flow problems (\#3, 4, and 7; Pruess and García, 2002b). A stand-alone report on the gas reservoir problems is presented in Oldenburg et al. (2002). 


\section{CO2 Disposal in Depleted Gas Reservoirs ${ }^{1}$}

The main processes of interest for $\mathrm{CO} 2$ storage in gas reservoirs are advection of a gas phase consisting of $\mathrm{CO} 2$ and $\mathrm{CH} 4$, interdiffusion of these two components, and gas dissolution in residual liquid. This section presents two gas flow problems that examine the interplay of these processes, accompanied by strong real gas effects during mixing.

Four numerical simulation codes have been used for physical property estimation and the test problems. These are as follows: CHEMTOUGH, developed by Industrial Research Limited, New Zealand, a geochemical modeling extension of TOUGH2 (Pruess et al., 1999); GEM, a reservoir simulator developed by Computer Modelling Group (CMG), Canada; SIMUSCOPP, a reservoir simulator developed by Institut Français du Pétrole (IFP), France; and TOUGH2/EOS7C, a special gas module for the TOUGH2 reservoir simulator (Pruess et al., 1999) developed by Lawrence Berkeley National Laboratory (LBNL), USA. Each of these codes uses its own methods for calculating physical properties of gas mixtures. Only CHEMTOUGH and TOUGH2/EOS7C share a common heritage and thus calculate flow and transport by the same methods.

\subsection{Problem Description}

The results of reservoir simulation are strongly dependent on the real gas properties of the gas mixtures. The first part of this study involved comparison of densities, viscosities, and solubilities from different simulators for the pure end-member gases $\left(\mathrm{CO}_{2}\right.$ and $\left.\mathrm{CH}_{4}\right)$ and $50 \%$ mole fraction mixtures. Two test problems were defined that engage key processes involved in $\mathrm{CO}_{2}-\mathrm{CH}_{4}$ mixing (Figure 2.1). Problem 1 considers the mixing by molecular diffusion and advection of a stably stratified one-dimensional column $100 \mathrm{~m}$ in height with the light gas $\left(\mathrm{CH}_{4}\right)$ on the top and the heavy gas $\left(\mathrm{CO}_{2}\right)$ on the bottom. Mixing around the interface is mostly by molecular diffusion, although nonzero permeability allows minor advection to occur as gas pressures increase upon mixing at the interface. Problem 2 considers the mixing by advection and diffusion of gases initially side by side in a vertical $100 \mathrm{~m}$ x $100 \mathrm{~m}$ reservoir. Gravity effects cause the dense $\mathrm{CO}_{2}$ gas to flow downward while the lighter $\mathrm{CH}_{4}$ migrates upward.

\subsection{Comparison of Physical Property Estimates}

To the extent that physical properties strongly affect flow and transport, the first comparison we present is for density $(\rho)$, viscosity $(\mu)$, and solubility of $\mathrm{CO}_{2}$ and $\mathrm{CH}_{4}$ gas mixtures. Carbon dioxide undergoes large changes in density and viscosity as it passes through the critical region. The critical pressure and temperature of $\mathrm{CO}_{2}\left(73.8\right.$ bars, $\left.31.0{ }^{\circ} \mathrm{C}\right)$ will be reached in the subsurface

${ }^{1}$ proposed by Curt Oldenburg; e-mail: CMOldenburg@lbl.gov 
at depths greater than approximately $800 \mathrm{~m}$. Thus $\mathrm{CO}_{2}$ will most commonly be supercritical in the subsurface. Therefore, we present estimates of physical properties at both subcritical (40 bars) and supercritical (100 bars) conditions. For brevity, we present in Tables 2.1 and 2.2 physical properties only for the end members and 50-50 mixtures. We have included reference values either from published data or from more detailed estimation methods as noted.

Test Problem 1

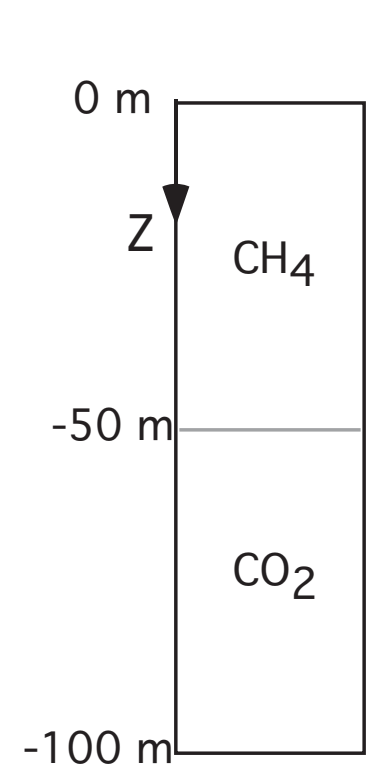

Test Problem 2

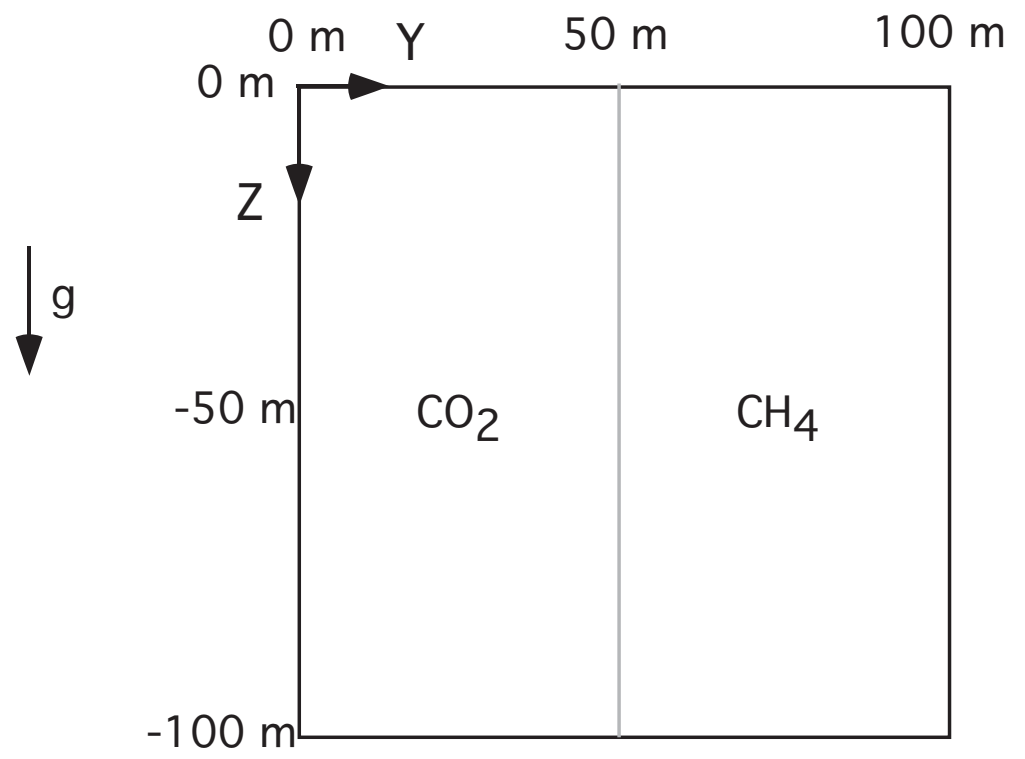

Initial Conditions

Pressure at top of domain 40 bars Temperature $40{ }^{\circ} \mathrm{C}$

0.1

1.0

1. $\mathrm{x} 10^{-7} \mathrm{~m}^{2} \mathrm{~s}^{-1}$

0.1

0. (immobile) $\mathrm{x}_{\mathrm{g}} \mathrm{CO} 2$ left half of domain 1 . $\mathrm{x}_{\mathrm{g}} \mathrm{CH} 4$ right half of domain 1 .

Residual liquid saturation

Relative permeability of liquid

Relative permeability of gas $\left(\mathrm{k}_{\mathrm{rg}}\right)$

Boundary Conditions

All boundaries are closed.

Figure 2.1 Schematic of test problems 1 and 2.

\subsection{Results for Problem 1. Mixing of Stably Stratified Gases}

In this problem, $\mathrm{CO}_{2}$ and $\mathrm{CH}_{4}$ gases are placed in contact one on top of the other and allowed to mix as controlled by diffusion and associated flow at 40 bars, $40{ }^{\circ} \mathrm{C}$. Mixing in the onedimensional system is limited because the denser gas $\left(\mathrm{CO}_{2}\right)$ is on the bottom and the lighter gas $\left(\mathrm{CH}_{4}\right)$ is on the top. The domain, properties, boundary and initial conditions are shown in Figure 2.1. All of the boundaries are closed and the problem is considered isothermal. Although the 
problem is dominated by diffusion, small advective fluxes arise as diffusive mixing around the interface leads to density changes that affect gas pressure.

The results of Problem 1 are shown in Figure 2.2a by the gas mole fraction of $\mathrm{CO}_{2}\left(\mathrm{x}_{\mathrm{g}}{ }^{\mathrm{CO} 2}\right)$, where $\mathrm{x}_{\mathrm{g}}{ }^{\mathrm{CH} 4}=1-\mathrm{x}_{\mathrm{g}}{ }^{\mathrm{CO} 2}$ in this binary system. As shown in Figure 2.2a, the fundamental process of binary diffusive mixing is captured by all of the codes, with slight differences in diffusion rate. Note in Figure 2.2b that the pressure in the system increases, a result of the mixing between $\mathrm{CO}_{2}$ and $\mathrm{CH}_{4}$. In direct relation to the overestimate of pure $\mathrm{CO}_{2}$ density and the underestimate of gas mixture density by CHEMTOUGH (see Table 2.1), this code predicts larger pressure increases than any of the other codes. Variations in the results are likely due mostly to differences in physical property estimates rather than to differences in modeling of the physical process of molecular diffusion and advection.

Table 2.1 Properties of $\mathrm{CO}_{2}-\mathrm{CH}_{4}$ gas mixtures and aqueous solubility at 40 bars, $40{ }^{\circ} \mathrm{C}$.

\begin{tabular}{|l|l|l|l|l|l|l|}
\hline & \multicolumn{5}{|c|}{ gas phase } & \multicolumn{2}{c|}{ aqueous phase } \\
\hline Simulation Code & $\mathrm{x}_{\mathrm{g}}^{\mathrm{CH}}$ & $\mathrm{x}_{\mathrm{g}}^{\mathrm{CO}}$ & $\rho\left(\mathrm{kg} \mathrm{m}^{-3}\right)$ & $\mu(\mathrm{Pa} \mathrm{s})$ & $\mathrm{x}_{1}{ }^{\mathrm{CH} 4}$ & $\mathrm{x}_{1}{ }^{\mathrm{CO} 2}$ \\
\hline \hline CHEMTOUGH & 0. & 1. & 105.39 & $1.49 \times 10^{-5}$ & 0. & $1.64 \times 10^{-2}$ \\
GEM & 0. & 1. & 85.41 & $1.75 \times 10^{-5}$ & 0. & $1.50 \times 10^{-2}$ \\
SIMUSCOPP & 0. & 1. & 85.35 & $1.02 \times 10^{-5}$ & 0. & $1.24 \times 10^{-2}$ \\
TOUGH2/EOS7C & 0. & 1. & 85.45 & $1.70 \times 10^{-5}$ & 0. & $1.62 \times 10^{-2}$ \\
\hline Reference Values & 0. & 1. & $83.79(\mathrm{a})$ & $1.73 \times 10^{-5}(\mathrm{a})$ & 0. & $1.37 \times 10^{-2}(\mathrm{~b})$ \\
\hline CHEMTOUGH & 0.5 & 0.5 & 46.88 & $1.34 \times 10^{-5}$ & $4.08 \times 10^{-4}$ & $7.45 \times 10^{-3}$ \\
GEM & 0.5 & 0.5 & 52.26 & $1.53 \times 10^{-5}$ & $3.82 \times 10^{-4}$ & $7.64 \times 10^{-3}$ \\
SIMUSCOPP & 0.5 & 0.5 & 52.29 & $1.11 \times 10^{-5}$ & $3.90 \times 10^{-4}$ & $6.20 \times 10^{-3}$ \\
TOUGH2/EOS7C & 0.5 & 0.5 & 51.97 & $1.44 \times 10^{-5}$ & $3.73 \times 10^{-4}$ & $8.07 \times 10^{-3}$ \\
\hline Reference Values & 0.5 & 0.5 & $51.33(\mathrm{a})$ & $1.67 \times 10^{-5}(\mathrm{a})$ & $3.66 \times 10^{-4}$ & $6.74 \times 10^{-3}$ \\
& & & & & $(\mathrm{c}, \mathrm{d}, \mathrm{e}, \mathrm{f})$ & $(\mathrm{c}, \mathrm{d}, \mathrm{e}, \mathrm{f})$ \\
\hline CHEMTOUGH & 1. & 0. & 24.58 & $1.16 \times 10^{-5}$ & $7.49 \times 10^{-4}$ & 0. \\
GEM & 1. & 0. & 26.48 & $1.22 \times 10^{-5}$ & $7.51 \times 10^{-4}$ & 0. \\
SIMUSCOPP & 1. & 0. & 26.46 & $1.26 \times 10^{-5}$ & $7.81 \times 10^{-4}$ & 0. \\
TOUGH2/EOS7C & 1. & 0. & 26.42 & $1.21 \times 10^{-5}$ & $7.43 \times 10^{-4}$ & 0. \\
\hline Reference Values & 1. & 0. & $26.10(\mathrm{a})$ & $1.23 \times 10^{-5}(\mathrm{a})$ & $7.22 \times 10^{-4}$ & 0. \\
& & & & & $(\mathrm{c}, \mathrm{d}, \mathrm{e}, \mathrm{f})$ & \\
\hline
\end{tabular}

(a) NIST, 1992.

(d) Johnson et al., 1992. (b) Wiebe and Gaddy, 1940.

(e) Shock et al., 1989. (c) Spycher and Reed, 1988.

(f) Wagman et al., 1982. 
Table 2.2 Properties of $\mathrm{CO}_{2}-\mathrm{CH}_{4}$ gas mixtures and aqueous solubility at 100 bars, $40{ }^{\circ} \mathrm{C}$.

\begin{tabular}{|l|l|l|l|l|l|l|}
\hline & \multicolumn{5}{|c|}{ gas phase } & \multicolumn{2}{c|}{ aqueous phase } \\
\hline Simulation Code & $\mathrm{x}_{\mathrm{g}}{ }^{\mathrm{CH}}$ & $\mathrm{x}_{\mathrm{g}}{ }^{\mathrm{CO} 2}$ & $\rho\left(\mathrm{kg} \mathrm{m}^{-3}\right)$ & $\mu(\mathrm{Pa} \mathrm{s})$ & $\mathrm{x}_{1}{ }^{\mathrm{CH} 4}$ & $\mathrm{x}_{1}{ }^{\mathrm{CO} 2}$ \\
\hline \hline CHEMTOUGH & 0. & 1. & 432.33 & $2.88 \times 10^{-5}$ & 0. & $4.09 \times 10^{-2}$ \\
GEM & 0. & 1. & 564.82 & $4.35 \times 10^{-5}$ & 0. & $2.39 \times 10^{-2}$ \\
SIMUSCOPP & 0. & 1. & 561.44 & $3.59 \times 10^{-5}$ & 0. & $2.30 \times 10^{-2}$ \\
TOUGH2/EOS7C & 0. & 1. & 566.00 & $4.35 \times 10^{-5}$ & 0. & $4.03 \times 10^{-2}$ \\
\hline Reference Values & 0. & 1. & $631.90(\mathrm{a})$ & $5.04 \times 10^{-5}(\mathrm{a})$ & 0. & $2.19 \times 10^{-2}(\mathrm{~b})$ \\
\hline CHEMTOUGH & 0.5 & 0.5 & 130.58 & $1.41 \times 10^{-5}$ & $1.14 \times 10^{-3}$ & $1.61 \times 10^{-2}$ \\
GEM & 0.5 & 0.5 & 158.10 & $1.88 \times 10^{-5}$ & $8.27 \times 10^{-4}$ & $1.33 \times 10^{-2}$ \\
SIMUSCOPP & 0.5 & 0.5 & 158.44 & $1.46 \times 10^{-5}$ & $9.08 \times 10^{-4}$ & $1.15 \times 10^{-2}$ \\
TOUGH2/EOS7C & 0.5 & 0.5 & 155.16 & $1.81 \times 10^{-5}$ & $9.43 \times 10^{-4}$ & $2.00 \times 10^{-2}$ \\
\hline Reference Values & 0.5 & 0.5 & 153.97 (a) & $1.94 \times 10^{-5}(\mathrm{a})$ & $7.95 \times 10^{-4}$ & $1.21 \times 10^{-2}$ \\
& & & & & $(\mathrm{c}, \mathrm{d}, \mathrm{e}, \mathrm{f})$ & $(\mathrm{c}, \mathrm{e}, \mathrm{f})$ \\
\hline CHEMTOUGH & 1. & 0. & 61.45 & $1.16 \times 10^{-5}$ & $1.87 \times 10^{-3}$ & 0. \\
GEM & 1. & 0. & 71.78 & $1.39 \times 10^{-5}$ & $1.58 \times 10^{-3}$ & 0. \\
SIMUSCOPP & 1. & 0. & 71.66 & $1.43 \times 10^{-5}$ & $1.82 \times 10^{-3}$ & 0. \\
TOUGH2/EOS7C & 1. & 0. & 71.57 & $1.41 \times 10^{-5}$ & $1.86 \times 10^{-3}$ & 0. \\
\hline Reference Values & 1. & 0. & 70.03 (a) & $1.41 \times 10^{-5}(\mathrm{a})$ & $1.54 \times 10^{-3}$ & 0. \\
& & & & & $(\mathrm{c}, \mathrm{d}, \mathrm{e}, \mathrm{f})$ & \\
\hline
\end{tabular}

(a) NIST, 1992.

(d) Johnson et al., 1992. (b) Wiebe and Gaddy, 1940.

(e) Shock et al., 1989. (c) Spycher and Reed, 1988.

(f) Wagman et al., 1982.
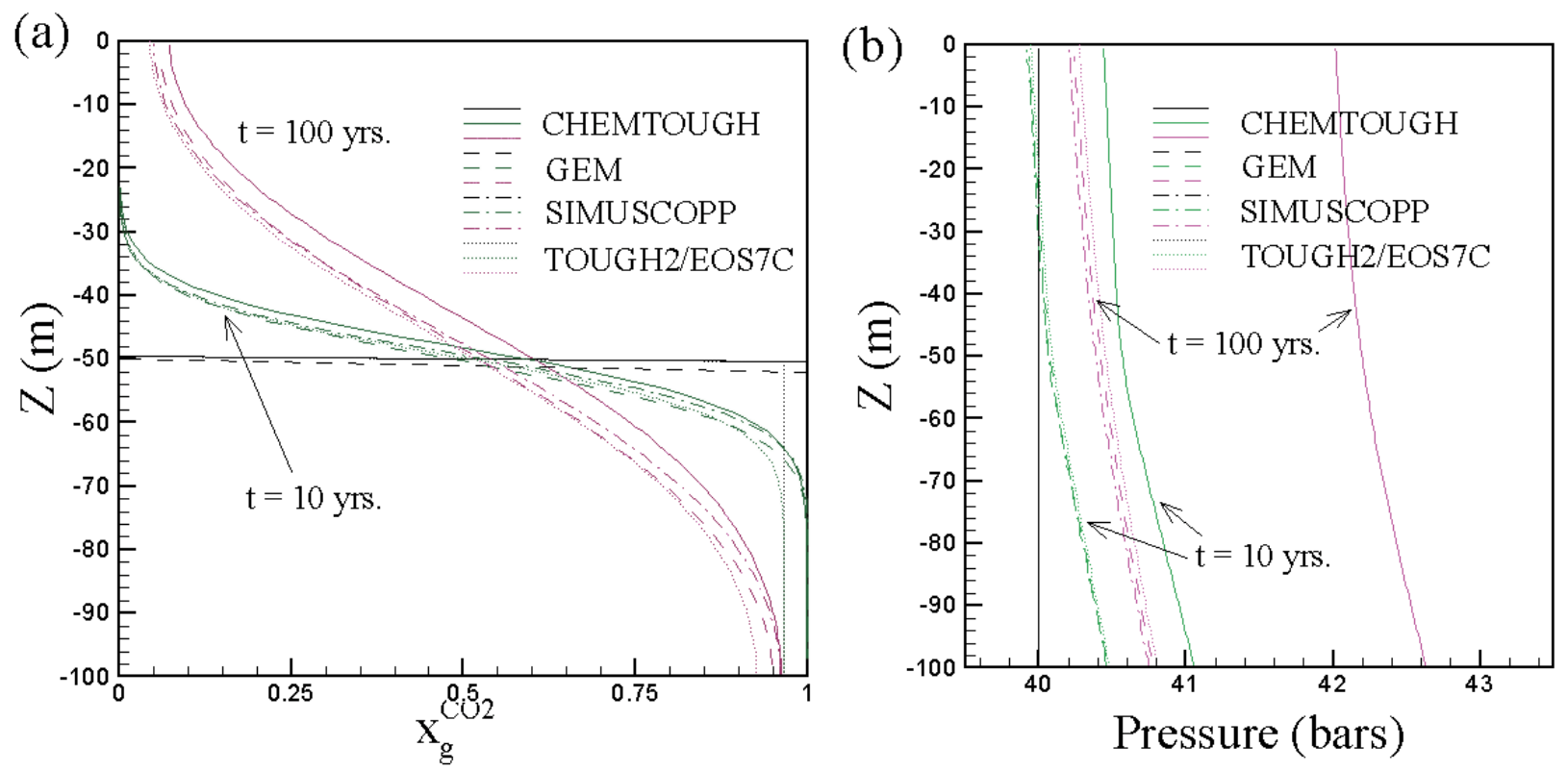

Figure 2.2 Mole fraction of $\mathrm{CO} 2$ in gas (a) and pressure (b) as a function of elevation $\mathrm{Z}$ for problem 1 at $\mathrm{t}=0,10$, and $100 \mathrm{yrs}$. 


\subsection{Results for Problem 2. Advective-Diffusive Mixing due to Lateral Density Gradient}

In this problem, $\mathrm{CO}_{2}$ and $\mathrm{CH}_{4}$ gases are placed side-by-side and allowed to mix. The strong lateral density gradient between the dense $\mathrm{CO}_{2}$ gas and the relatively light $\mathrm{CH}_{4}$ gas causes a strong density-driven flow where $\mathrm{CO}_{2}$ tends to move downward and $\mathrm{CH}_{4}$ tends to move upward to the top of the reservoir. Problem specifications and domain schematic are presented in Figure 2.1. An example of the computed results at $\mathrm{t}=1 \mathrm{yr}$ is shown in Figure 2.3a by the density field as computed by GEM. Comparison of results is presented in Figure 2.3b as horizontal profiles of mole fraction of $\mathrm{CO}_{2}$ in the gas at two different times. As shown in Figure 2.3b, variations in results between the four codes are more pronounced than for Problem 1, showing that larger differences can be expected for cases of more complex flow and transport. It should be noted, however, that concentrations along the profile at $\mathrm{Z}=-50 \mathrm{~m}$ are very sensitive to small variations in the simulation at late times since the interface between the gases is located in this region, and the profile effectively follows this interface.
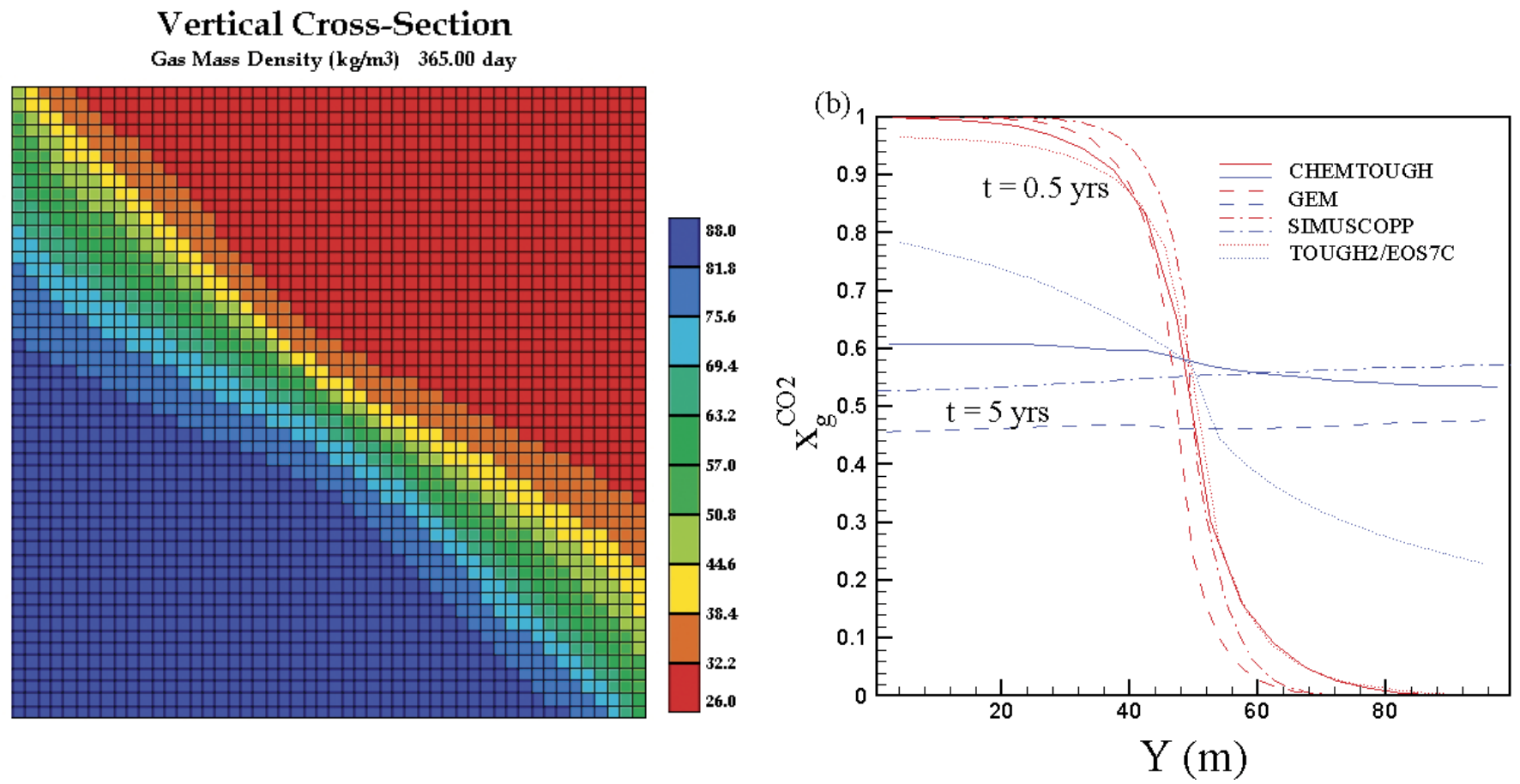

Figure 2.3 Two-dimensional density field (a) and horizontal profiles of $\mathrm{x}_{\mathrm{g}}{ }^{\mathrm{CO} 2}$ at elevation $\mathrm{Z}=-50 \mathrm{~m}$ (b) for Problem 2. 


\subsection{Discussion and Conclusions}

Physical property estimates and simulation results for the mixing of $\mathrm{CO}_{2}$ and $\mathrm{CH}_{4}$ gases show fair to good agreement. Overall, the four simulation codes model the general processes of molecular diffusion and density-driven flow and advective mixing similarly, although results differ in details. This comparison has brought to light differences in physical property estimates to which differences in simulated results are likely attributable. While process description and problem setup are subjective since they are influenced by the experience and approach of the analyst, physical properties are objective and relatively well known. Code developers should endeavor to make physical property estimates more accurate. Nevertheless, in the actual practice of numerical simulation of subsurface processes, the largest differences between simulation results will likely be due to the conceptual models used, including assumptions about reservoir heterogeneity, as opposed to the algorithmic details of codes or physical property estimates. 


\section{Test Problem 3. Radial Flow from a CO2 Injection Well ${ }^{2}$}

\subsection{Problem Description}

This is a basic $\mathrm{CO} 2$ injection problem that addresses two-phase flow of $\mathrm{CO} 2$ and water for simplified flow geometry and medium properties. The aquifer into which injection is made is assumed infinite-acting, homogeneous, and isotropic. Gravity and inertial effects are neglected, injection is made at a constant rate, and flow is assumed 1-D radial (line source). The list of processes studied includes:

- Two-phase flow of $\mathrm{CO} 2$ and water subject to relative permeability and capillary effects.

- Change of fluid density, viscosity, and $\mathrm{CO} 2$ solubility with pressure and salinity.

- Formation dry-out with precipitation of salt.

Problem specifications are given in Appendix $\mathrm{C}$ and in the original intercomparison report (Pruess et al., 2000). Variations are limited to two cases, namely, with and without salinity. During the CO2 Code Comparison Workshop held at Lawrence Berkeley National Laboratory in October, 2001, five groups presented preliminary results (LBNL, LANL, IFP, IRL, and CSIRO). At the workshop, reporting requirements were altered from the original specifications and were agreed upon as follows. "Results are to be given for pressure, gas saturation, dissolved CO2 mass (or mole) fraction, and "solid saturation" (fraction of pore volume containing solid precipitate). The problem as posed is known to have a similarity solution, with all parameters depending on radial distance $R$ and time tonly through the similarity variable $\xi=R^{2} / t$. Results can be given either as radial profiles at a fixed time, or as time series at a fixed radial distance. It is preferred that both kinds of results should be submitted, to allow checking on the similarity property. It is desired that results should be provided for such a range of times and distances that the similarity variable covers the range $10^{-8} \mathrm{~m}^{2} / \mathrm{s} \leq \xi \leq 10^{1} \mathrm{~m}^{2} / \mathrm{s}$. In addition, fluid property data should be given at $T=$ $45^{\circ} \mathrm{C}$ for pressures $P=120,160,200$, and 240 bar, for aqueous phase salinities of 0 and 15 weight-\%, and for phase conditions of (a) single-phase aqueous, $(b)$ two-phase aqueous-gas. The fluid property data should include densities and viscosities of aqueous and gas phases, and $\mathrm{CO}_{2}$ mass (or mole) fractions in the aqueous phase."

\subsection{Results Without Salinity}

This report includes results from LBNL, CSIRO, IFP, IRL, ARC ${ }^{3}$ and PNNL. A brief overview of the submitted results and simulation codes used is provided in Table 3.1. All results

\footnotetext{
2 proposed by Karsten Pruess; e-mail: K_Pruess@lbl.gov

3 David Law of ARC wishes to acknowledge help from Peter Sammon and Mohamed Hassam with the GEM simulations.
} 
were reported according to the requirements specified during the 2001 code comparison workshop at LBNL.

Table 3.1 Reported Results

\begin{tabular}{|c|c|c|}
\hline GROUP & CODE & Comments and Observations 1 \\
\hline $\mathrm{LBNL}^{\mathrm{a}}$ & $\begin{array}{l}\text { TOUGH2- } \\
\text { ECO2 }\end{array}$ & $\begin{array}{l}\text { Preliminary version of Module ECO2 (Pruess and García, } \\
\text { 2002a, b; Pruess et al. 1999) } \\
\text { Density of liquid phase according to García (2001) } \\
\text { Solubility includes fugacity correction and Poynting effect }\end{array}$ \\
\hline $\mathrm{CSIRO}^{\mathrm{a}}$ & $\begin{array}{l}\text { modified } \\
\text { TOUGH2 }\end{array}$ & $\begin{array}{l}\mathrm{CO} 2 \text { module modified from an early version of } \mathrm{ECO} 2 \\
\text { Span and Wagner's (1996) equation of state for } \mathrm{CO}_{2} \\
\text { Solubility includes fugacity correction and Poynting effect }\end{array}$ \\
\hline $\mathrm{IFP}^{\mathrm{a}}$ & SIMUSCOPP & $\begin{array}{l}\text { No salt precipitation and no dry-out modeled } \\
\text { Water viscosity function of temperature and salinity only } \\
\text { Gas properties are defined using Peng-Robinson EOS } \\
\text { Soreide \& Whitson (1992) EOS equilibrium constants for } \\
\text { CO2-H2O }\end{array}$ \\
\hline $\mathrm{IRL}^{\mathrm{b}}$ & $\begin{array}{l}\text { modified } \\
\text { TOUGH2 }\end{array}$ & Solubility includes fugacity correction and Poynting effect \\
\hline $\mathrm{ARC}^{\mathrm{b}}$ & GEM & GEM is a general-purpose compositional simulator \\
\hline $\mathrm{PNNL}^{\mathrm{a}}$ & STOMP & \\
\hline
\end{tabular}

1 Based on personal communication via email

a Results with and without salinity

$\mathrm{b}^{\mathrm{b}}$ Results without salinity only

Figure 3.1 shows the evolution of the gas saturation front for times of up to 10,000 days (LBNL results). An important advantage of this radial flow problem is that it admits a similarity solution, even when taking into account all the non-linearities due to PVT properties and two-phase flow (O'Sullivan, 1981; Doughty and Pruess, 1992). The space discretization employed for finite difference simulation will violate the rigorous $\mathrm{R}^{2} / \mathrm{t}$ invariance, so that the similarity property will be maintained only approximately. Accuracy of the numerical simulation can be checked by plotting the results as a function of the similarity variable $\mathrm{R}^{2} / \mathrm{t}$. Figure 3.2 shows the results for pressure as a function of the similarity variable. Simulated results are presented at four different times $(t=30$, 
$100,1000,10000$ days) and two fixed locations ( $\mathrm{R}=25.25,1011 \mathrm{~m})$. The agreement is good, confirming the similarity property of the numerical solution. Figures 3.3 and 3.4 show simulated results for gas saturation and dissolved $\mathrm{CO} 2$ mass fraction plotted as a function of the similarity variable. Gas saturation results show three distinct regions emerging from the $\mathrm{CO} 2$ injection process. The first region, $\mathrm{R}^{2} / \mathrm{t} \leq 5 \times 10^{-7} \mathrm{~m}^{2} / \mathrm{s}$, corresponds to a zone where complete dry-out of the aqueous phase has occurred. This region is followed by an intermediate region extending to $\mathrm{R}^{2} / \mathrm{t} \approx$ $10^{-2} \mathrm{~m}^{2} / \mathrm{s}$, where liquid and gas phases coexist. Finally, in the outer region with $\mathrm{R}^{2} / \mathrm{t}>10^{-2} \mathrm{~m}^{2} / \mathrm{s}$ single-phase liquid conditions prevail.

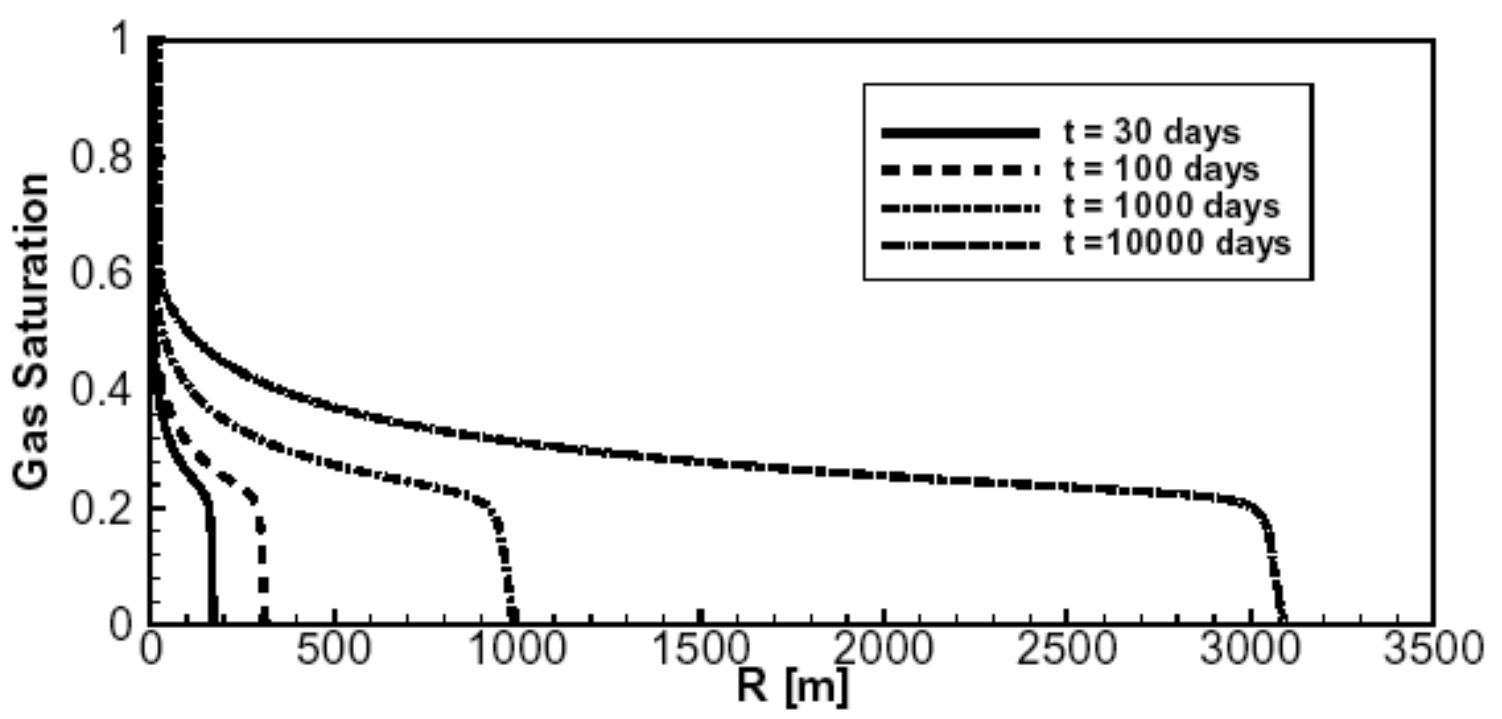

Figure 3.1 Simulated gas saturation front (no salinity, results from LBNL group). 


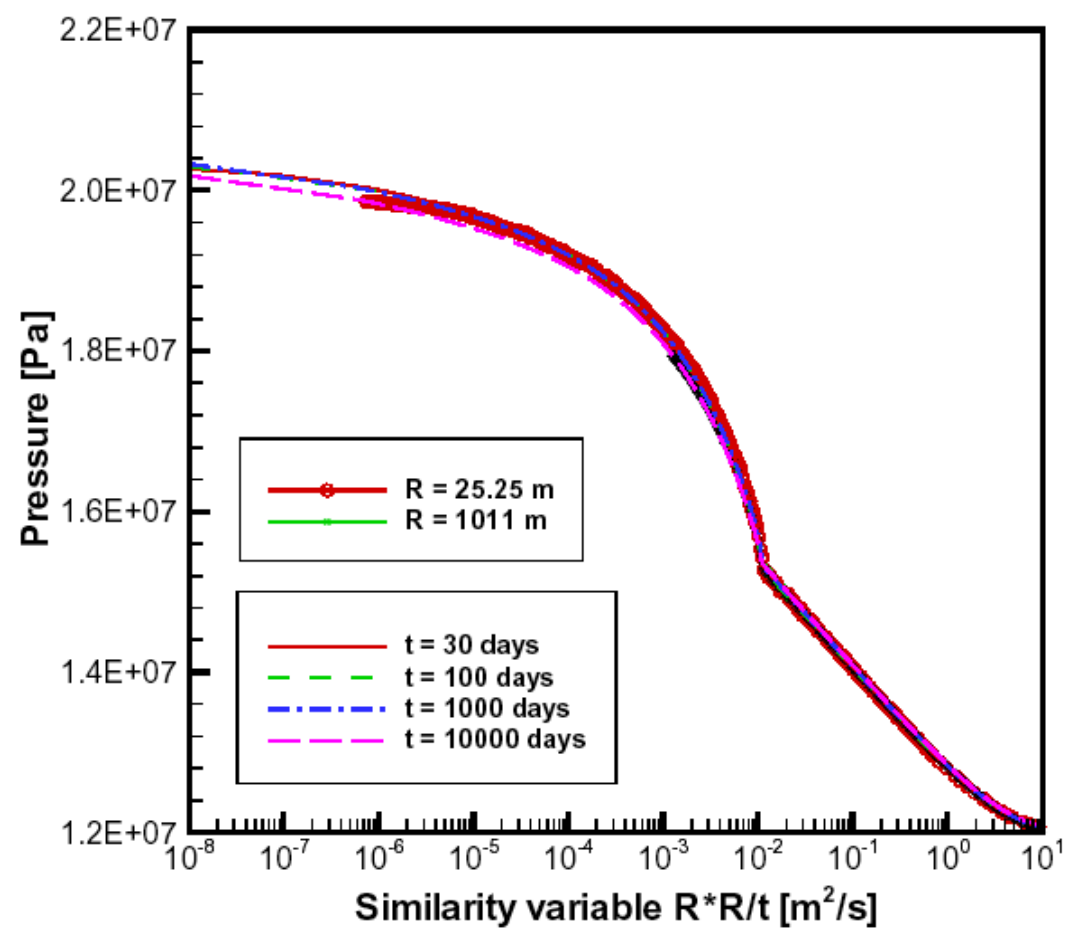

Figure 3.2 Simulated pressures as a function of the similarity variable (no salinity, results from LBNL group).

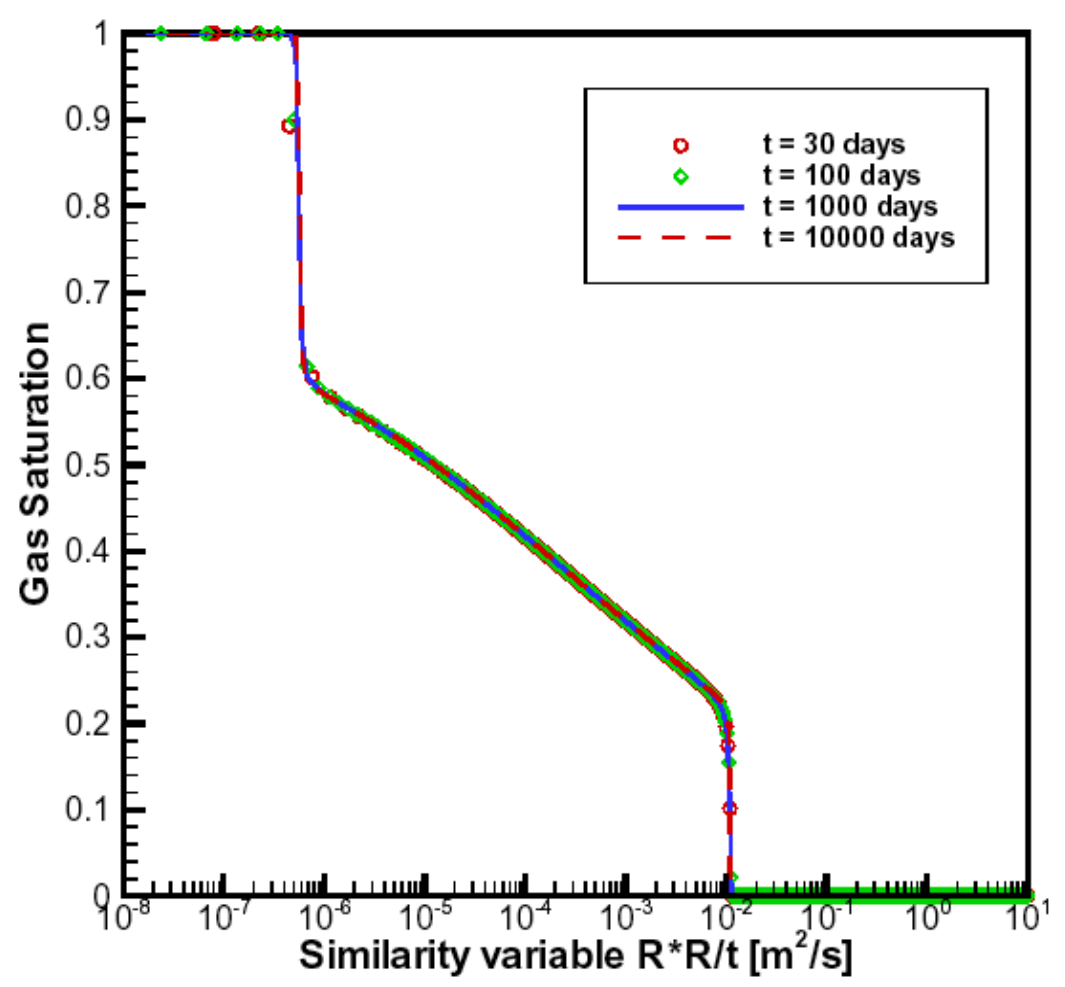

Figure 3.3. Simulated gas saturation as a function of similarity variable (no salinity, results from LBNL group). 


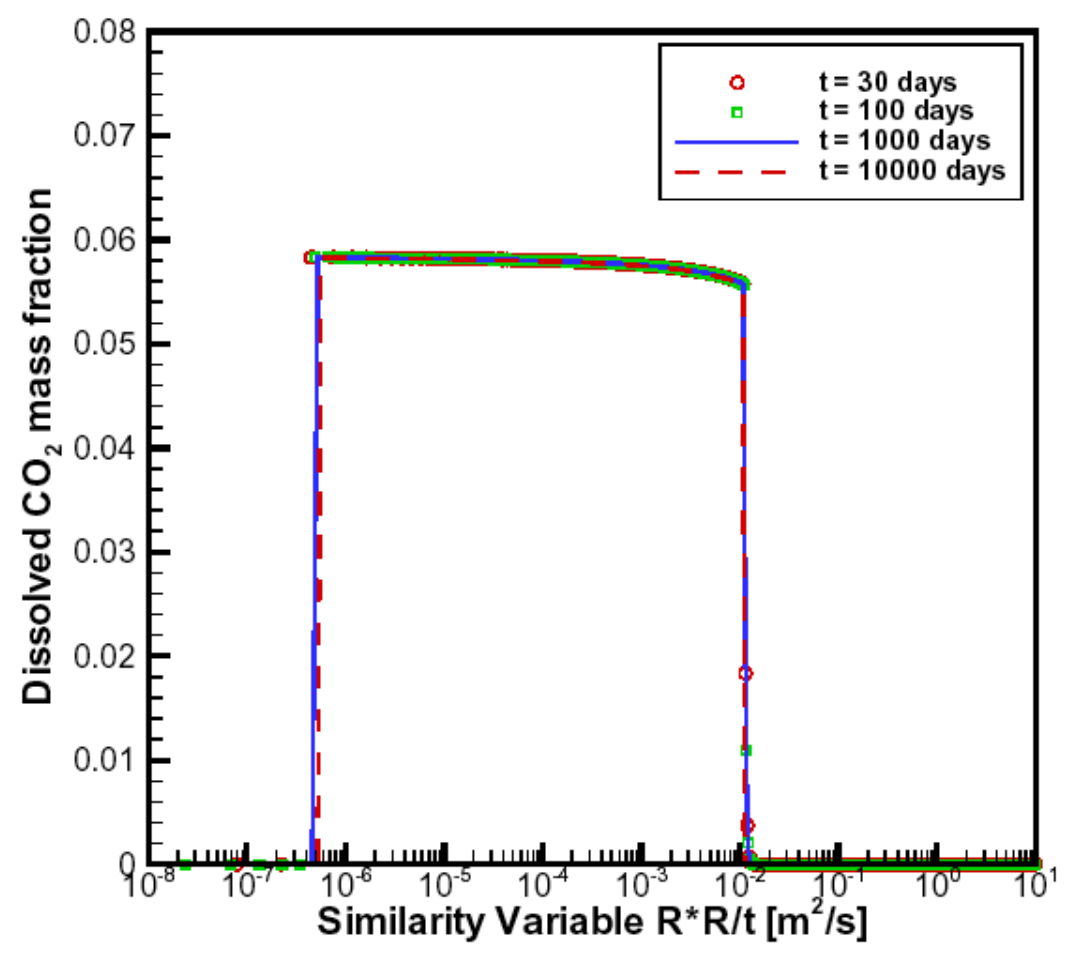

Figure 3.4 Simulated dissolved $\mathrm{CO}_{2}$ mass fraction as a function of similarity variable (no salinity, results from LBNL group).

LBNL, CSIRO and IRL provided results for radial profiles at fixed time(s) and time series at fixed radial distance(s). IFP, ARC and PNNL reported results only for radial profiles. For all groups, a similarity check was performed by plotting the results for different times or locations as a function of the similarity variable. Among the different groups, IFP was the only one showing small deviations from the similarity property for the pressure profile. IFP results for gas saturation and dissolved $\mathrm{CO} 2$ mass fraction showed that the similarity property was well preserved. A possible explanation for the behavior of pressure is that pressure is more sensitive to grid discretization and boundary effects (IFP, Yann le Gallo, personal communication).

In order to perform the comparison between the codes we selected a profile from each group and plotted them together in a single graph. Pressure results from different groups are shown in Figure 3.5; the agreement is satisfactory. Results for $\mathrm{CO} 2$ gas saturations in Fig. 3.6 expose some differences, especially near the well $\left(\mathrm{R}^{2} / \mathrm{t} \leq 5 \times 10^{-6} \mathrm{~m}^{2} / \mathrm{s}\right)$, since not all models can treat formation dry-out. The codes agree in placing the transition from two-phase to single-phase liquid conditions at the same location, $\mathrm{R}^{2} / \mathrm{t} \approx 10^{-2} \mathrm{~m}^{2} / \mathrm{s}$. The logarithmic scale for the similarity variable makes differences in gas saturations appear more significant than they are. Note that the region $R^{2} / t$ $\leq 10^{-6} \mathrm{~m}^{2} / \mathrm{s}$ with largest differences represents at most $(\mathrm{t}=10,000$ days $)$ the first 30 meters. 


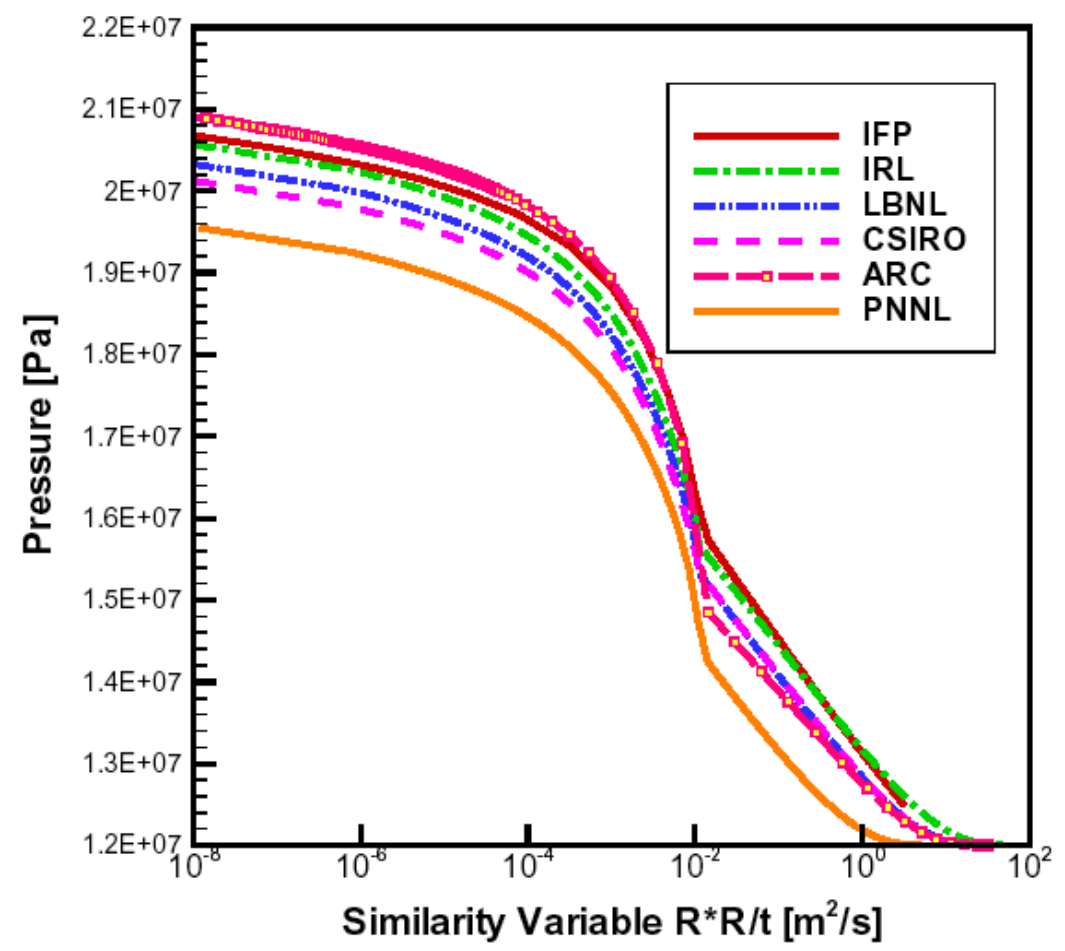

Figure 3.5 Simulated pressures in Problem 3 (no salinity).

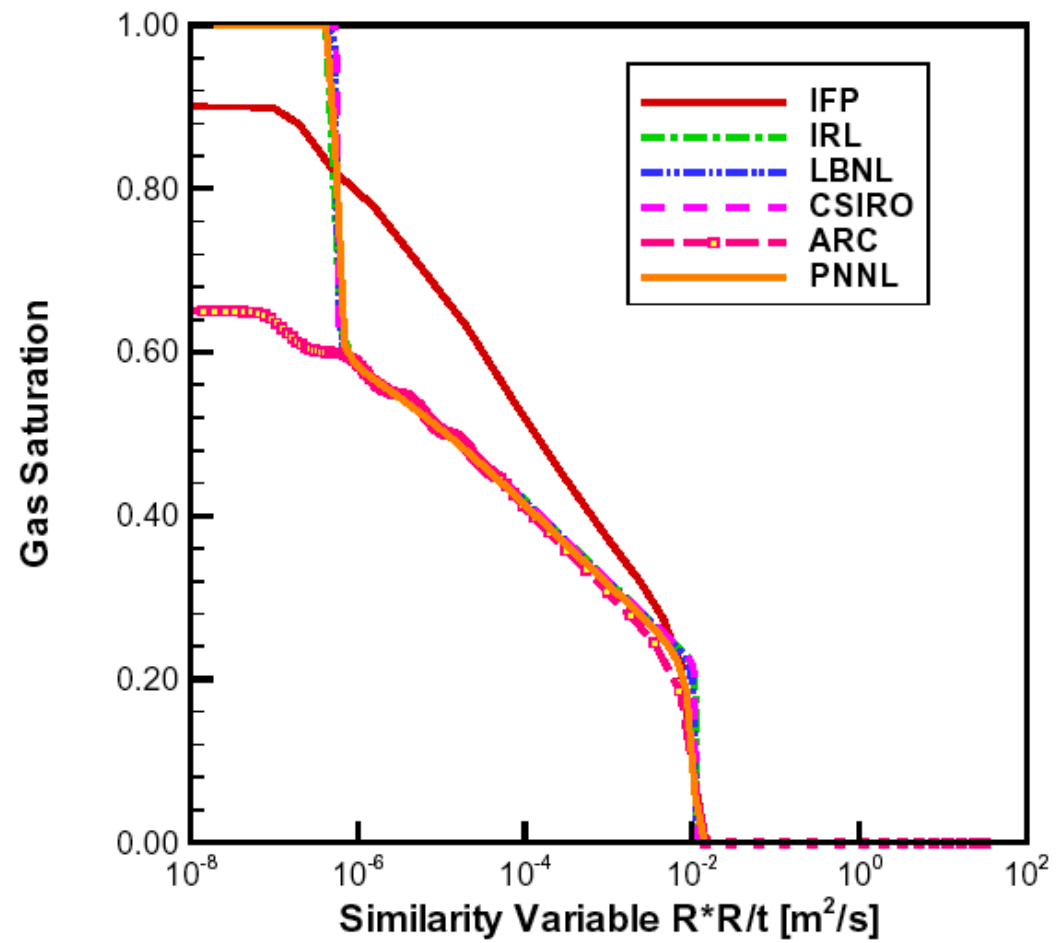

Figure 3.6 Simulated gas saturations in Problem 3 (no salinity). 
Figure 3.7 shows that dissolved CO2 mass fractions span a range of values between 0.044 to 0.066 , reflecting differences in solubility formulations between the codes.

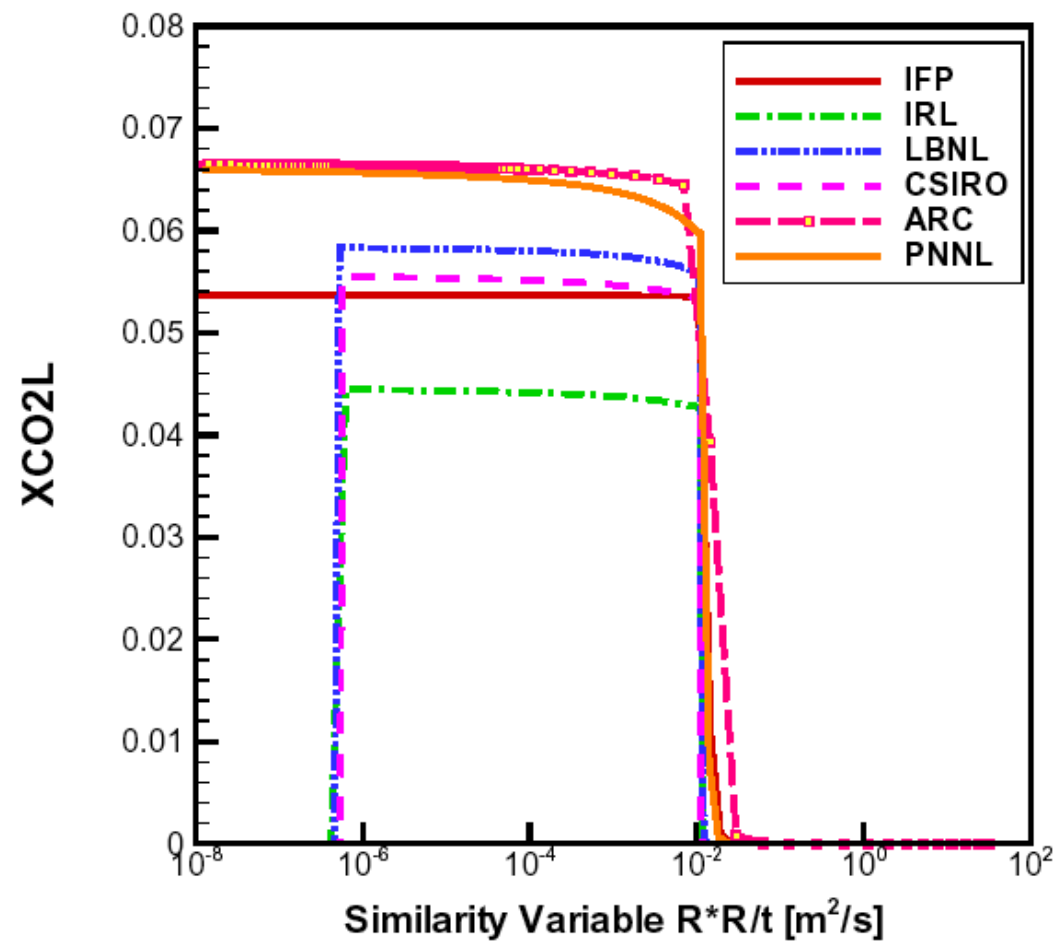

Figure 3.7 Simulated mass fractions of $\mathrm{CO} 2$ dissolved in the aqueous phase in Problem 3 (no salinity).

Reported fluid properties as used in the simulations by different groups for the case without salinity are shown in Figures 3.8 and 3.9. Fluid property data are given at $\mathrm{T}=45^{\circ} \mathrm{C}$ for pressures of $\mathrm{P}=120,160,200$, and 240 bar. Some significant differences are apparent, with high and low values differing by about $1.8 \%$ for water density, $3.5 \%$ for density of water with dissolved CO2, $10.9 \%$ for $\mathrm{CO} 2$ density, $0.7 \%$ for water viscosity, $6.6 \%$ for viscosity of aqueous solutions of $\mathrm{CO} 2$, and as much as $33 \%$ for $\mathrm{CO} 2$ viscosity, and $52 \%$ for $\mathrm{CO} 2$ solubility. No details on PVT correlations or solubility models used were provided by the individual groups. It is recommended that the code developers check their property correlations against experimental data and improve on inaccuracies that may be present. 

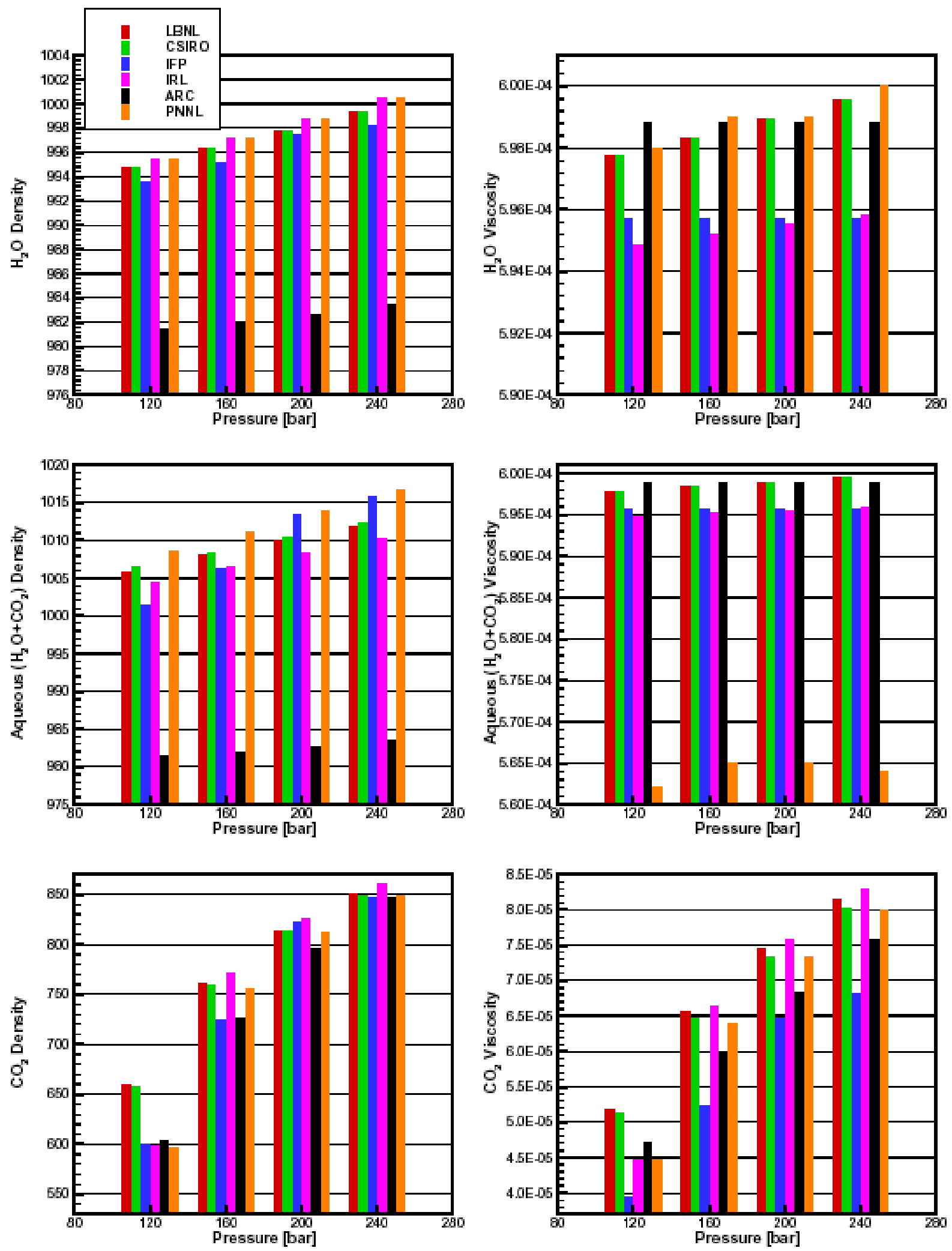

Figure 3.8 Properties of pure fluids and aqueous phase at $\mathrm{T}=45^{\circ} \mathrm{C}$ (no salinity; the bars are arranged from left to right in the same order as in the legend). 


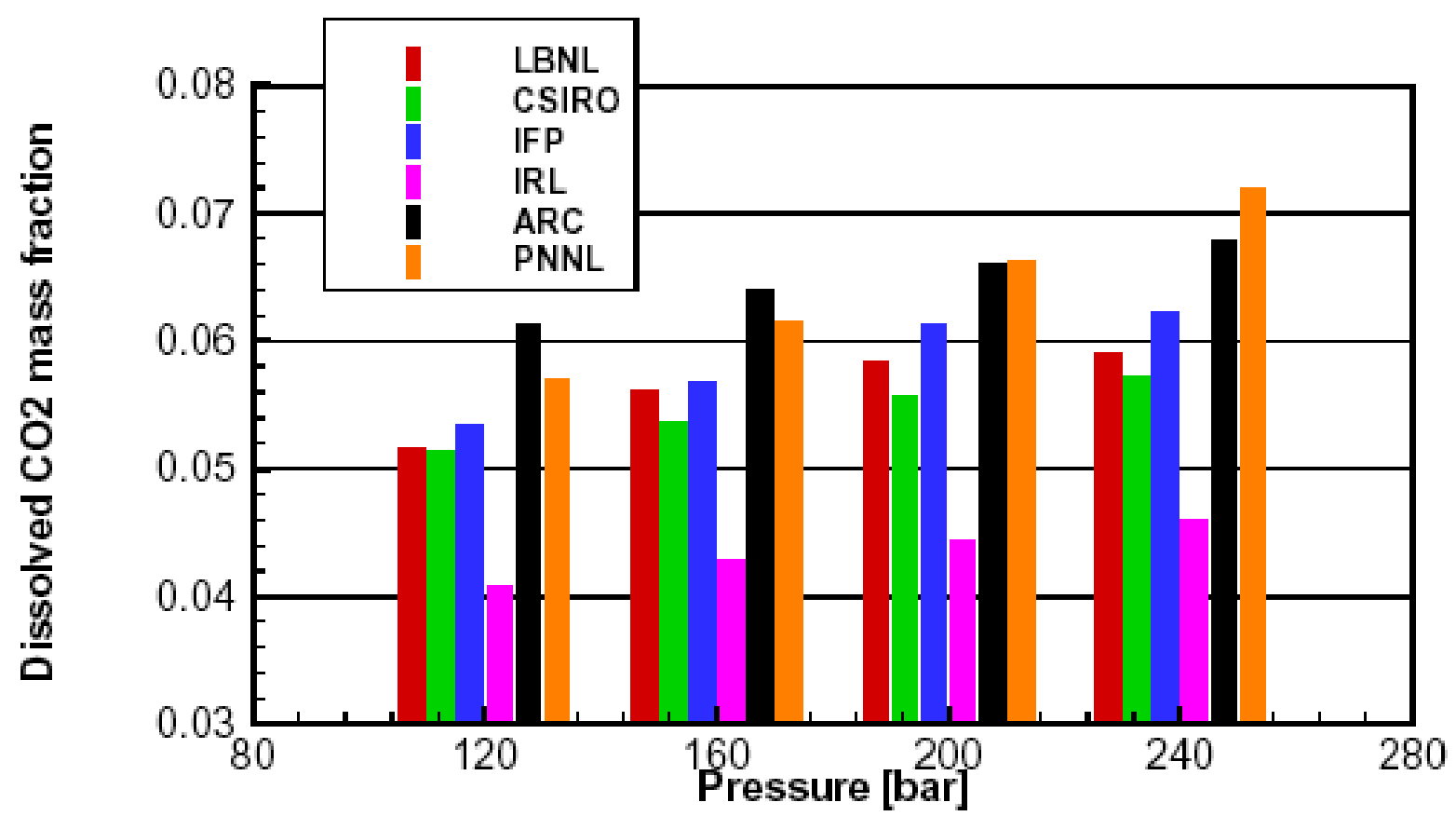

Figure 3.9 Dissolved CO2 mass fraction in aqueous phase at $\mathrm{T}=45^{\circ} \mathrm{C}$ (no salinity).

\subsection{Results With Salinity}

The presence of salt in the system induces additional processes, particularly salt precipitation near the injection well. Not all of the codes have a capability for modeling salt precipitation and tracking the corresponding solid phase saturation. Four groups submitted results that include salinity effects, namely LBNL, CSIRO, IFP and PNNL.

Figures 3.10 through 3.13 compare results for pressure, gas saturation, dissolved CO2 mass fraction and solid saturation (salt precipitation) as a function of the similarity variable. The LBNL and CSIRO results are almost identical. IFP and PNNL pressures are approximately $3 \%$ high and low, respectively, in comparison. Dissolved mass fractions are similar except for the dryout region at small $\mathrm{R}^{2} / \mathrm{t}$. IFP shows a considerably different profile of gas saturation.

Figures 3.14 and 3.15 present the reported fluid properties used in the simulations by different groups, again at $\mathrm{T}=45^{\circ} \mathrm{C}$ and pressures of $\mathrm{P}=120,160,200$, and 240 bar, with a salinity of $15 \%$ by weight in the aqueous phase. Differences between high and low values are $1.3 \%$ for brine density, $0.9 \%$ for aqueous phase density with dissolved $\mathrm{CO} 2,4.6 \%$ for brine viscosity with or without dissolved $\mathrm{CO} 2$, and $26 \%$ for $\mathrm{CO} 2$ solubility. Again, comparisons with experimental data are recommended to confirm a realistic description of fluid properties. 


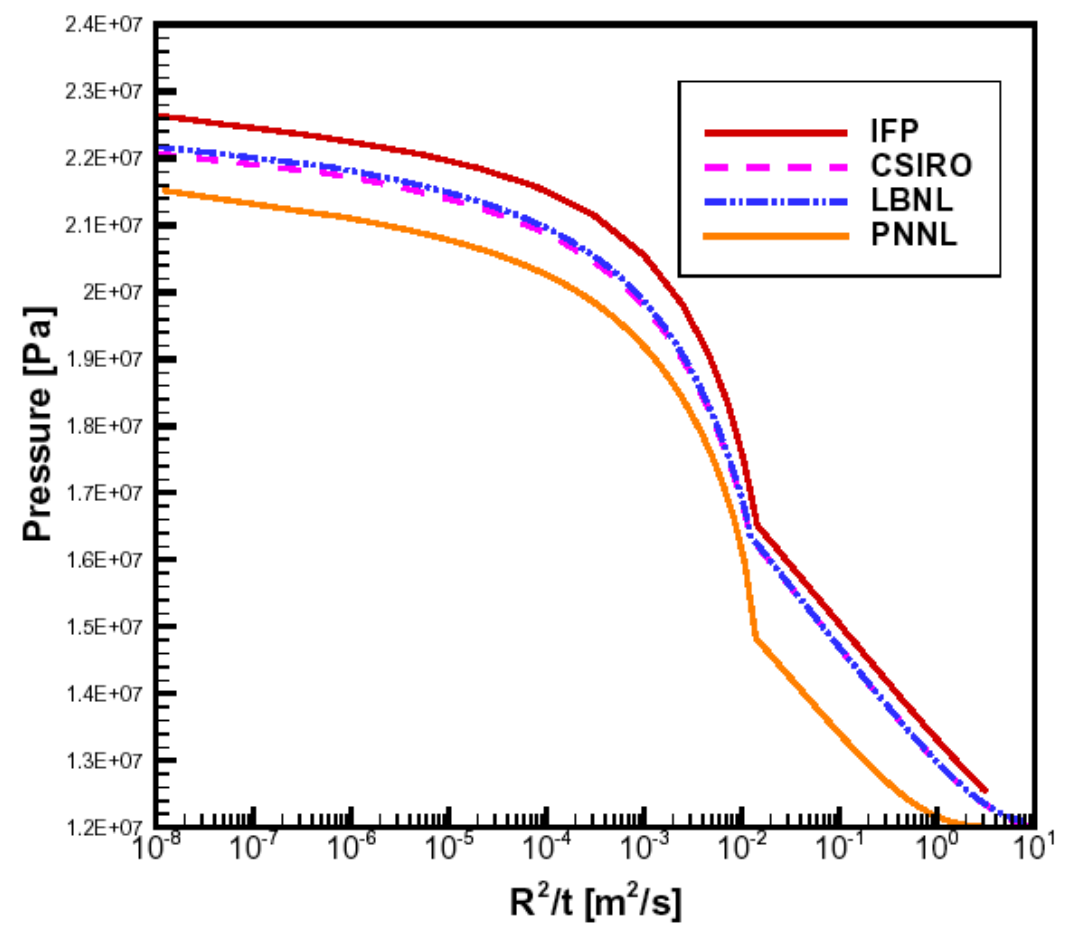

Figure 3.10 Simulated pressures in Problem 3 (15 weight \% salinity).

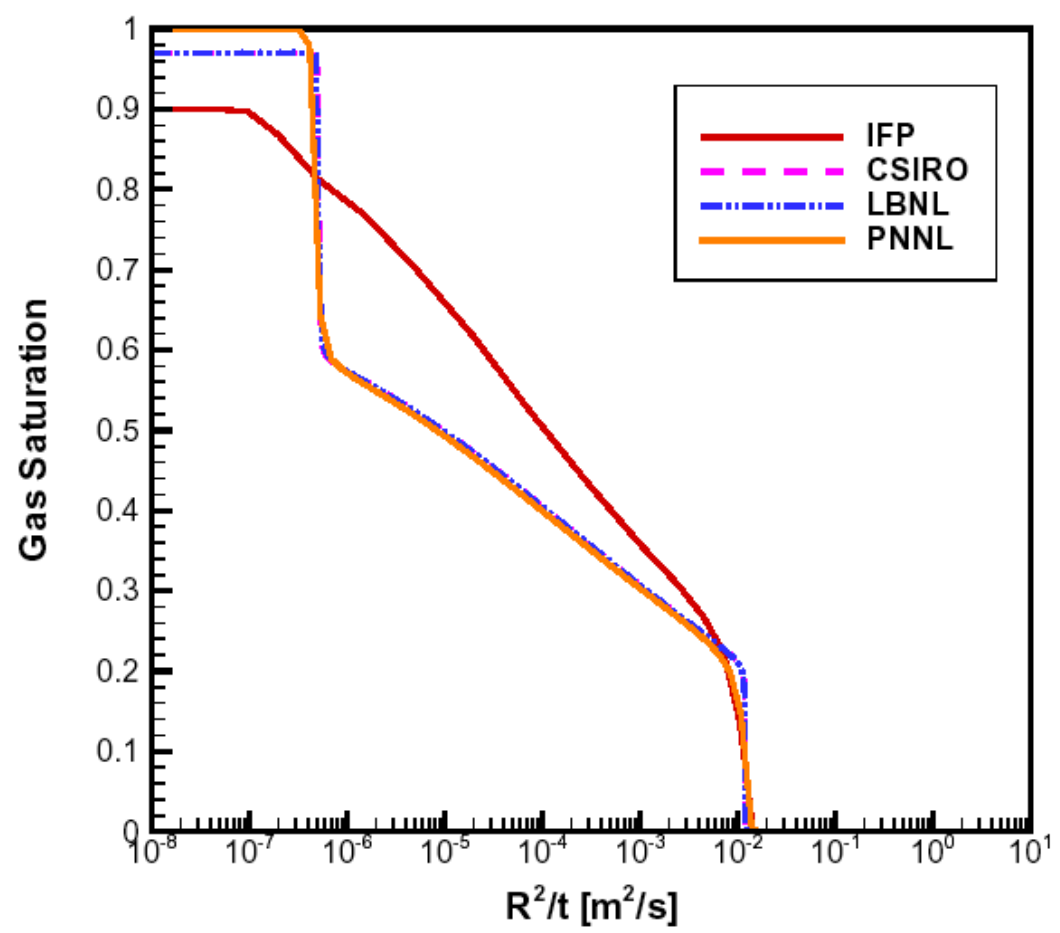

Figure 3.11 Simulated gas saturations in Problem 3 (15 weight \% salinity). 


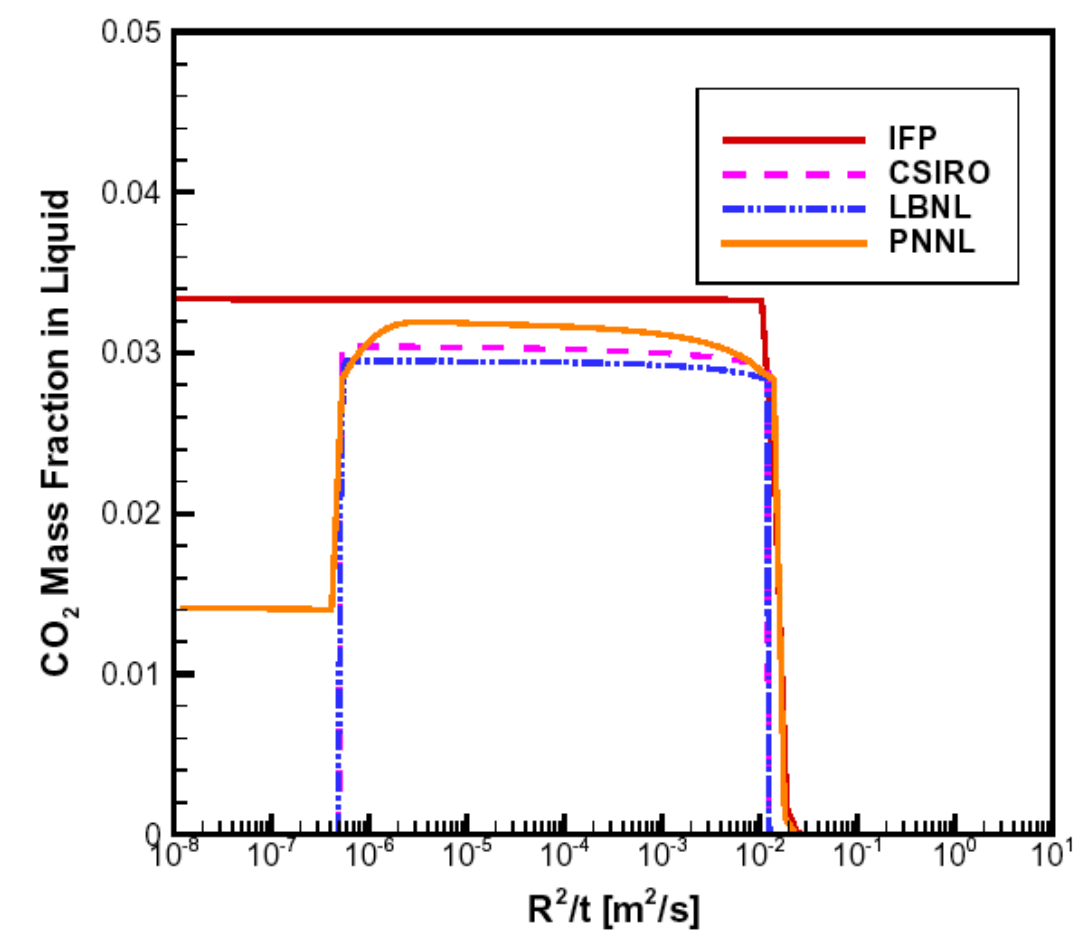

Figure 3.12 Simulated mass fractions of $\mathrm{CO} 2$ dissolved in the aqueous phase in Problem 3 (15 weight \% salinity).

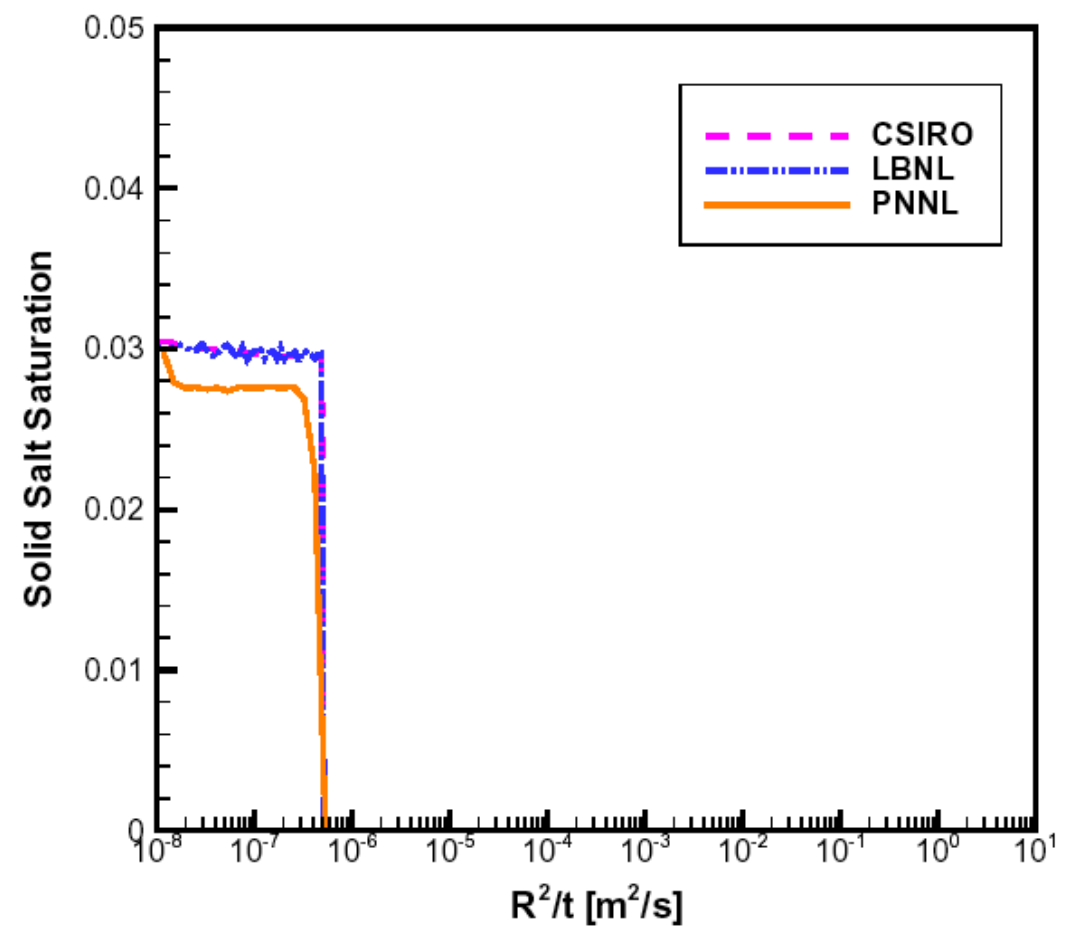

Figure 3.13 Simulated solid saturations in Problem 3 (15 weight \% salinity). 

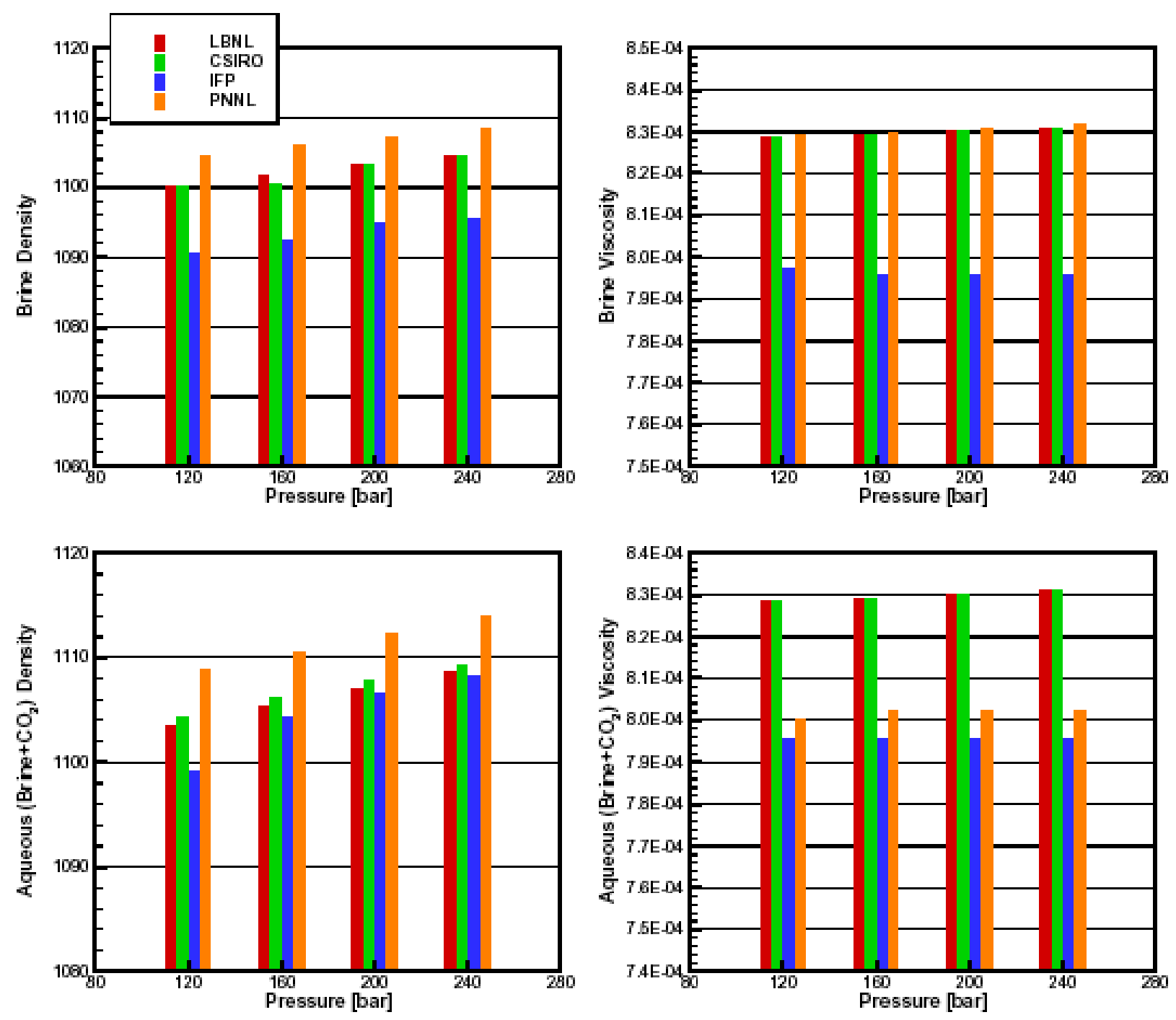

Figure 3.14 Properties of aqueous fluids at $\mathrm{T}=45^{\circ} \mathrm{C}$ (15 weight $\%$ salinity). 


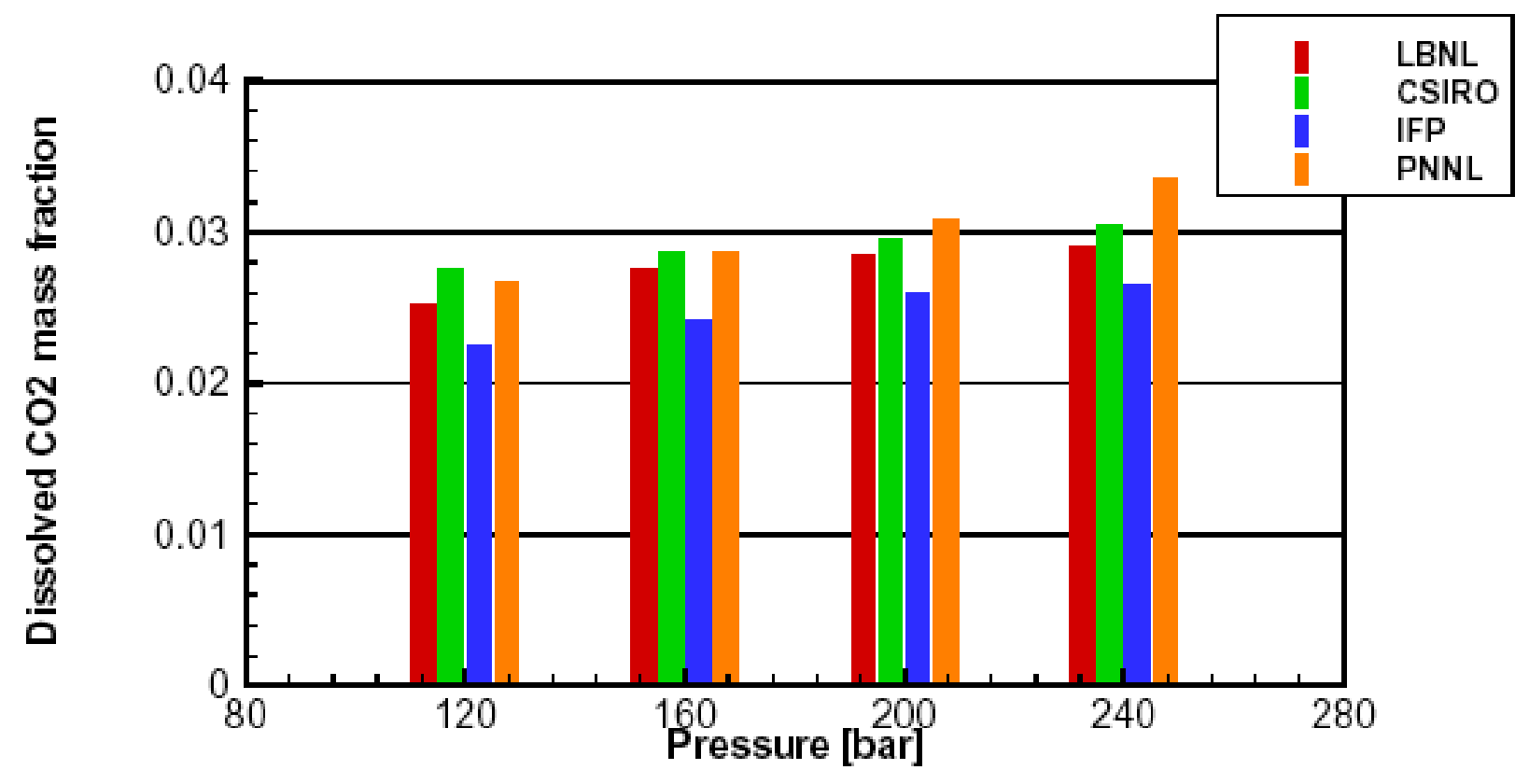

Figure 3.15 Dissolved CO2 mass fraction in aqueous phase at $\mathrm{T}=45^{\circ} \mathrm{C}(15$ weight $\%$ salinity). 


\section{Test Problem 4. CO2 Discharge Along a Fault Zone ${ }^{4}$}

\subsection{Problem Description}

This problem explores CO2 loss from storage through a leaky fault, using a highly simplified 1-D linear flow geometry. It is envisioned that an aquifer into which $\mathrm{CO} 2$ disposal is made is intersected by a vertical fault, which establishes a connection through an otherwise impermeable caprock to another aquifer $500 \mathrm{~m}$ above the storage aquifer (Fig. 4.1a). This situation is idealized by assuming 1-D flow geometry and constant pressure boundary conditions as shown in Fig. 4.1b (Pruess and García, 2002a, b)

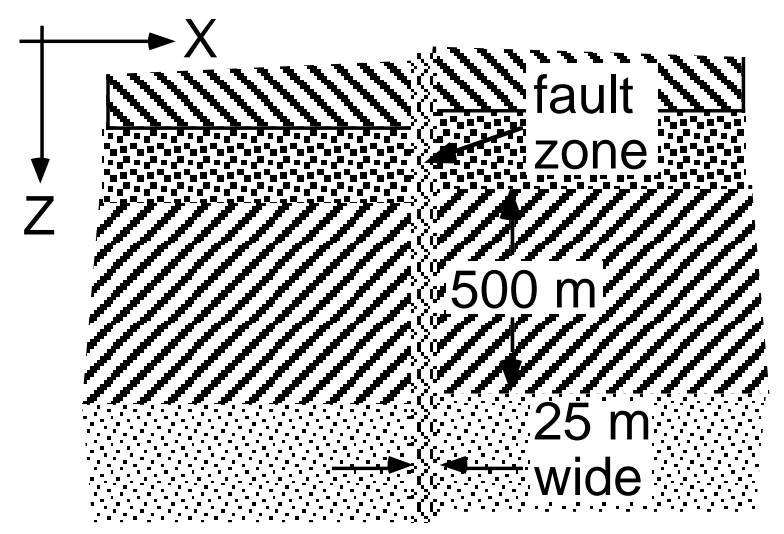

(a)

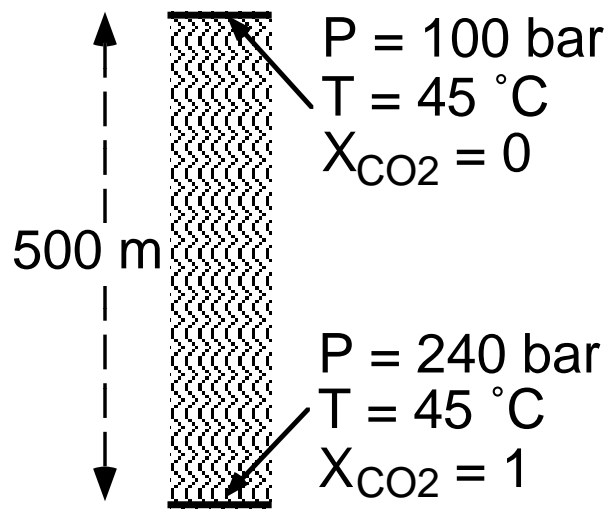

(b)

Figure 4.1 Schematic of the fault zone model (a) and applied boundary conditions (b).

At the workshop in October 2001, it was decided that the original problem specifications should be used without any changes, and that possible problem variations envisioned in the specifications would not be pursued. Reporting requirements were agreed upon as follows. "Give results for mass fluxes of $\mathrm{CO}_{2}\left(\mathrm{~kg} / \mathrm{m}^{2} \mathrm{~s}\right)$, summed over liquid and gas phases, at inlet (bottom) and outlet (top). Also give aqueous phase flux at the outlet. Fluxes should be reported for a range of times $10^{3} \mathrm{~s} \leq t \leq 10^{11} \mathrm{~s}$. Also provide profiles of gas saturation and $\mathrm{CO}_{2}$ mass (or mole) fraction at times of $10^{7}$ and $2 \times 10^{7}$ s. Report $\mathrm{CO}_{2}$ inventory at times of $10^{7}$ and $2 \times 10^{7} \mathrm{~s}$, separately for aqueous and gas phases."

\subsection{Results}

The main process in this problem is immiscible displacement of water by $\mathrm{CO} 2$. In response to the step change in pressure $\mathrm{CO} 2$ enters the system at the lower boundary and migrates up the fault, displacing some of the water and also partially dissolving in residual water. Two snapshots of

\footnotetext{
${ }^{4}$ proposed by Karsten Pruess; e-mail: K_Pruess@lbl.gov
} 

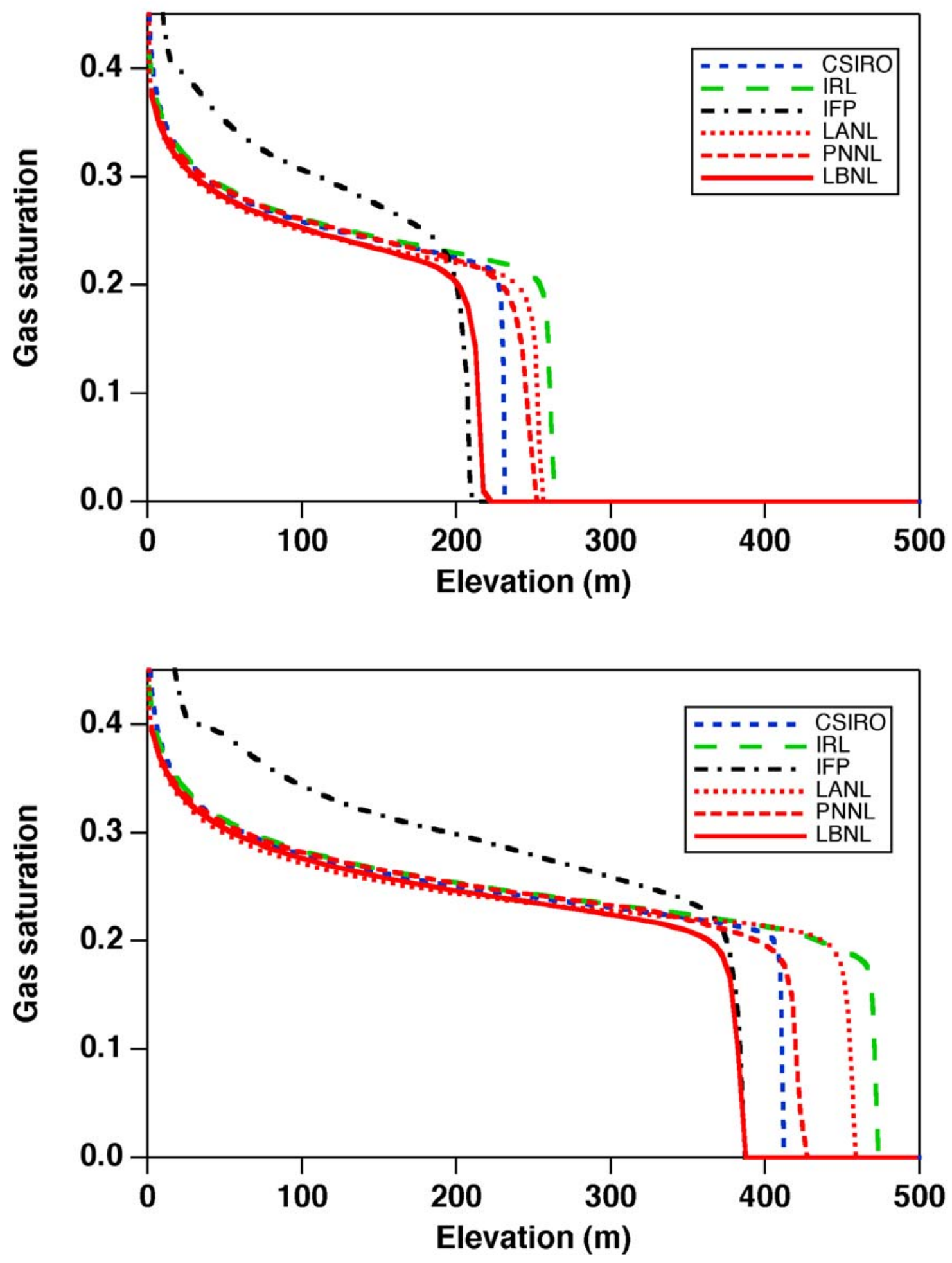

Figure 4.2 Gas saturations for $\mathrm{CO} 2$ migrating up a fault zone at times of $10^{7}$ seconds (top) and $2 \times 10^{7}$ seconds (bottom). 
the displacement front at times of $10^{7}$ and $2 \times 10^{7}$ seconds, respectively, are shown in Fig. 4.2. Here and in what follows we refer to the supercritical CO2-rich phase as "gas" for simplicity. All simulations except IFP are seen to agree well for the displacement profile, but there is a considerable range in the predicted location of the displacement front, indicating differences in total $\mathrm{CO} 2$ volume in the gas phase. The different shape of the saturation profile calculated by IFP suggests differences in fractional flow (relative mobilities) of gas and liquid phases (Buckley and Leverett, 1942). It was hypothesized that this may be due to differences in relative permeabilities and/or fluid viscosities, but an effort to determine the cause(s) of the discrepancy remained unsuccessful. Differences in fluid properties such as CO2 viscosity may account for some of the differences, but do not seem to be able to fully explain them (fluid properties here are the same as for problem 3, see above). PNNL also found an error in their calculation of aqueous phase densities, that has some impact on simulation results (Mark White, personal communication). Their revised results were submitted too late to be included in this report, but the $\mathrm{CO} 2$ inventories corresponding to the corrected solution are given in Table 4.1, below.

Differences in the advancement of the saturation front can be explained in terms of differences in $\mathrm{CO} 2$ solubilities between the codes, see Fig. 4.3. Dissolution of CO2 in the liquid (aqueous) phase for the thermodynamic conditions of this problem (temperature of $45^{\circ} \mathrm{C}$, pressures in the range of 100 to 250 bar) is subject to strong non-idealities, which are approximated differently by the different codes. The solubility formulation used by IRL, CSIRO, and LBNL shows a very small increase of dissolved CO2 mass fractions for the higher pressures at lower elevations, while LANL, IFP, and PNNL have significant increases in dissolved CO2 mass fractions at the higher pressures below the displacement front. A review of experimental data indicates that $\mathrm{CO} 2$ solubility in water is proportional to $\mathrm{CO} 2$ partial pressures at pressures of a few bars, but increases only very weakly with pressure beyond 100 bar (Ennis-King, private communication 2001; Spycher et al., 2002). An earlier simulation of problem 4 by LBNL had neglected the Poynting correction for CO2 solubility (Prausnitz et al., 1986), and resulted in solubilities that were too large and increased too much with pressure (Pruess et al., 2002).

For the three simulations with nearly pressure-independent CO2 solubility (IRL, CSIRO, LBNL), the relative positions of the displacement fronts are consistent with the solubility differences, with lowest solubility (IRL) corresponding to the most advanced front. Differences in gas front position between LANL and PNNL are also consistent with their differences in solubilities. 

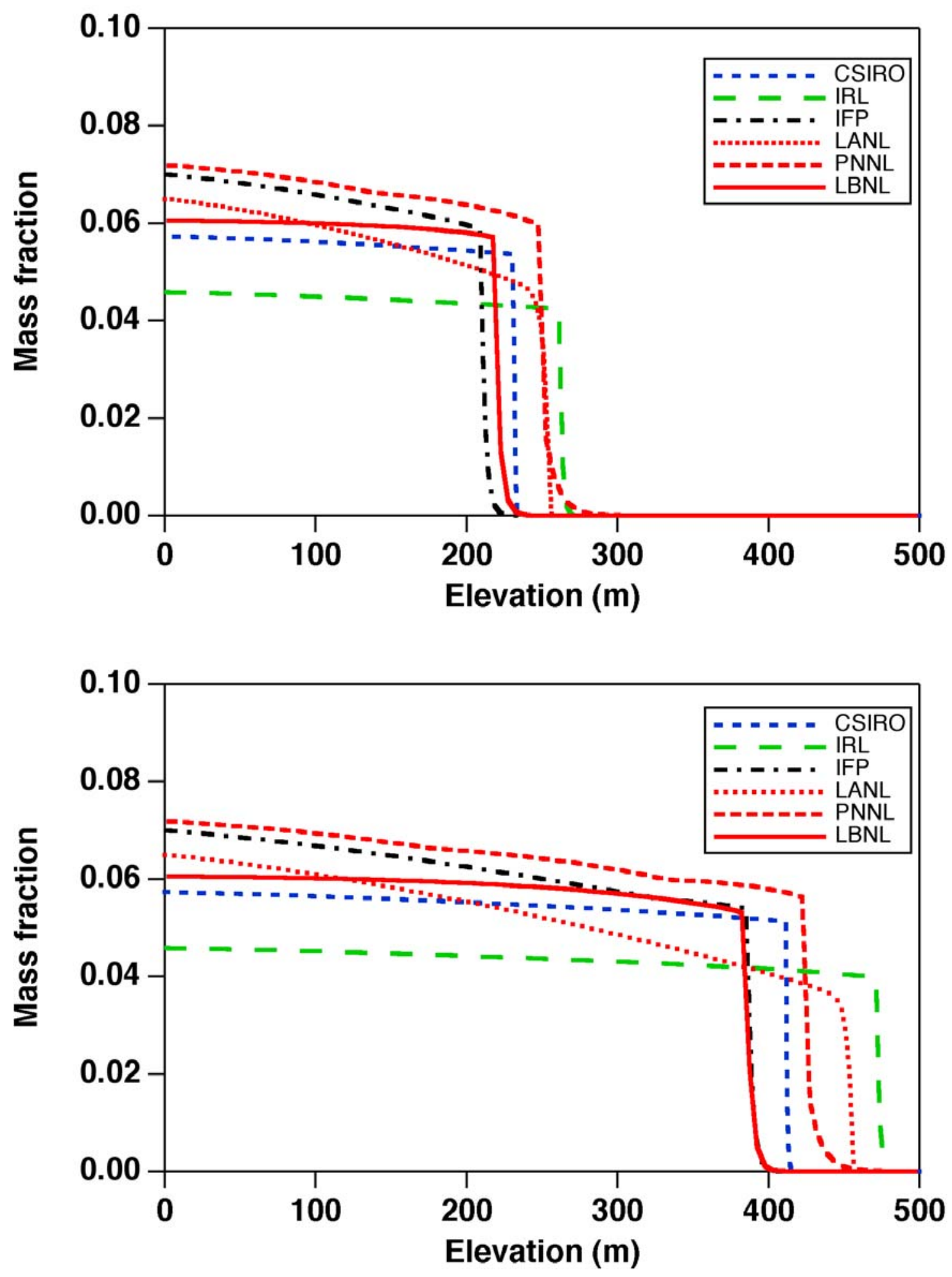

Figure 4.3 Mass fractions of $\mathrm{CO} 2$ dissolved in the liquid (aqueous) phase at times of $10^{7}$ seconds (top) and $2 \times 10^{7}$ seconds (bottom). 
Another interesting aspect of the fault discharge problem is the time dependence of water and $\mathrm{CO} 2$ fluxes, see Figs. 4.4 through 4.6. $\mathrm{CO} 2$ flux entering the fault is very large at early time, due to the step change in boundary conditions, and then slowly decreases until, at about $2.5 \times 10^{7} \mathrm{~s}$, the $\mathrm{CO} 2$ front breaks through at the top boundary (Figs. 4.4, 4.5). Outflow of water at the top starts after about $10^{4} \mathrm{~s}$, when the pressure pulse from $\mathrm{CO} 2$ injection reaches the top boundary. Water outflow increases rapidly at first, then goes through a quasi-steady period as the displacement front advances up the fault. $\mathrm{CO} 2$ breakthrough at the top is accompanied by a rapid drop in water flux, followed by a long period of slow decline which corresponds to the gradual drying out of the system as water evaporates into the $\mathrm{CO} 2$ stream. The simulations shown in Figs. 4.4 - 4.6 agree well in the representation of this complicated transient behavior. Non-monotonic behavior is evident in the PNNL simulation for $\mathrm{CO} 2$ inlet flux at early times, which is probably due to space and time discretization effects.

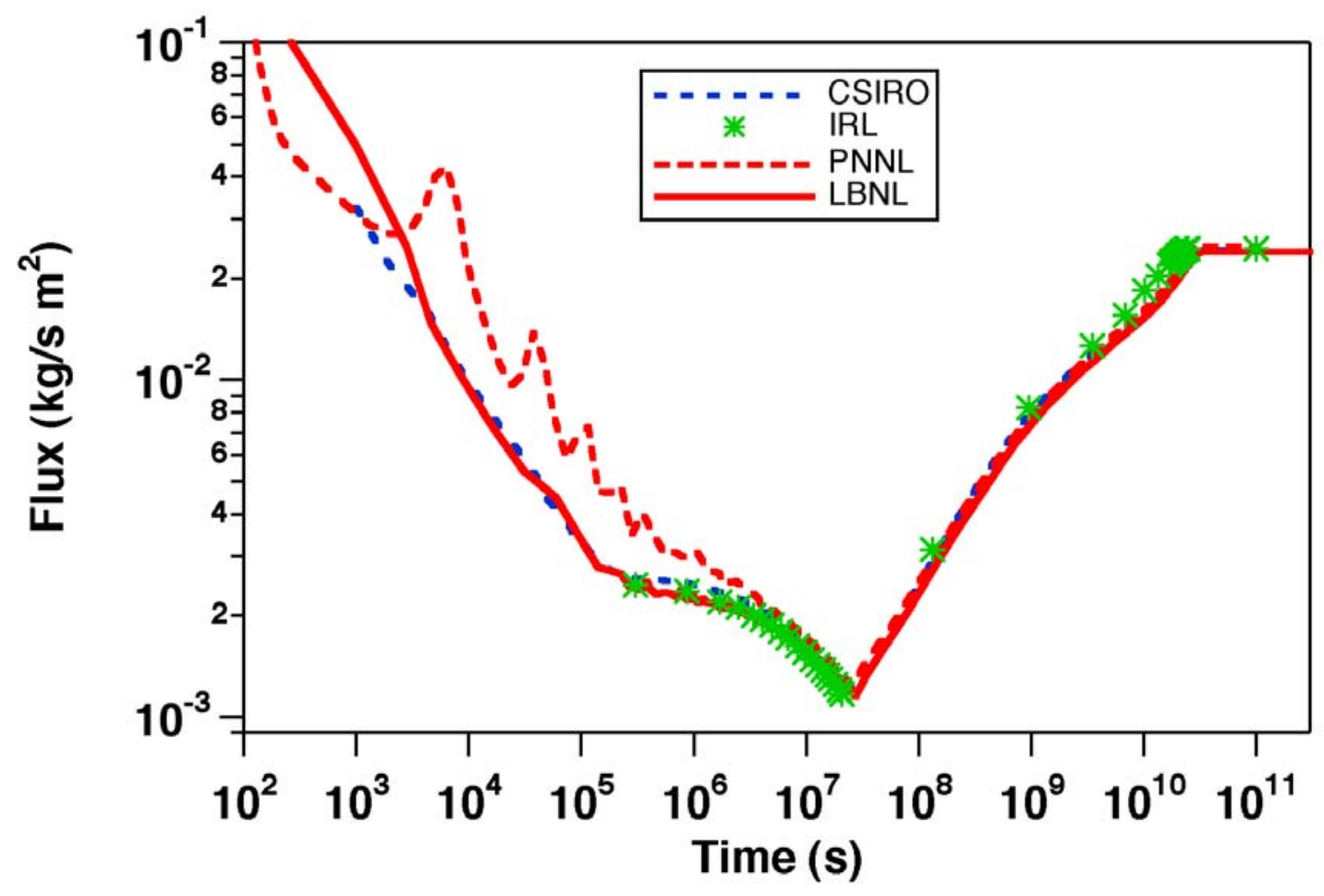

Figure 4.4 CO2 flux at the bottom of the fault zone. 


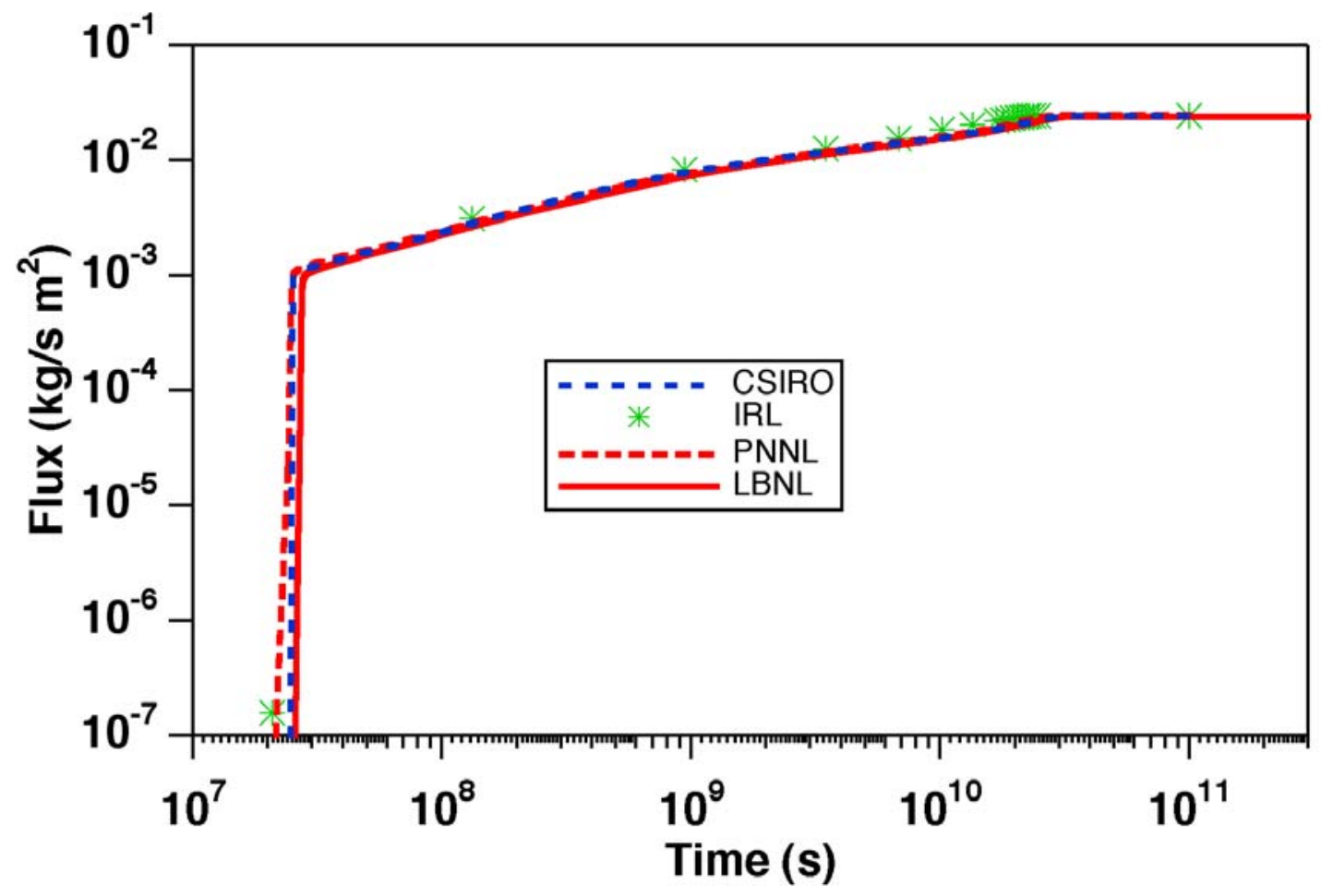

Figure 4.5 CO2 flux at the top of the fault zone.

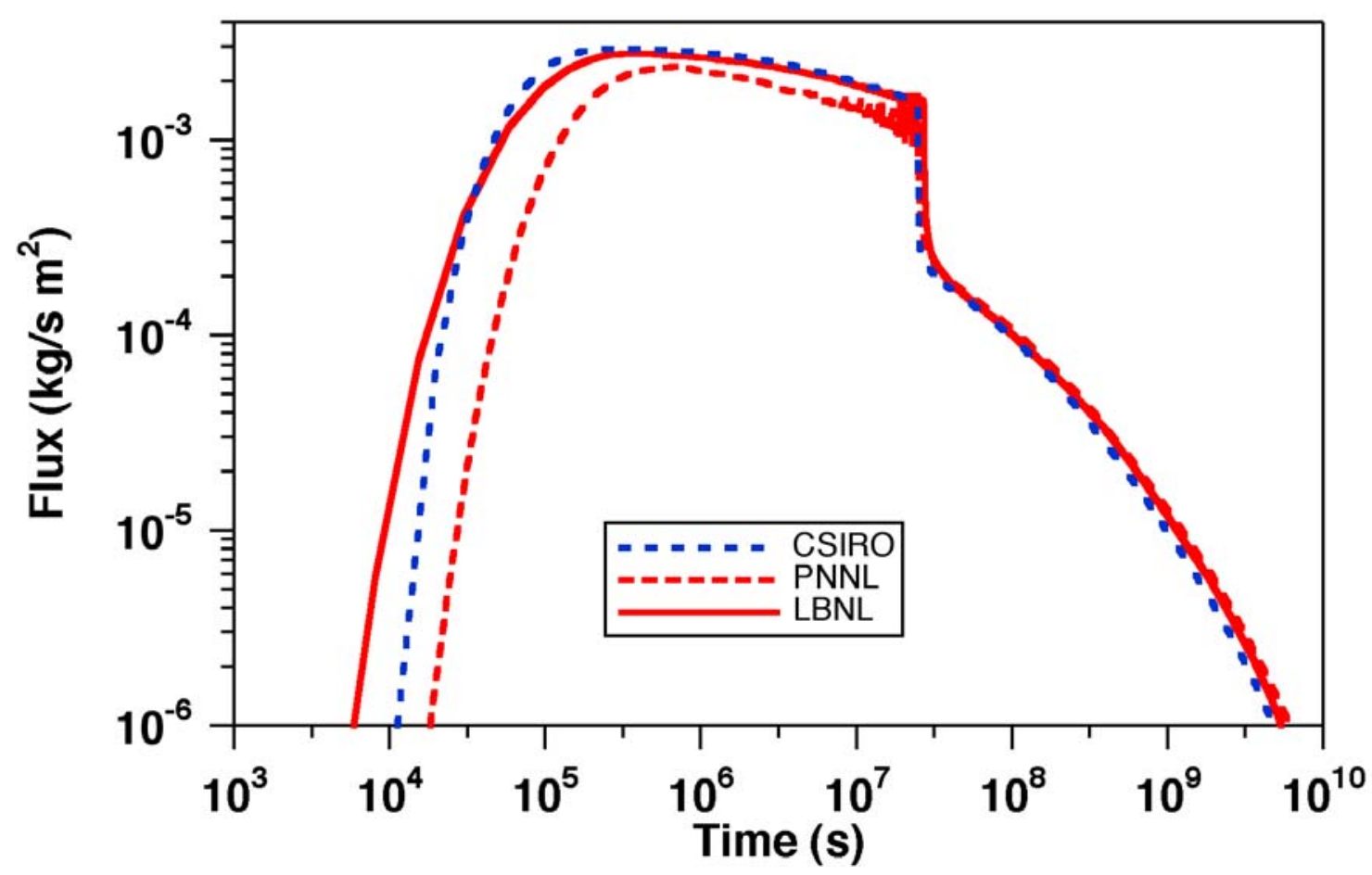

Figure 4.6 Water flux at the top of the fault zone. 
Total CO2 inventories in the fault zone are given in Table 4.1 for two different times, separately for gas and liquid phases. (Results labeled "PNNL I" correspond to the simulation results given in the figures, above, while "PNNL II" is for a revised calculation in which an error in the aqueous phase density calculation was corrected.) For some parameters there is close agreement between different groups, while for others, such as inventory of $\mathrm{CO} 2$ dissolved in the liquid phase, discrepancies are almost a factor 2 between the IRL and PNNL I calculations. The main reason for the large differences in dissolved CO2 inventory is the substantially larger dissolved mass fraction in the PNNL I calculation (Fig. 4.3), due to different correlations for CO2 solubility. Gas phase inventories are in better agreement, with differences between highest and lowest figures of $15.1 \%$ at $\mathrm{t}=10^{7} \mathrm{~s}$, and $9.2 \%$ at $2 \times 10^{7} \mathrm{~s}$. The LBNL calculation shows the least advancement of the saturation front (Fig. 4.2), hence the lowest gas inventory. CO2 densities of CSIRO and LBNL are very close (Fig. 3.8), and the differences in gas phase inventories between these two calculations are consistent with the CSIRO saturation front being somewhat more advanced, Fig. 4.2. PNNL I shows considerably higher gas inventories than IRL, even though the latter has a larger gas volume (Fig. 4.2), and slightly larger $\mathrm{CO} 2$ density (Fig. 3.8). It does not seem possible to reconcile this particular discrepancy with the data reported in Figs. 3.8 and 4.2.

Table 4.1 Simulated CO2 inventories (metric tonnes) per $1 \mathrm{~m}$ thickness of the fault zone in gas and liquid phases after $10^{7}$ and $2 \times 10^{7}$ seconds.

\begin{tabular}{|rr|c|c|c|c|c|}
\hline & CSIRO & IRL & PNNL I & PNNL II & LBNL \\
\hline \hline $10^{7} \mathrm{~s} \quad$ gas & 437.7 & 420.0 & 456.6 & 398.0 & 396.7 \\
\hline & liquid & 84.7 & 65.0 & 126.8 & 102.5 & 86.8 \\
\hline $2 \times 10^{7} \mathrm{~s}$ gas & 746.7 & 700.0 & 754.1 & 692.7 & 690.5 \\
\hline & liquid & 148.5 & 116.0 & 206.2 & 171.5 & 147.9 \\
\hline
\end{tabular}

In conclusion we note that the codes used for problem 4 are capable of simulating twophase flow subject to pressure, gravity, and capillary forces, and partial dissolution of $\mathrm{CO} 2$ in the aqueous phase. Intercomparison of results showed substantial agreement, as well as some differences that are partially due to differences in fluid property correlations, may partially be due to discretization effects, and in some cases remain unexplained. Examples of the latter include the different shape of the saturation profile in the IFP calculation (Fig. 4.2), and the modest but unexplained discrepancies in gas inventories between IRL and PNNL. 


\section{Test Problem 5. Mineral Trapping in a Glauconitic Sandstone Aquifer ${ }^{5}$}

\subsection{Problem Description}

This problem addresses geochemical effects of $\mathrm{CO}_{2}$ injection into a glauconitic sandstone aquifer, and analyzes the impact of $\mathrm{CO}_{2}$ immobilization through carbonate precipitation. Batch reaction modeling of the geochemical evolution of this aquifer is performed in the presence of $\mathrm{CO}_{2}$ at high pressure. The problem is based on Gunter et al. (1997), who modeled water-rock reactions when $\mathrm{CO}_{2}$ is injected into a glauconitic sandstone aquifer in the Alberta Sedimentary Basin, Canada. The current modeling considers (1) equilibrium aqueous-aqueous and aqueous-gas reactions, (2) redox, (3) the presence of organic matter, (4) the kinetics of chemical interactions between the host rock minerals and the aqueous phase, and (5) $\mathrm{CO}_{2}$ solubility dependence on pressure, temperature and salinity of the system.

The glauconitic sandstone aquifer (Alberta Sedimentary Basin, Canada) is a medium- to fine-grained litharenite. The average mineral composition is $87 \%$ quartz, $2 \%$ potassium-feldspar, $1 \%$ plagioclase, $5 \%$ glauconite, $2 \%$ kaolinite, $1 \%$ calcite, $1 \%$ dolomite, and $1 \%$ siderite. The average porosity is $12 \%$. Gunter et al. (1997) modeled water-rock reactions driven by the formation of carbonic acid when $\mathrm{CO}_{2}$ is injected into deep aquifers using PATHARC.94 (Perkins and Gunter, 1995). In their simulations, the $\mathrm{CO}_{2}$ injection pressure was set at 260 bar. Annite was used as a substitute for glauconite. Plagioclase was simulated by assuming the presence of discrete fractions of end member components, anorthite and albite. In developing the specifications for the present problem, LBNL initially assumed the same mineralogy as Gunter et al. (1997). The simulation showed that annite is rapidly destroyed with precipitation of siderite $\left(\mathrm{FeCO}_{3}\right)$, the latter being the

principal mineral trap for $\mathrm{CO}_{2}$. A maximum of about $40 \mathrm{~kg}$ of $\mathrm{CO}_{2}$ per $\mathrm{m}^{3}$ of host rock medium could be sequestered in mineral phases. Results were similar to those of Gunter et al. (1997).

The use of annite as a substitute for glauconite overestimates the availability of $\mathrm{Fe}^{2+}$, the amount of siderite $\left(\mathrm{FeCO}_{3}\right)$ precipitation, and hence the degree of $\mathrm{CO}_{2}$ sequestration. Therefore, the model mineral assemblage was modified to reflect more closely the composition expected in a glauconitic sandstone. A representative glauconite chemical composition and thermodynamic properties were estimated from descriptions of the mineralogical compositions of glauconite and its paragenesis as reported in the published literature (Xu et al., 2001). Oligoclase was incorporated as a solid solution of plagioclase, and the thermodynamic properties of oligoclase were calculated from calorimetric studies of plagioclase solid solutions reported in the literature. Furthermore, organic

5 proposed by Tianfu Xu; e-mail: Tianfu_Xu@lbl.gov 
matter was assumed to be present in the glauconitic sandstone, and was represented by the generic composition, $\mathrm{CH}_{2} \mathrm{O}$. The decomposition of organic matter is a complex process. A more realistic representation of organic matter should be investigated in the future. Also, instead of using muscovite as a proxy for illite, illite was actually included as a primary mineral. We believe the modified mineralogy more accurately represents the natural conditions. The problem considers redox-sensitive couples such as $\mathrm{Fe}^{3+} / \mathrm{Fe}^{2+}, \mathrm{CO}_{2}(\mathrm{aq}) / \mathrm{CH}_{4}(\mathrm{aq}), \mathrm{H}_{2} \mathrm{O}(\mathrm{aq}) / \mathrm{H}_{2}(\mathrm{aq})$, and $\mathrm{SO}_{4}{ }^{2-} / \mathrm{HS}^{-}$, which are very important in the geochemical evolution of sedimentary basins.

The specifications originally stipulated for Problem 5 are given in appendix E, Table E.1. Mineral abundances are based on previous work (Hitchon, 1996, p. 138), but with the addition of a $2.64 \%$ volume fraction of organic matter. In the course of this study, goethite $(\mathrm{FeOOH})$ was added as a possible secondary mineral phase, following a suggestion from Peter Lichtner (private communication, 2002). This was the only revision made to the original problem specifications as given in appendix E. Goethite precipitates and competes with siderite for iron, which could reduce the amount of $\mathrm{CO}_{2}$ sequestration. Goethite parameters were chosen identical to smectite-Ca, see Table E.1. The primary mineral dissolution is considered to be kinetically-controlled, as given by Eq. (E.2) in appendix E. Precipitation of possible secondary minerals (Table E.1, with an initial mineral volume fraction of zero) is represented using the same kinetic rate expression as that for dissolution. However, precipitation can differ in several respects, as nucleation, Ostwald ripening, crystal growth processes, and reactive surface areas must be taken into account in some circumstances (Plummer et al., 1978; Steefel and van Capellen, 1990). To simplify the description of precipitation kinetics, the precipitation kinetic constant for a secondary mineral is assumed to be one order of magnitude greater than its corresponding dissolution rate constant. Note that all rate constants in Table E.1 (including secondary phases) are for dissolution. Because the rate constants assumed for precipitation reactions are larger than those for dissolution, formation of secondary minerals occurs effectively at conditions close to local equilibrium. The reactive surface areas for secondary minerals are set to $0.25 \mathrm{~m}^{2} / \mathrm{dm}^{3}$ at all times. Surface areas for illite, kaolinite, smectite$\mathrm{Na}$, and smectite- $\mathrm{Ca}$ are increased by two orders of magnitude, corresponding to the actual predicted geometric surface area based on the assumption that the particles are in the range of 0.1 to $1 \mu \mathrm{m}$ in diameter and $0.01-0.1 \mu \mathrm{m}$ thick. The surface area for glauconite is increased by only one order of magnitude because authigenic glauconite is usually more coarsely crystalline than other clay minerals, as it is commonly observed in crystallites up to $10 \mathrm{~mm}$ in diameter.

The geochemical simulations consider $1 \mathrm{~m}^{3}$ of water-saturated medium. $\mathrm{A} \mathrm{CO}_{2}$ injection pressure of 260 bar was considered. This pressure is the same as that chosen by Gunter et al. (1997) for the glauconitic sandstone aquifer, and is based on the assumption that the aquifer is 
$1500 \mathrm{~m}$ deep, and can sustain $\mathrm{CO}_{2}$ disposal injection pressures of that magnitude. In the present simulation, the $\mathrm{CO}_{2}$ gas pressure is assumed to be in equilibrium with the solution at all times. Thus, the $\mathrm{CO}_{2}$ gas is treated as an exterior boundary condition with a constant pressure. The solubility of $\mathrm{CO}_{2}$ in the aqueous phase depends on pressure, temperature, and salinity. The detailed formulation of these factors in the model is given in Xu et al. (2001). Reactant phases are those minerals initially present in the aquifer formation. The reactant minerals dissolve progressively into the formation water, thus modifying the water composition and leading to precipitation of product phases, with sequestration of $\mathrm{CO}_{2}$ upon precipitation of carbonates.

\subsection{Results and Discussion}

Simulation results were reported by three groups, LBNL, LANL, and IRL, using the simulators TOUGHREACT (Xu and Pruess, 2001), FLOTRAN (Lichtner, 2001) amd CHEMTOUGH (White, 1995), respectively. With the instantaneous imposition of a constant $\mathrm{CO}_{2}$ pressure of 260 bar on the formation water, the reactant minerals dissolve and secondary mineral phases precipitate. Initially a lower $\mathrm{pH}$ (Figure 5.1) is obtained, which is mainly buffered by the $\mathrm{CO}_{2}$ gas pressure. Later $\mathrm{pH}$ increases gradually due to mineral dissolution and precipitation. Note that the time in Fig. 5.1 is plotted in logarithmic scale, in order to show the detailed evolution at early time. The aqueous oxygen concentrations (redox indicator) are presented in Figure 5.2.

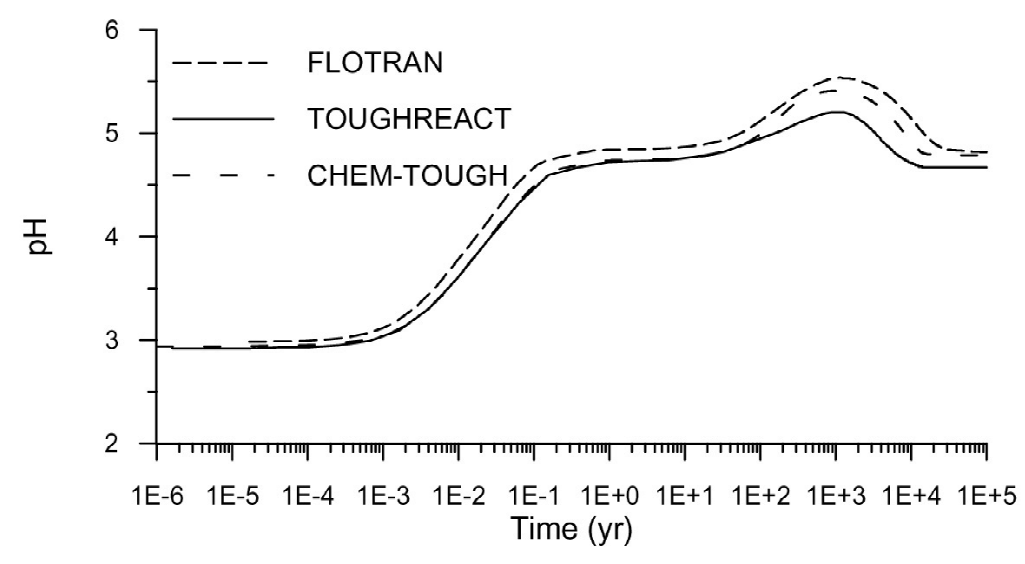

Figure $5.1 \mathrm{pH}$ evolution in glauconitic sandstone with $\mathrm{CO}_{2}$ injected at 260 bar.

The cumulative sequestration of $\mathrm{CO}_{2}$, including dissolution in water (solubility trapping) and precipitation of carbonate minerals (mineral trapping), is presented in Figure 5.3. Results from the three codes agree closely. The mineral trapping is caused by alteration of primary minerals and precipitation of secondary minerals. The evolution of individual mineral phases is presented in Figure 5.4. Illite, glauconite, oligoclase, and kaolinite (Figures 5.4a through 5.4d) dissolve under the high gas pressure. Calcite dissolution and dolomite precipitation occur to a limited extent (Figures 
5.4e and 5.4f). Siderite precipitation (Figure 5.4g) is significantly greater than dolomite because of lower solubility and rapid glauconite dissolution. Most $\mathrm{CO}_{2}$ is sequestered through siderite $\left(\mathrm{FeCO}_{3}\right)$ precipitation. The pattern of the $\mathrm{CO}_{2}$ sequestration curve (Figure 5.3) is consistent with that of siderite precipitation. Only minor quantities of $\mathrm{CO}_{2}$ are sequestered through dolomite precipitation. Goethite initially precipitates, competing for iron with siderite, but later dissolves when glauconite disappears. Precipitation of k-feldspar and smectite-Na can also be observed (Figures $5.4 \mathrm{i}$ and $5.4 \mathrm{j})$.

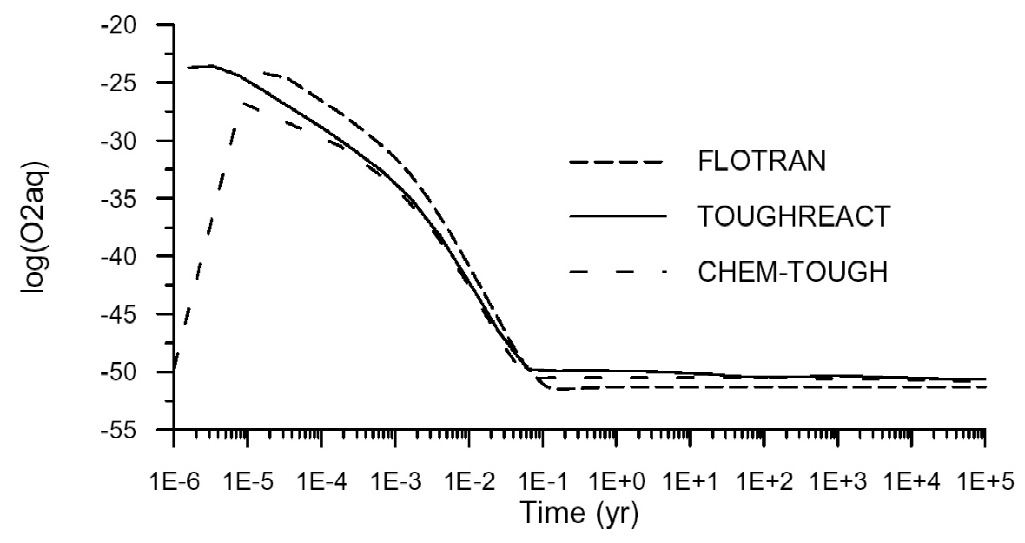

Figure 5.2 Evolution of aqueous oxygen concentration.

Results from the three codes agree reasonably well. Very similar patterns of mineral dissolution and precipitation were obtained in all cases, with some differences in the magnitude of values. The differences in abundances of some minerals may be caused by the slight differences in $\mathrm{pH}$. For example, the TOUGHREACT simulation has the lowest $\mathrm{pH}$ (4.67), leading to more calcite dissolution and dolomite precipitation. The primary reason for the difference could be differences in the $\mathrm{CO}_{2}$ solubility correction as a function of pressure, temperature and salinity. It may be also caused by the following possible differences among the three simulations: (1) thermodynamic data, (2) interpolation coefficients and functions for equilibrium constants, (3) activity coefficients of aqueous species, (4) numerical methods, and (5) time stepping. 


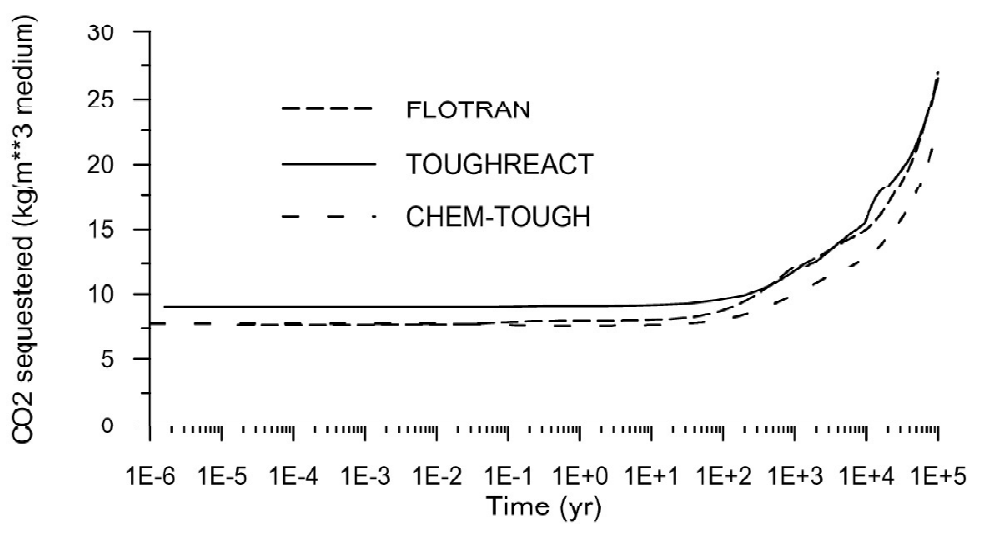

Figure 5.3 Cumulative $\mathrm{CO}_{2}$ sequestration in glauconitic sandstone with $\mathrm{CO}_{2}$ injected at 260 bar.

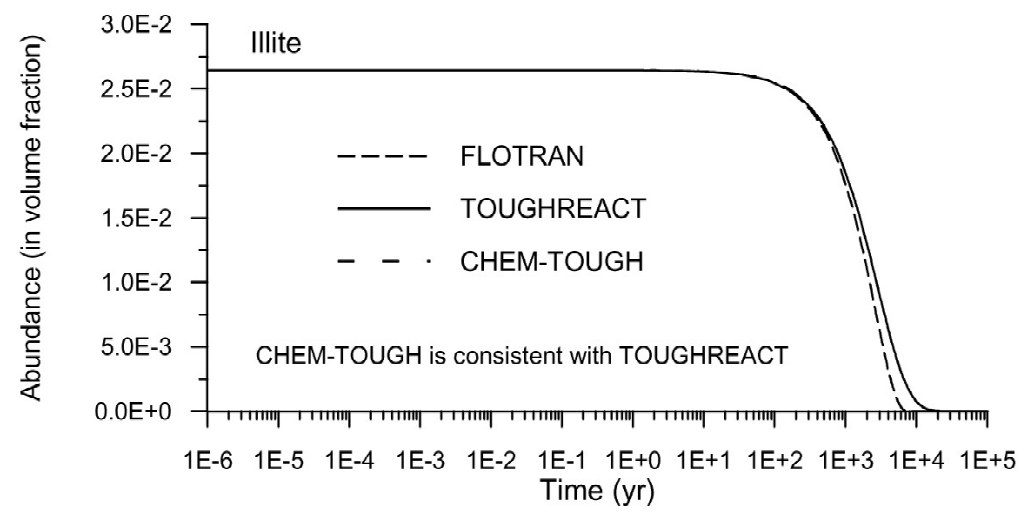

Figure 5.4a

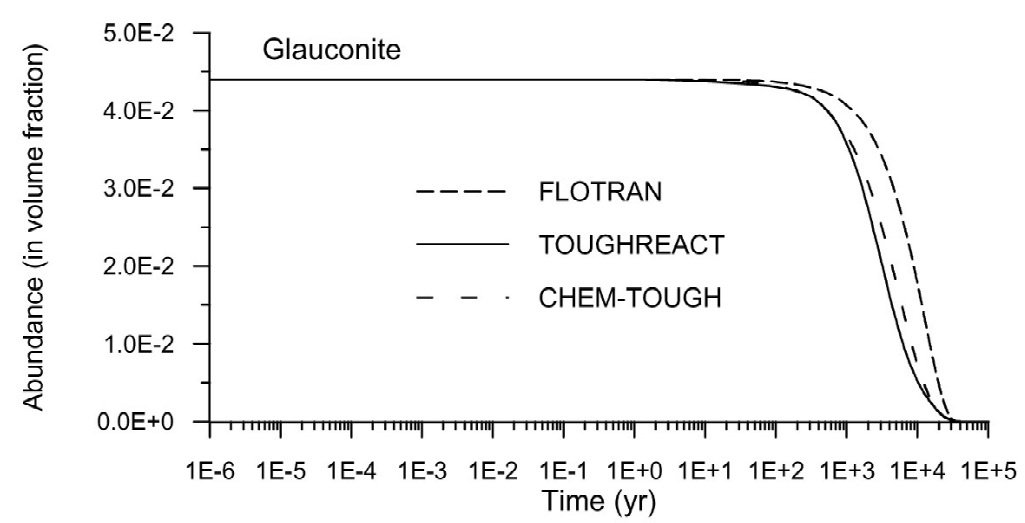

Figure 5.4b 


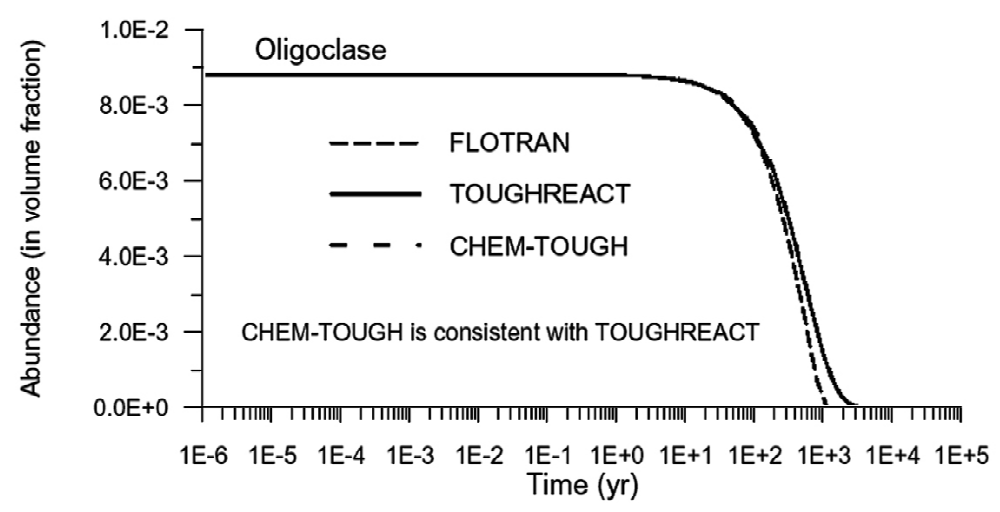

Figure 5.4c

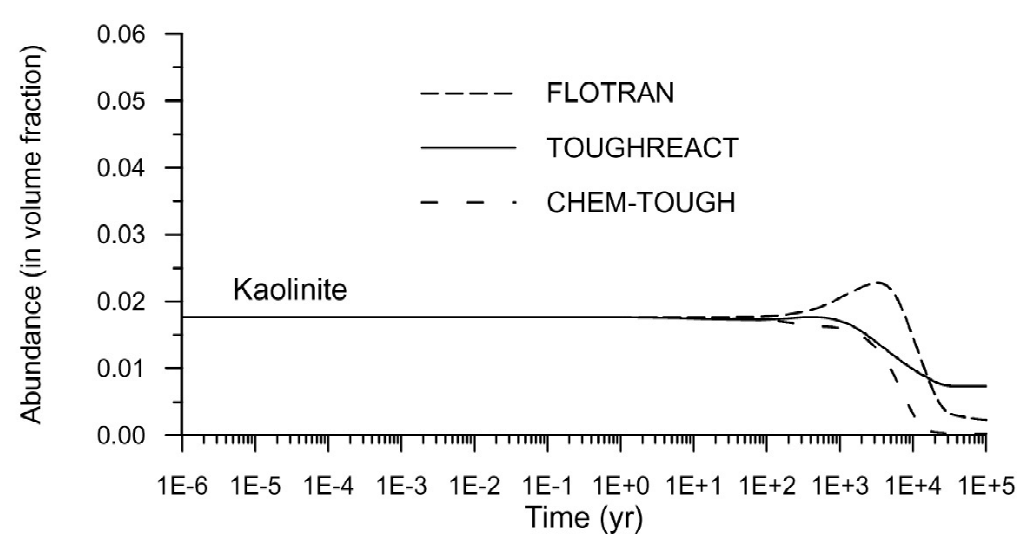

Figure 5.4d

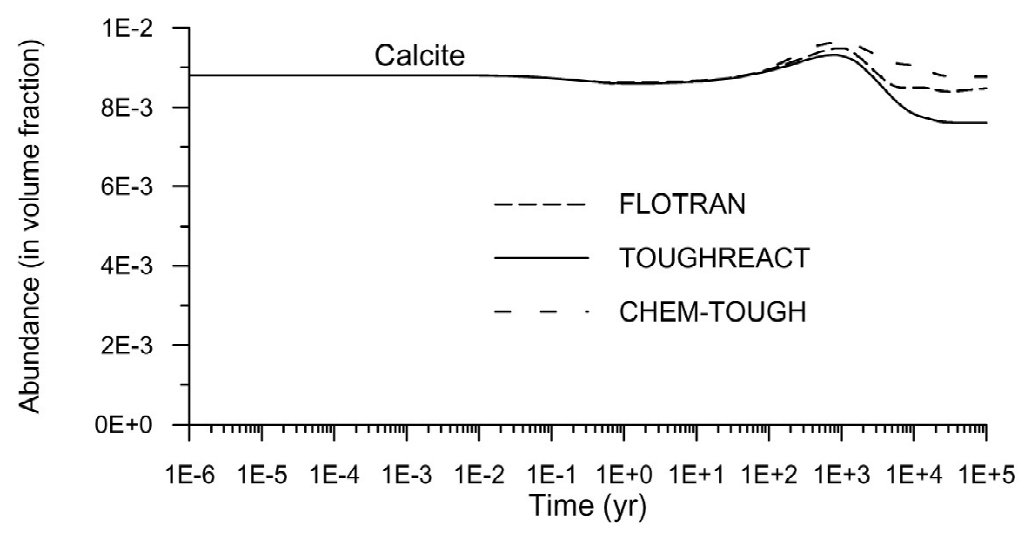

Figure $5.4 \mathrm{e}$ 


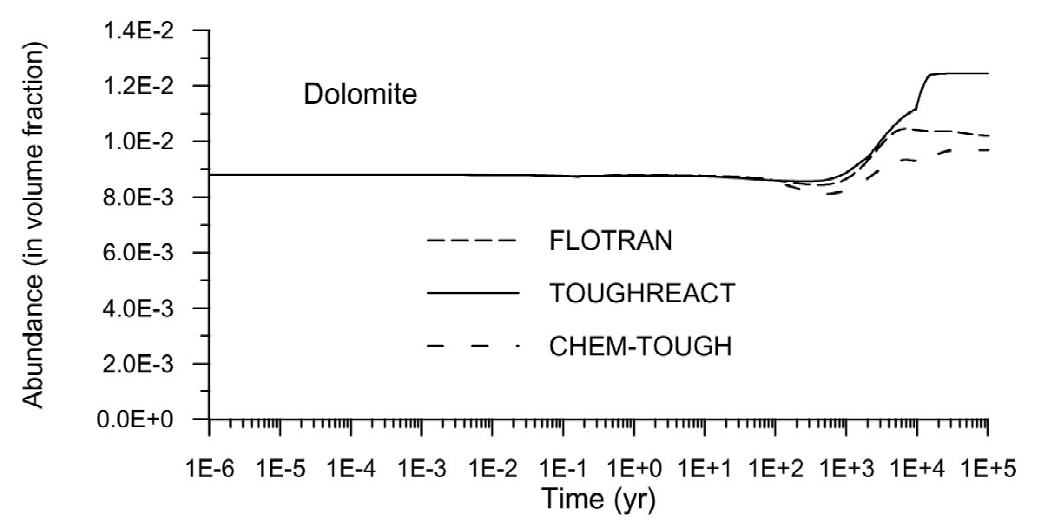

Figure 5.4f

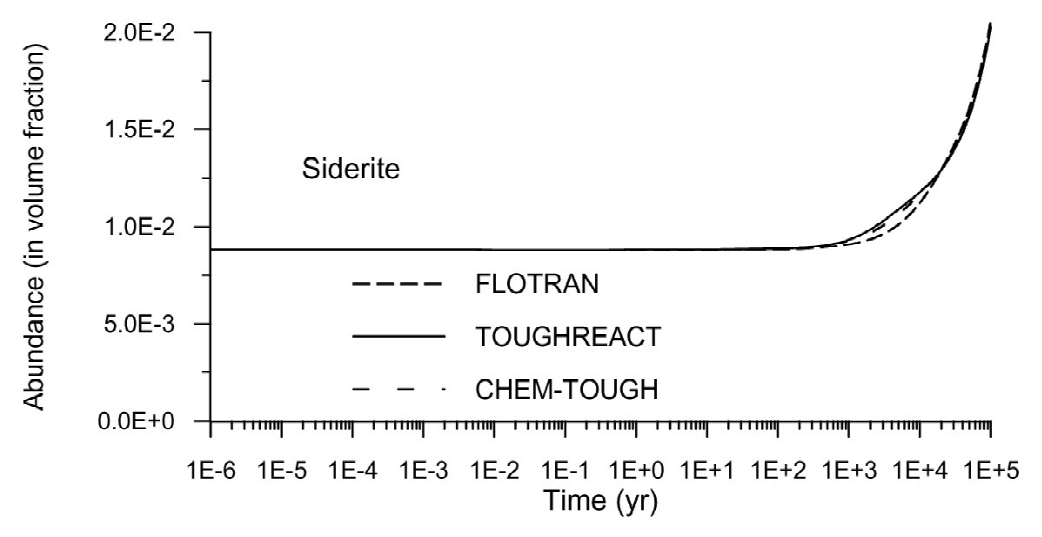

Figure 5.4g

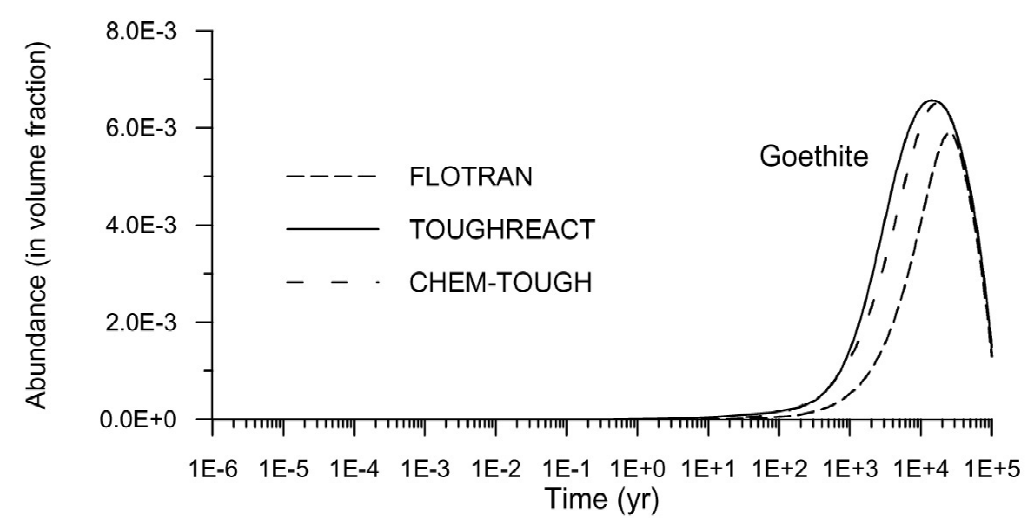

Figure 5.4h 


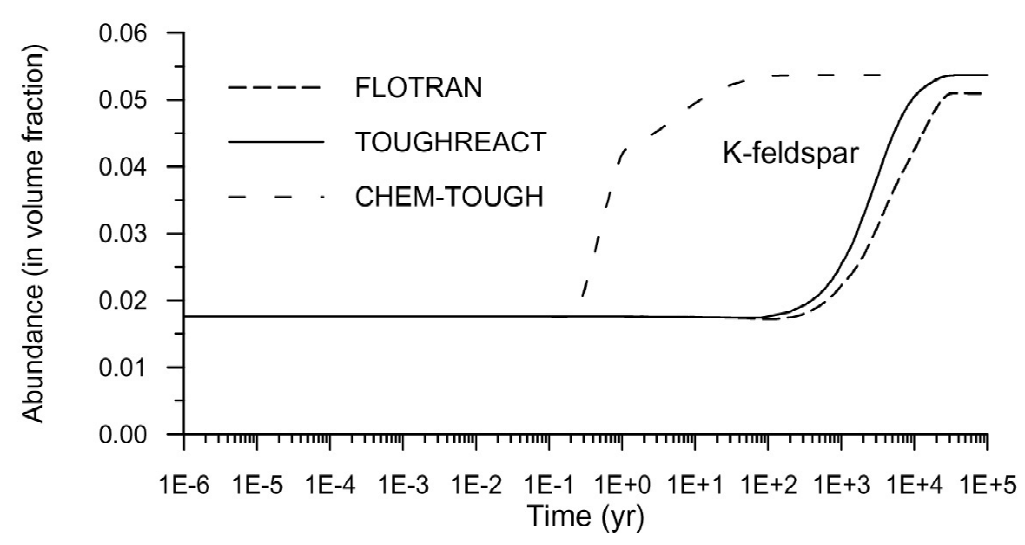

Figure 5.4i

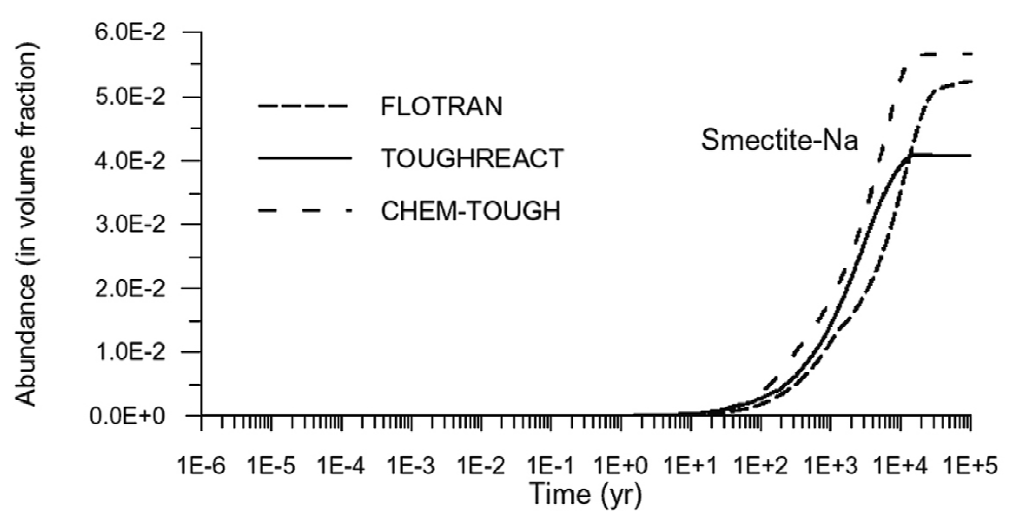

Figure 5.4j

Figure 5.4 Evolution of mineral abundances in glauconitic sandstone with $\mathrm{CO}_{2}$ injected at 260 bar. 


\section{Test Problem 6. Hydromechanical Responses During $\mathrm{CO} 2$ Injection into an Aquifer- Caprock System ${ }^{5}$}

\subsection{Problem Description}

Test Problem 6 addresses coupled hydromechanical (HM) changes in an aquifer-caprock system during injection of $\mathrm{CO} 2$ (Figure 6.1). In general, coupled HM interactions during underground fluid injection are governed by changes in effective stress and pore volume, which are accompanied by changes in hydraulic and mechanical properties (Rutqvist and Stephansson, 2003). This test problem is limited to elastic (reversible) deformation with associated changes in porosity and permeability.

Test Problem 6 is simplified to a one-dimensional column according to Figure 6.1. Detailed specifications including material properties, initial conditions and boundary conditions are given in Appendix F. The aquifer has a porosity of $10 \%$ and a permeability of $1 \times 10^{-13} \mathrm{~m}^{2}$, while the caprock has a porosity of $1 \%$ and a permeability of $1 \times 10^{-16} \mathrm{~m}^{2}$. The medium above the caprock is assumed to have the same properties as the aquifer. Both porosity and permeability depend on the effective mean stress, where the effective mean stress is the total mean stress less fluid pressure. The injection operation is simulated by injecting pure CO2 at 1500 meters depth (Figure 6.1). During an injection period of 30 years, the injection pressure is kept constant at $30 \mathrm{MPa}$, which is about $90 \%$ of the lithostatic pressure at 1500 meters depth.

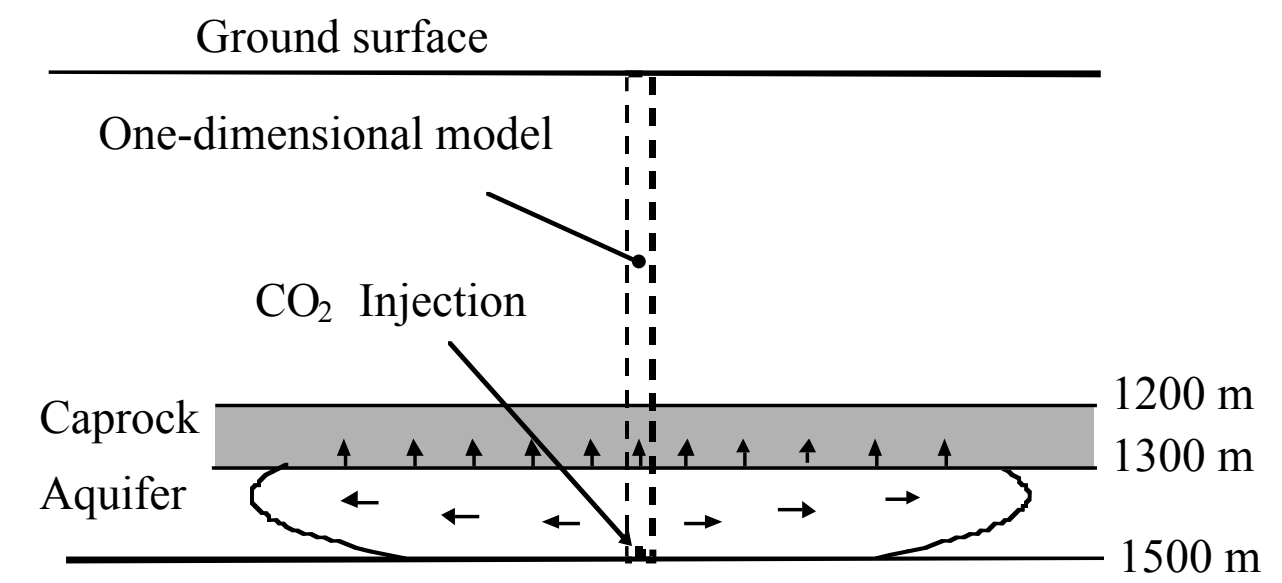

Figure 6.1 One-dimensional model of Test Problem 6 in a general three-dimensional aquifercaprock system. The exact boundary and initial conditions of the one-dimensional model are given in Appendix F.

5 proposed by Chin-Fu Tsang and Jonny Rutqvist; e-mail: CFTsang@lbl.gov, JRutqvist@lbl.gov 


\subsection{Results}

Test Problem 6 has been solved by LBNL using the TOUGH-FLAC simulator (Rutqvist et al., 2002). No solutions were obtained from other groups, and the results should be considered preliminary until confirmed by an independent simulation. The most relevant results of the LBNL solution are presented below.

Figure 6.2 presents fluid pressure versus depth. An apparent steady pressure distribution is obtained after 1 year of injection. At the injection point (1500 meter), the fluid pressure is about $90 \%$ of the lithostatic stress. At the lower part of the caprock (1300 meter), the fluid pressure is slightly lower than the lithostatic stress. However, fluid pressure does not exceed lithostatic stress at any part of the column (Figure 6.2).

Figure 6.3 presents effective mean stress versus depth. The initial effective mean stress (at $\mathrm{t}$ $=0$ ) is equal to the initial isotropic in situ stress minus initial hydrostatic fluid pressure. The figure shows that effective mean stress reduces by about $5 \mathrm{MPa}$ in the aquifer, except near the bottom, where a larger reduction is obtained. The $5 \mathrm{MPa}$ decrease in effective mean stress obtained in the aquifer (Figure 6.3) is about 1/3 of the increase in fluid pressure (Figure 6.2). Effective mean stress changes less than fluid pressure because the effective stress cannot change in two horizontal directions (in the plane of Figure 6.1 and normal to it) as no lateral expansion is allowed in the model. The vertical effective stress, on the other hand, reduces by a magnitude of $\Delta \sigma_{\mathrm{V}}^{\prime}=\Delta \sigma_{\mathrm{V}}-\Delta \mathrm{P}$ $=0-15=-15 \mathrm{MPa}$. In this calculation the total stress in the vertical direction is constant (i.e $\left.\Delta \sigma_{\mathrm{v}}=0\right)$ because the ground surface is mechanically free. The resulting change in effective mean stress can then be calculated as $\Delta \sigma_{\mathrm{m}}=\left(\Delta \sigma_{\mathrm{v}}+\Delta \sigma_{\mathrm{H} 1}+\Delta \sigma_{\mathrm{H} 2}\right) / 3=(-15-0-0) / 3=-5 \mathrm{MPa}$.

The flow of $\mathrm{CO} 2$ through the aquifer-caprock system is depicted in Figures 6.4 to 6.6. Figure 6.4 shows that $\mathrm{CO} 2$ breaks through the upper part of the cap (1200 meters depth) after about 19 years, and the flow rate reaches a maximum at 30 years, when the injection is stopped. After 30 years, $\mathrm{CO} 2$ continues to flow trough the cap as long as an excess fluid pressure (above hydrostatic) remains in the aquifer. Figure 6.5 shows that it takes more than 10 years for the $\mathrm{CO} 2$ to reach the lower part of the cap, but after 30 years the $\mathrm{CO} 2$ has already penetrated the cap and migrated up to about 1000 meters depth. Figure 6.6 shows that after 100 years, the CO2 saturation above the cap and in the lower part of the injection aquifer is close to the value of residual gas saturation $\left(S_{g r}=0.05\right)$ assigned for the $\mathrm{CO} 2$ relative permeability function. In the upper part of the aquifer, the gas saturation is close to $1-S_{l r}$ where $S_{l r}=0.3$ is the residual liquid saturation. 
The effect of hydromechanical coupling is depicted in Figures 6.7 and 6.8. Figure 6.7 shows that $\mathrm{CO} 2$ migrates upwards slightly faster when HM coupling is considered. This increased $\mathrm{CO} 2$ migration rate is caused by a stress-induced increase in permeability as shown in Figure 6.8. However, for the material properties assumed in Test Problem 6, stress-induced changes in permeability are small, a factor 2 or less. Consequently, the effect of HM coupling in Figure 6.7 is small also.

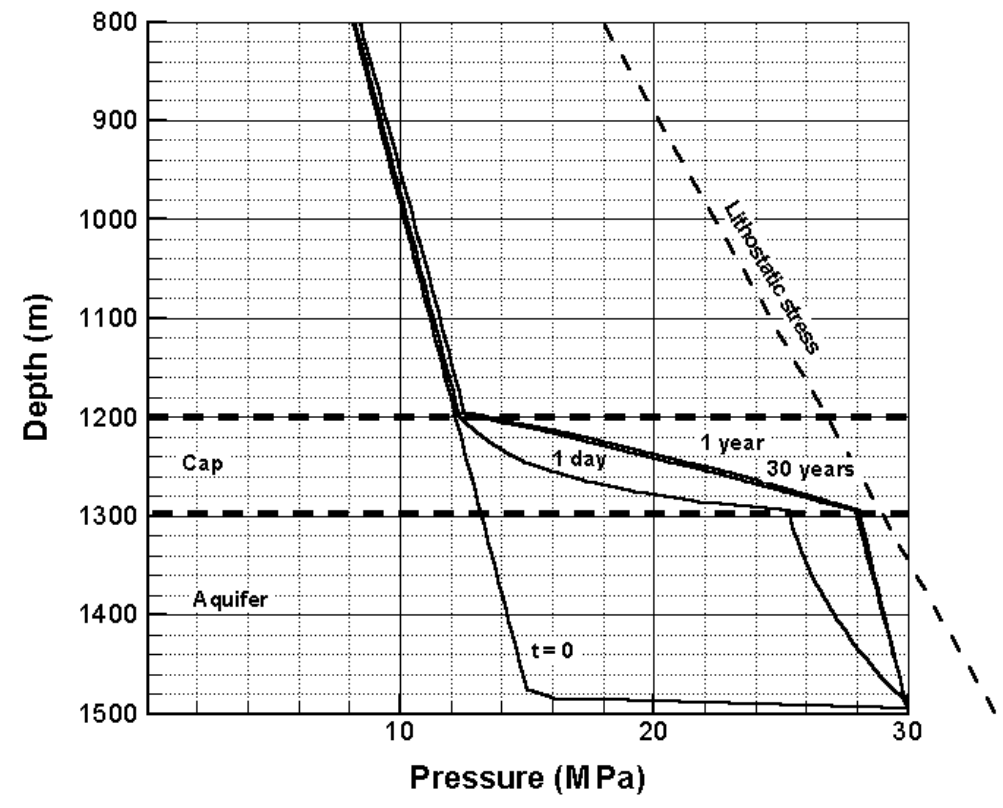

Figure 6.2 Calculated fluid pressure using the TOUGH-FLAC simulator. Note that the fluid pressure does not exceed the lithostatic stress at any point in the vertical column. 


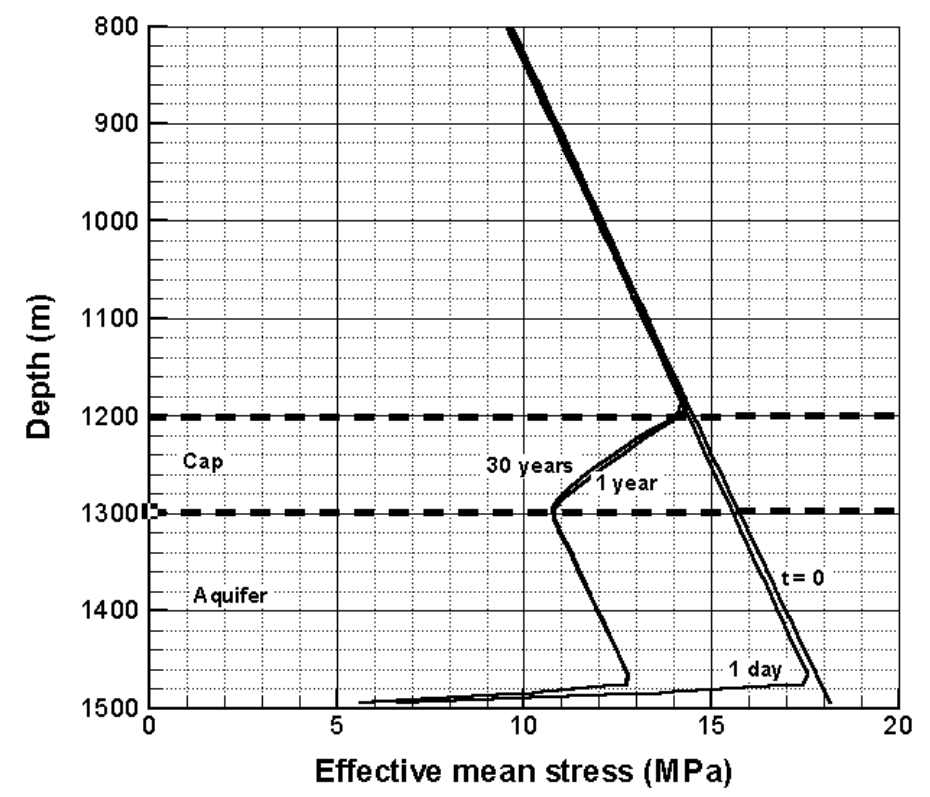

Figure 6.3 Calculated effective mean stress using TOUGH-FLAC simulator. Note that the magnitude of effective means stress changes about $1 / 3$ of the fluid pressure changes at corresponding depth.

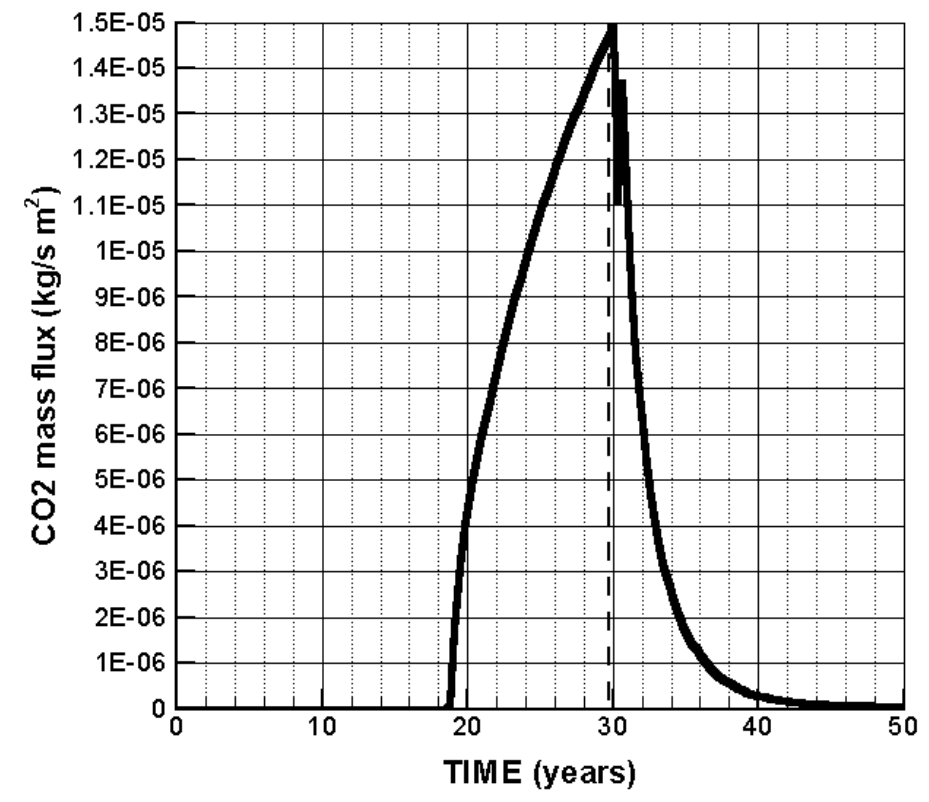

Figure 6.4 Calculated CO2 mass flux through the upper part of the caprock (1200 meters). Note that CO2 penetrates the cap at 19 years. 


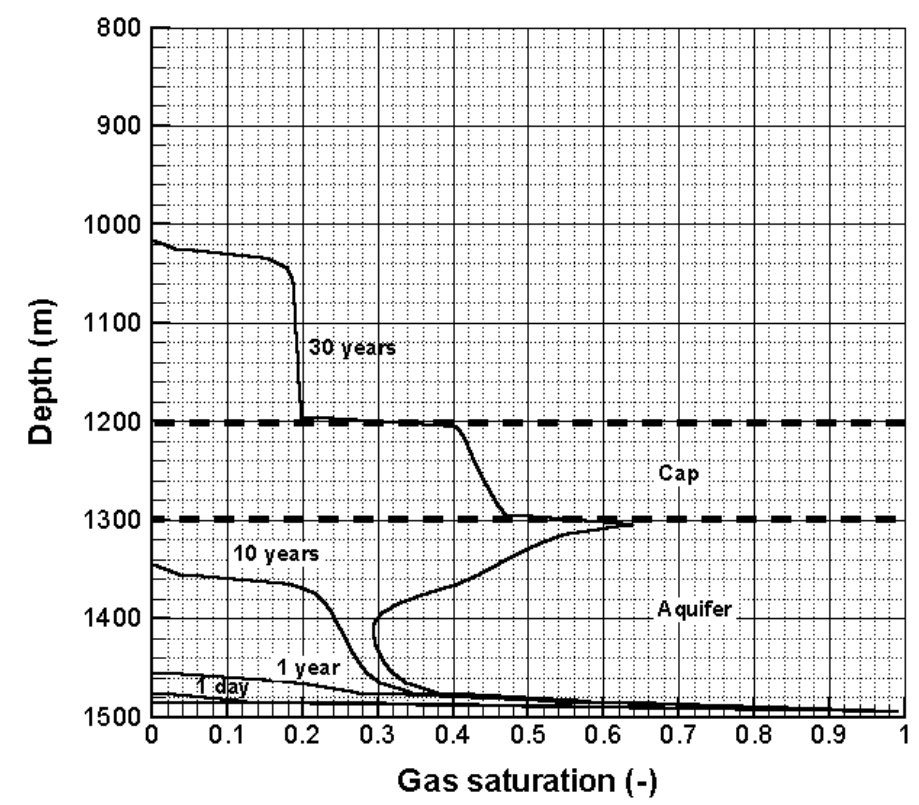

Figure 6.5 Calculated $\mathrm{CO} 2$ gas saturation at various times during 30-year injection of $\mathrm{CO} 2$.

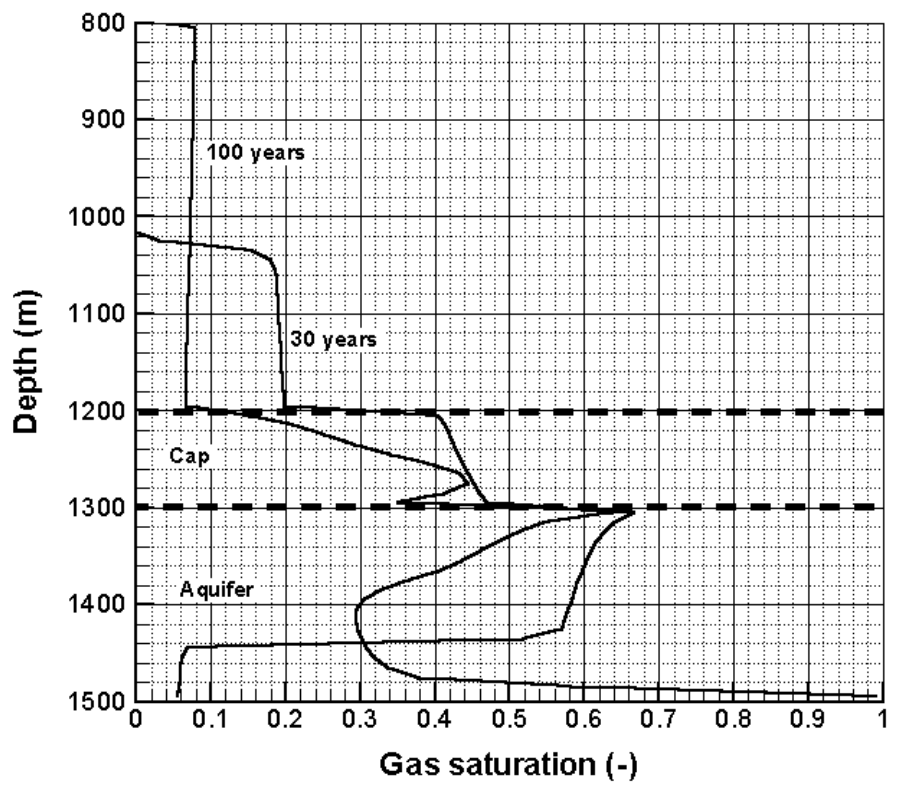

Figure 6.6 Calculated $\mathrm{CO} 2$ gas saturation after 30 and 100 years. The $\mathrm{CO} 2$ injection stopped at 30 years. 


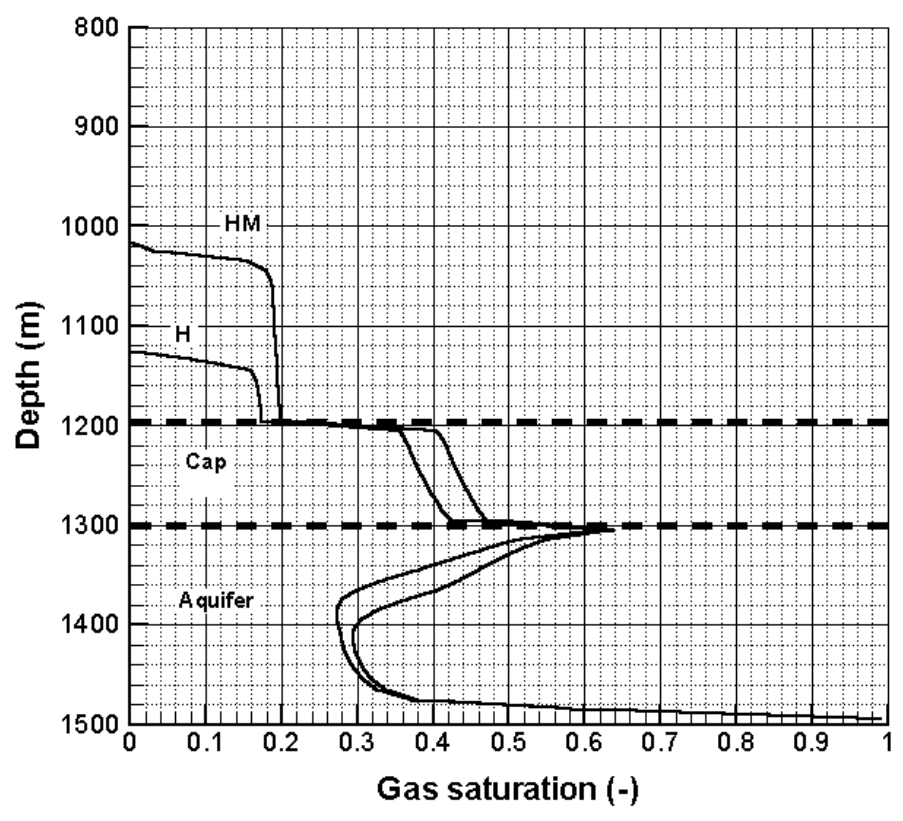

Figure 6.7 Calculated $\mathrm{CO} 2$ gas saturation at 30 years for a pure hydraulic calculation $(\mathrm{H})$ and a coupled hydromechanical (HM) calculation.

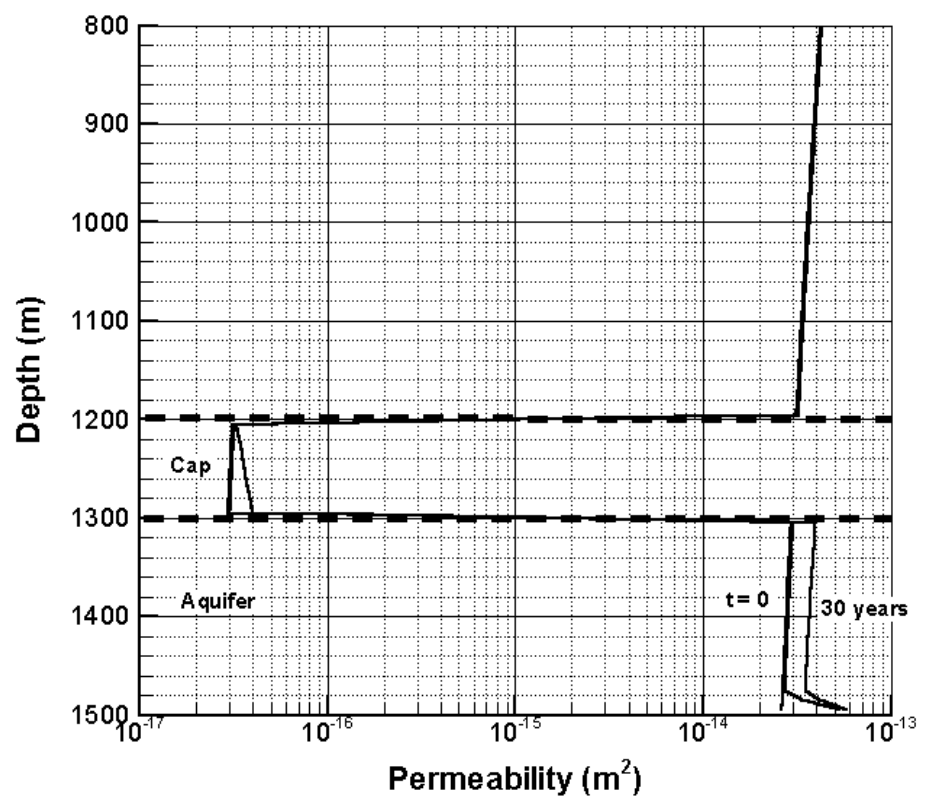

Figure 6.8 Calculated permeability profile at various times. The maximum change of permeability after 30 years is less than a factor of 2 . 


\subsection{Discussion}

This problem can be considered a first basic test of HM capabilities of coupled THMC codes for analysis of geologic sequestration of $\mathrm{CO} 2$. In this test case, the effect of HM coupling is small for the properties assumed. With the assumed stress-permeability function, the permeability could theoretically increase by one order of magnitude if the mean stress would go to zero. However, as shown in Figure 6.3, the mean stress changes much less than the increase in fluid pressure, and therefore the permeability does not change dramatically. A far more dramatic effect on permeability could be obtained in fractured media and especially if fracture opening and shear slip is induced along pre-existing fractures (Rutqvist and Stephansson, 2003). Analysis of shear-slip and local fracture opening in a heterogeneous aquifer-caprock system would require two- or threedimensional analysis as conducted by Rutqvist and Tsang (2002). Such problems in HM coupling should be tackled in code intercomparison studies once the one-dimensional problem has been solved by several independent codes. 


\section{Test Problem 7. $\mathrm{CO}_{2}$ Injection into a 2-D Layered Brine Formation ${ }^{7}$}

\subsection{Introduction and General Description}

This problem is intended to represent the dominant physical processes associated with the injection of supercritical $\mathrm{CO}_{2}$ into the Utsira Formation at the Sleipner gas field in the North Sea (Kongsjorden et al., 1997; Lindeberg et al., 2002). Many of the features of the actual injection are captured in the test problem, including the thickness of the overall Utsira Formation at the injection site, the $\mathrm{CO}_{2}$ injection rate $(1,000,000$ tonnes per year), the permeability of the sand layers in the Utsira, and the approximate pressure of the Utsira. In order to make a tractable problem for comparison of the various codes, however, some simplifications of the real situation at Sleipner have been made, the most important of which is the assumption of isothermal conditions $\left(37{ }^{\circ} \mathrm{C}\right)$. Injection of the supercritical $\mathrm{CO}_{2}$, which is less dense than the saline formation waters of the Utsira, causes it to rise through the formation. Its rate of ascent, however, is limited by the presence of four relatively low permeability shales included in the simulation, the presence of which are suggested by seismic profiling of the $\mathrm{CO}_{2}$ plume at the Sleipner field. The top and bottom of the Utsira Formation are assumed to be impermeable. The only reactive chemistry considered in this problem is the dissolution of $\mathrm{CO}_{2}$ in the aqueous phase. Problem specifications are given in appendix G. All numerical and mesh specifications were left to the users. It was determined that a $5 \%$ difference in results between final modeling results for the test case is acceptable.

\subsection{Results}

A large "bubble" of supercritical $\mathrm{CO}_{2}$ forms in the aquifer as the result of injection over the course of two years (Figure 7.1). The ascent of the $\mathrm{CO}_{2}$ is impeded by the presence of four relatively low permeability shale horizons, which also cause the plume to spread laterally. The simulations predict some slight overpressuring of the formation, with pressures rising from $11 \mathrm{MPa}$ (110 bars) at the injection well before the start of injection to about $12.6 \mathrm{MPa}$ (126 bars) after two years of injection (Figure 7.2). Predictions of the amount of $\mathrm{CO}_{2}$ "sequestered" in the aqueous phase vary between the different codes from about $21 \%$ to $31 \%$ (see Table 7.1 ).

\footnotetext{
${ }^{7}$ proposed by Carl Steefel; e-mail: steefel1@1lnl.gov
} 

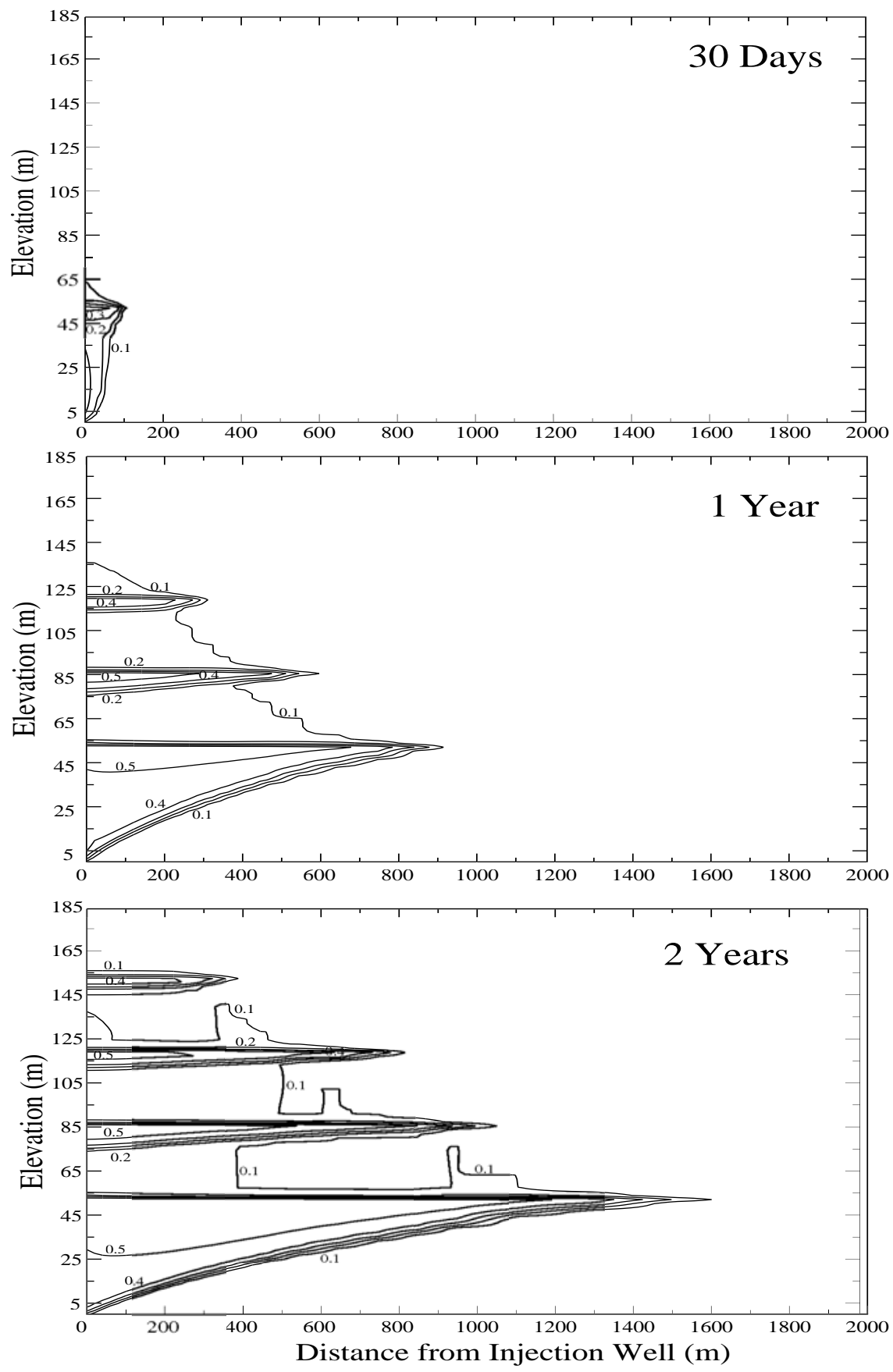

Figure 7.1 Supercritical $\mathrm{CO}_{2}$ phase saturation as a function of time in Problem 7. 
Table 7.1 Comparison of $\mathrm{CO}_{2}$ mass balances (in units of $\mathrm{kg}$ ) and "sequestration efficiency" after 2 years of injection.

\begin{tabular}{|l|l|l|l|l|l|}
\hline Code & Total $\mathrm{CO}_{2}$ & $\begin{array}{l}\mathrm{CO}_{2} \\
\text { injected }\end{array}$ & Aqueous $\mathrm{CO}_{2}$ & $\begin{array}{l}\text { Supercritical } \\
\mathrm{CO}_{2}\end{array}$ & $\begin{array}{l}\text { Fraction } \mathrm{CO}_{2} \text { in } \\
\text { Aqueous }\end{array}$ \\
\hline NUFT & $9.991 \times 10^{6}$ & $1 \times 10^{7}$ & $3.085 \times 10^{6}$ & $6.906 \times 10^{6}$ & 0.309 \\
\hline TOUGH2 & $9.999 \times 10^{6}$ & $1 \times 10^{7}$ & $2.149 \times 10^{6}$ & $7.849 \times 10^{6}$ & 0.215 \\
\hline
\end{tabular}

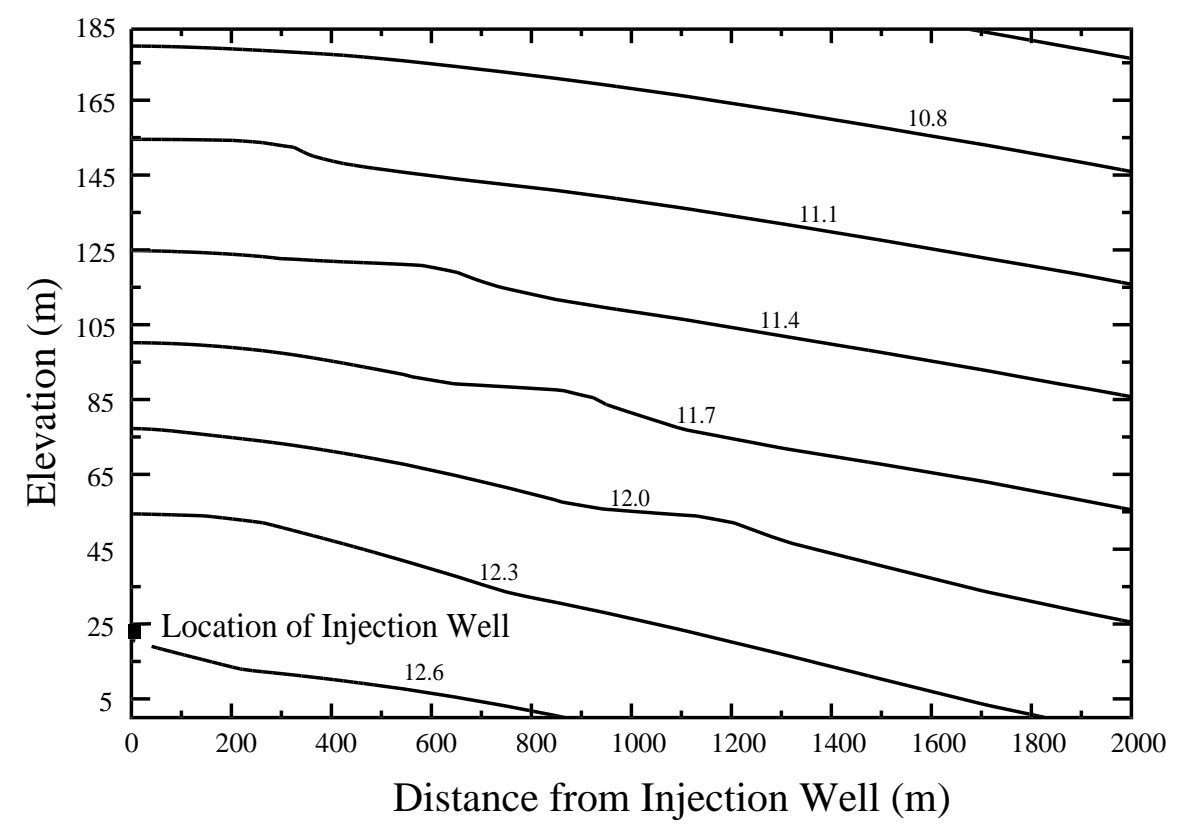

Figure 7.2 Pressure distribution after two years of $\mathrm{CO}_{2}$ injection.

In evaluating the results from the multiphase flow codes, probably the most unambiguous comparison is provided by time history plots of the amount of $\mathrm{CO}_{2}$ in the various horizons within the formation. Figure 7.3 compares the total amount of $\mathrm{CO}_{2}$ (aqueous and supercritical fluid) in the five different sands within the formation as a function of time. Sand 1 is the lowest in the formation and contains the injection well, Sand 5 is the highest. Results are presented for the LBNL (TOUGH2), LLNL (NUFT), and CSIRO multiphase flow codes for the case of a saline pore water (3.2 wt \% NaCl). In Sand 1, the agreement is excellent between the three codes. The discrepancy between NUFT and the other two codes worsens as successively higher sands within the formation are considered, but this is primarily the result of the use of too large an initial $\mathrm{CO}_{2}$ concentration in the case of the NUFT runs (compare the masses of $\mathrm{CO}_{2}$ in the topmost sand at 30 days). This difference is magnified when smaller total $\mathrm{CO}_{2}$ masses are considered, as is the case in Sand 5 . 

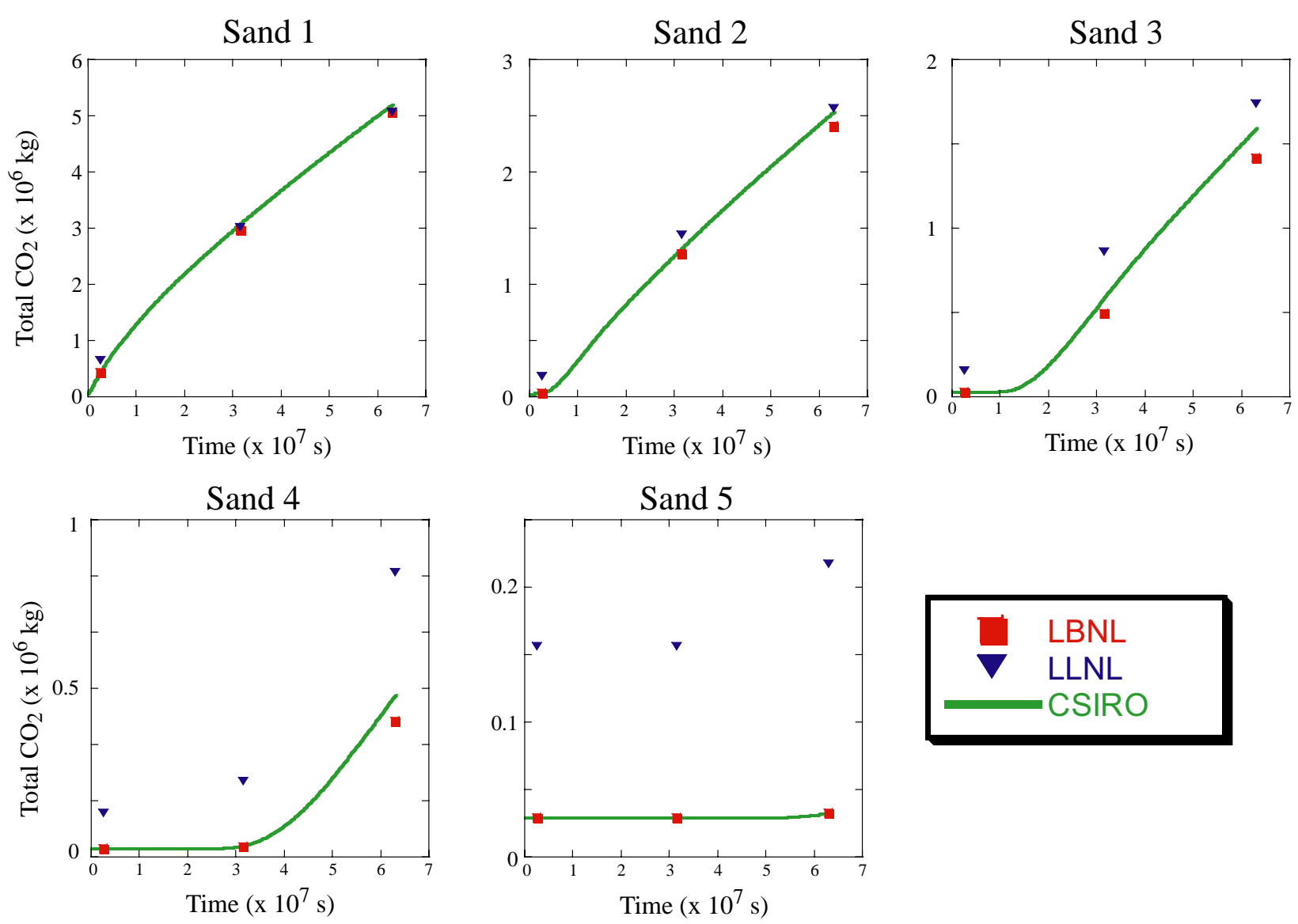

Figure 7.3 Time histories of total $\mathrm{CO}_{2}$ for the various sands within the formation. Sand 1 is the lowest sand in the formation, Sand 5 the highest. The discrepancy in total $\mathrm{CO}_{2}$ apparent in Sands 4 and 5 is primarily the result of the use of a higher initial concentration of $\mathrm{CO}_{2}$ in the aqueous phase in the case of LLNL.

Another difference between the NUFT results and both TOUGH2 and the CSIRO codes, however, is apparent in the time history for Sand 4 (Figure 7.3). The discrepancy becomes slightly larger with time due to the use of a lower Henry's Law coefficient for $\mathrm{CO}_{2}$ in the case of NUFT, thus resulting in slightly higher partitioning of $\mathrm{CO}_{2}$ into the aqueous phase. This is also apparent in the total mass balances of $\mathrm{CO}_{2}$ in the aqueous and supercritical phases (which provide a measure of the "sequestration efficiency") calculated by TOUGH2 and NUFT, with NUFT predicting almost 31 $\%$ of the total $\mathrm{CO}_{2}$ injected being partitioned into the aqueous phase while TOUGH2 predicts about $21 \%$.

Comparisons between the saline and "fresh" pore water cases indicate only very small differences in the results. Since a larger group carried out the fresh pore water simulations, only these will be considered further here. Figure 7.4 shows vertical profiles of the $\mathrm{CO}_{2}$ supercritical 
phase distribution as a function of time at a horizontal distance of 10 meters from the injection well. At 30 days and 2 years, all of the codes predict the position of the leading edge of the $\mathrm{CO}_{2}$ bubble within about $5 \%$ or less. At 1 year, the discrepancy is slightly larger, with the MUFTE_UG code (University of Stuttgart, Germany) and NUFT predicting the $\mathrm{CO}_{2}$ bubble to have risen about 20 to 30 meters past the position predicted by the other codes. Spatial snapshots of this kind, however, can be somewhat deceptive, since a slightly earlier breakthrough through a low permeability shale unit can result in significant spatial separation as the $\mathrm{CO}_{2}$ bubble then moves through the high permeability sand. Some of the discrepancy may also be due to the slightly lower pressure used in the MUFTE_UG runs which is traceable to a lack of clarity in the original problem formulation on the part of the problem organizer (Figure 7.5). The use of slightly different pressure boundary conditions results in about 4 to 5 bars lower pressure in the case of the MUFTE_UG results, which in turn results in slightly lower densities for the $\mathrm{CO}_{2}$ phase. This slightly lower $\mathrm{CO}_{2}$ density may account for the slightly faster rate of ascent of the $\mathrm{CO}_{2}$ bubble. A higher buoyancy for the $\mathrm{CO}_{2}$ bubble in the MUFTE_UG and perhaps in the IFP case may also account for less lateral spreading of the $\mathrm{CO}_{2}$ plume that is apparent after 1 year of injection (Figure 7.6).
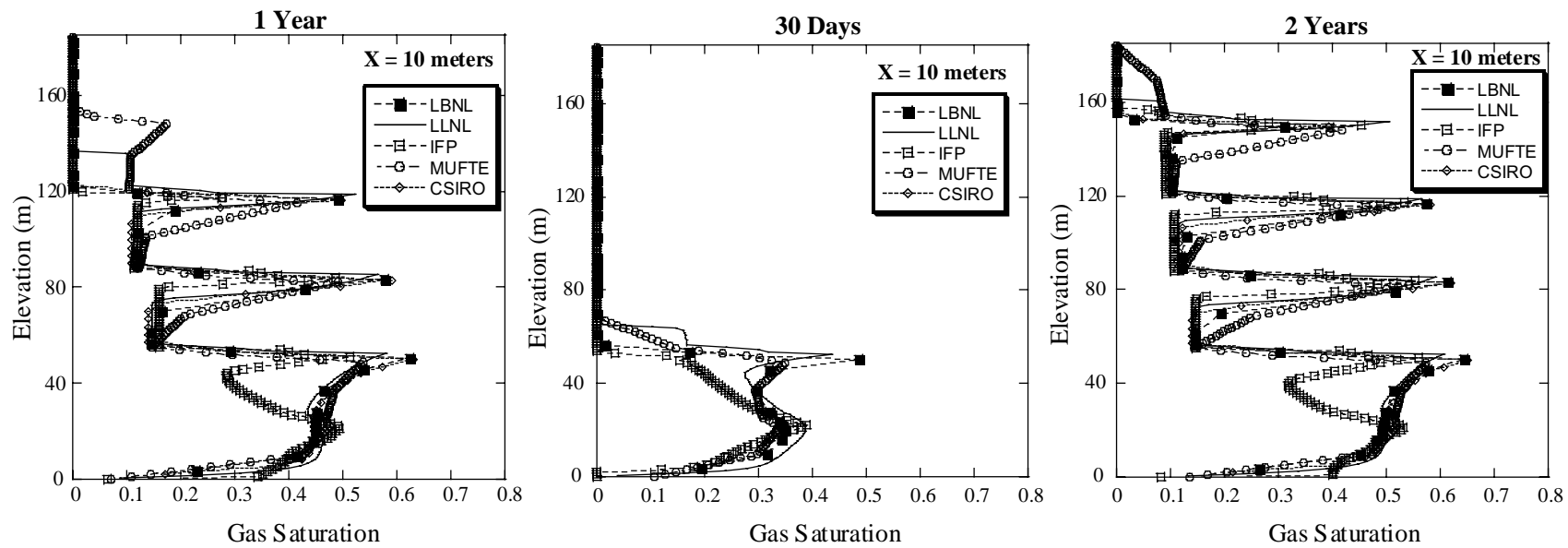

Figure 7.4 Vertical profiles of $\mathrm{CO}_{2}$ phase saturation at a horizontal distance of 10 meters from the injection well. 

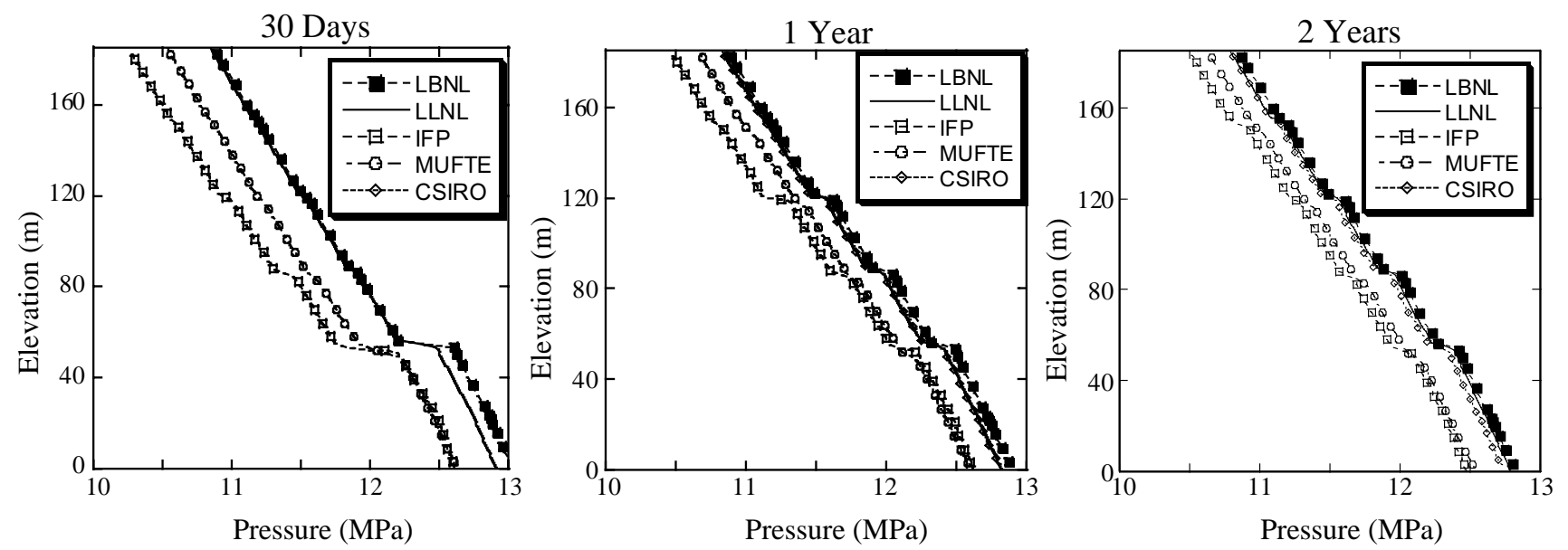

Figure 7.5 Pressure distributions at a horizontal distance of 10 meters from the injection well.
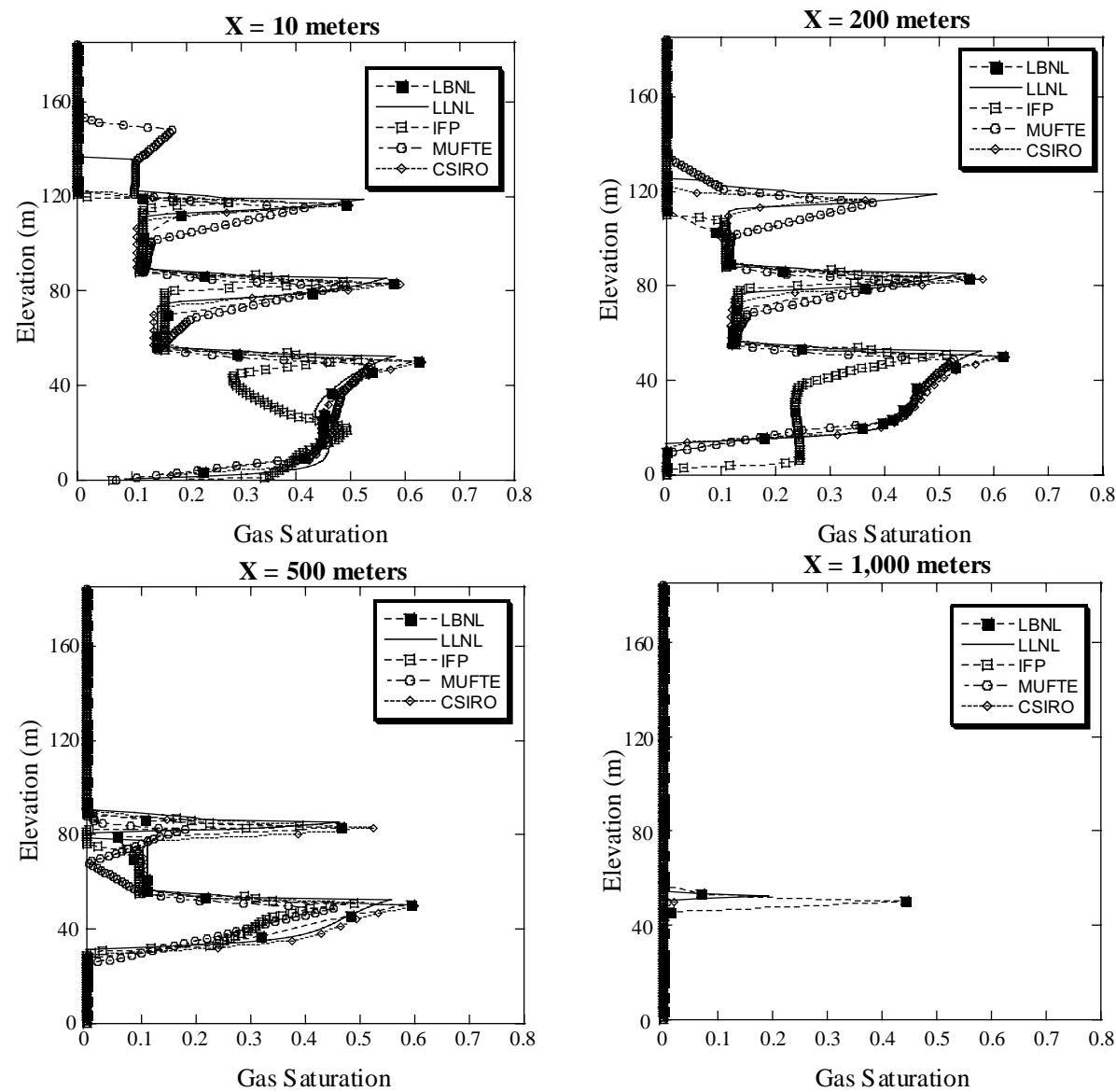

Figure 7.6 Vertical profiles of $\mathrm{CO}_{2}$ phase saturations after 1 year of injection at various horizontal distances from the injection well. 
This same feature, however, is not really apparent after 2 years of injection, with all of the codes giving very similar results (Figure 7.7). Any differences in the $\mathrm{CO}_{2}$ phase saturation apparent in Figures 7.3 through 7.7 cannot be attributed to the use of differing equations of state. Densities and viscosities of the $\mathrm{CO}_{2}$ phase as a function of pressure (at the ambient temperature of $37^{\circ} \mathrm{C}$ ) used by the various codes are very similar (Figure 7.8).
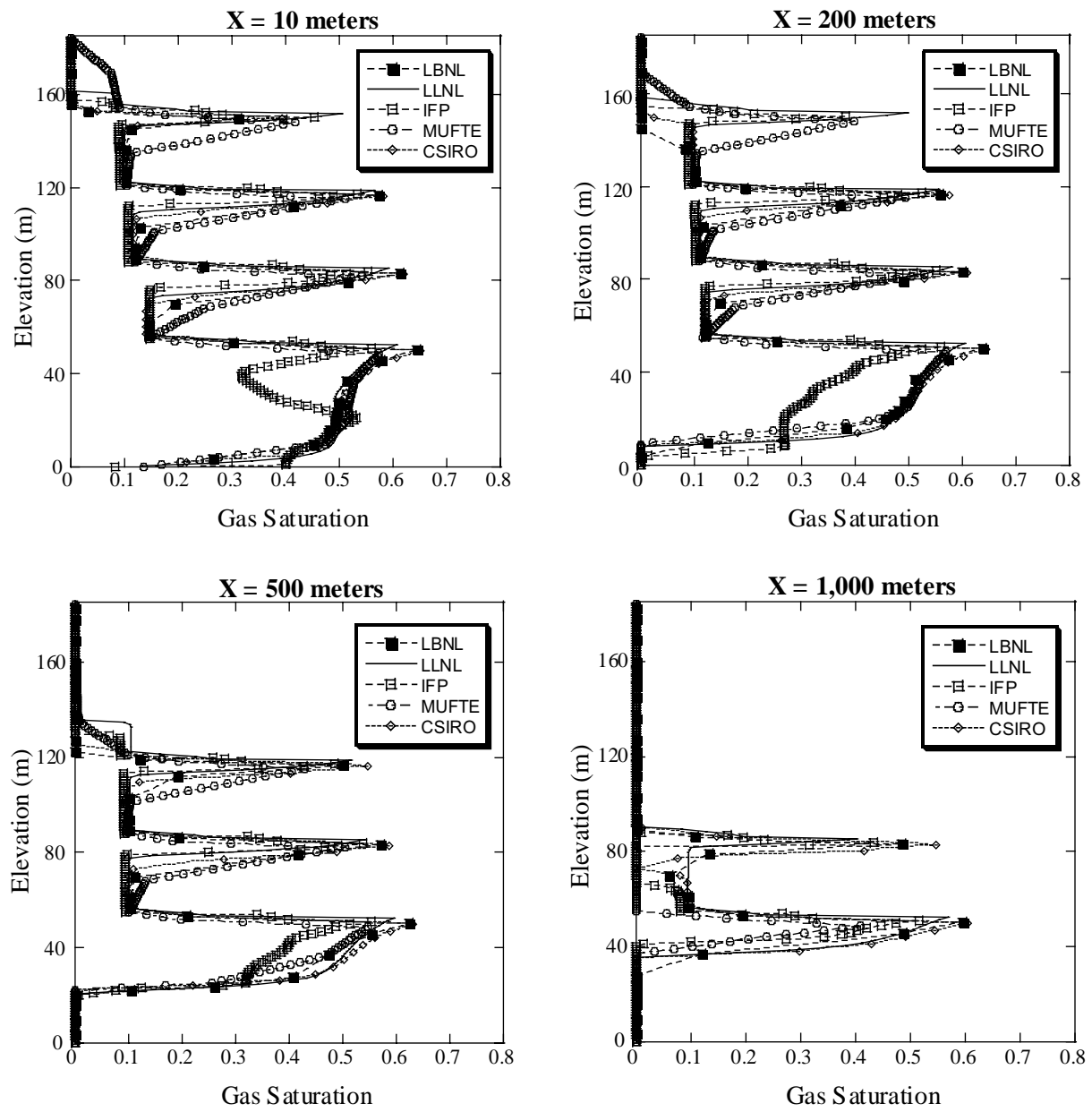

Figure 7.7 Vertical profiles of $\mathrm{CO}_{2}$ phase saturations after 2 years of injection at various horizontal distances from the injection well. 

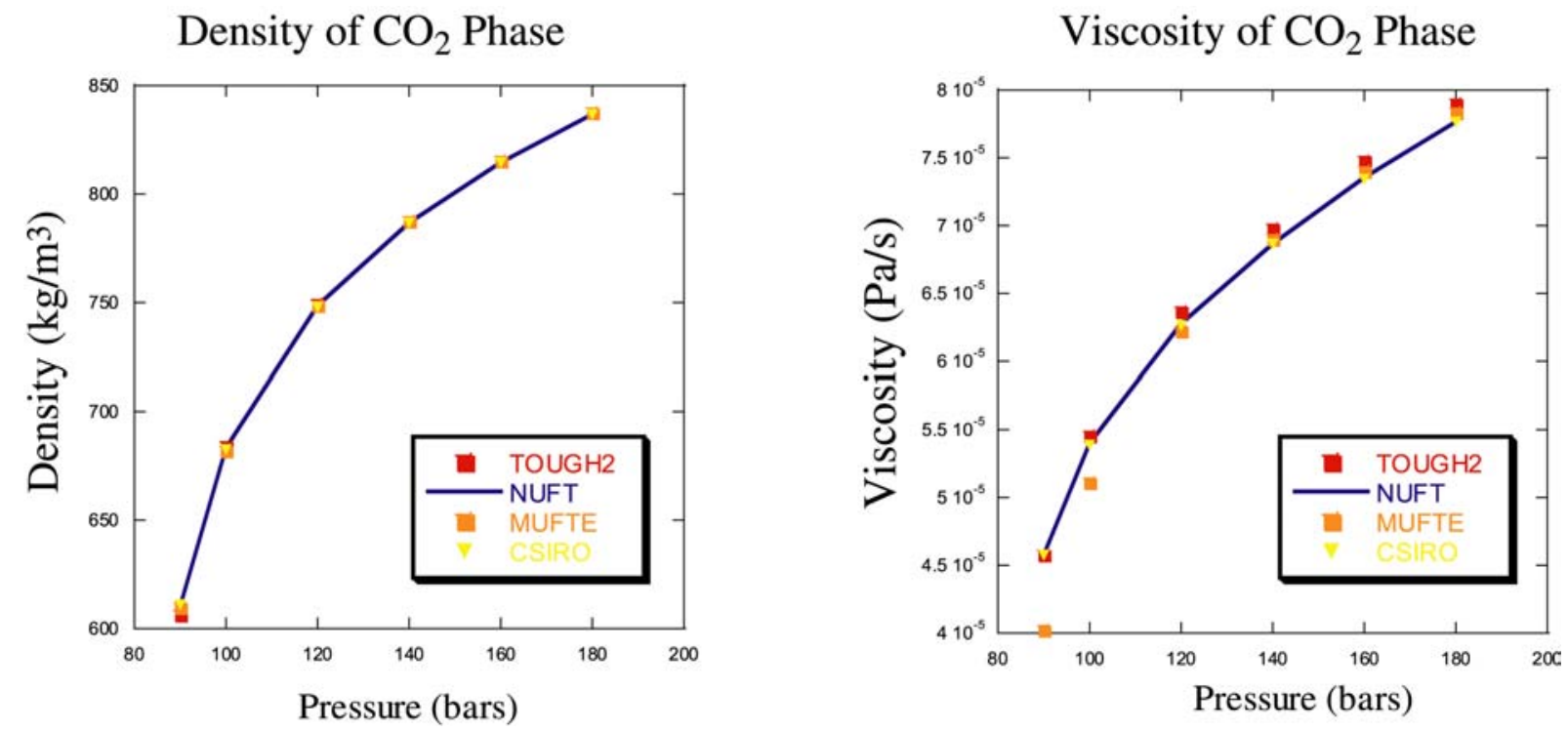

Figure 7.8 Density and viscosity of the supercritical $\mathrm{CO}_{2}$ phase at $37^{\circ} \mathrm{C}$ as a function of pressure used by the various codes applied to Problem 7 . 


\section{Test Problem 8. CO2-Oil Displacement and Phase Behavior ${ }^{1}$}

\subsection{Problem Description}

This problem examines our ability to predict the interplay of $\mathrm{CO}_{2}$-oil phase behavior with multiphase flow. $\mathrm{CO}_{2}$ is injected into an oil-containing medium under two different conditions leading to immiscible and miscible displacement. Numerical exercises study the representation of multiphase flow, the description of miscibility and phase behavior in the presence of $\mathrm{CO}_{2}$, the formulation of constitutive relations (such as density, viscosity, and $\mathrm{CO}_{2}$ solubility), and the degree of dispersion in numerical solutions.

The problem is posed in a one-dimensional geometry so that direct comparison can be made to analytical solutions available for the $\mathrm{CO}_{2}$-oil flow problem (Monroe et al. 1990, Orr et al. 1993). These solutions do not include the effects of capillary and hydrodynamic dispersion, but the effect of volume change on mixing is computed. Input data consist of oil composition, injection composition, and multiphase flow properties, see Appendix H.

\subsection{Results}

Solutions obtained were generated: (1) analytically, (2) by Stanford University (SU) using a research finite-difference simulator, (3) by Alberta Research Council (ARC) via the commercial code GEM (CMG, 2001), and (4) by Los Alamos National Laboratory (LANL) using the commercial code ECLIPSE 300 (Schlumberger, 2001). The research simulator is based on a fullyexplicit formulation, whereas GEM and ECLIPSE 300 are finite-difference simulators with variable implicitness and automatic time stepping. GEM and ECLIPSE simulations were run with 5000 and 50 grid blocks, respectively, in the fully implicit mode.

Gas or vapor saturation, $S_{\mathrm{g}}$, and the total mole fraction composition, $\mathrm{z}_{\mathrm{i}}$, of each component along the one-dimensional medium were requested. For consistency and to obtain a dimensionless formulation, the abscissa is plotted as $\mathrm{x}_{\mathrm{D}} / \mathrm{t}_{\mathrm{D}}$ where the dimensionless distance, $\mathrm{x}_{\mathrm{D}}$, is defined as $\mathrm{x} / \mathrm{L}$, the dimensionless time, $\mathrm{t}_{\mathrm{D}}$, is $\mathrm{q}_{\mathrm{inj}} \mathrm{t} / \phi \mathrm{AL}$, and $\mathrm{A}$ is the cross-sectional area of the medium.

Case (1) represents immiscible injection of $\mathrm{CO}_{2}$. Results are summarized in Fig. 8.1. The solid line marked "MOC" denotes the analytical solution obtained by the method of characteristics. The other lines are labeled by participant: SU, ARC, and LANL. Figure 8.1 demonstrates that all results track well, generally, the position of the gas saturation front. Nevertheless all numerical

\footnotetext{
1 proposed by Tony Kovscek; email: kovscek@pangea.stanford.edu
} 
solutions display dispersion. Both the research code and GEM were run with 5000 grid blocks and these solutions still display dispersion. The research code displays less dispersion because time stepping occurs in a fully-explicit fashion. The research code run with 100 grid blocks, labeled "SU 100", and ECLIPSE 300 run with 50 grid blocks examine the effect of discretization on dispersion. As the results in Fig. 8.1 demonstrate, resolution decreases with the number of grid blocks.

Similarly, Fig. 8.1 shows that the numerical solutions track the position and shape of the profiles of each component with accuracy that increases as the number of grid blocks increases. The interplay of phase behavior and two-phase flow causes chromatographic separation of the components. The components present in the oil form banks and waves that are ordered according to their equilibrium $\mathrm{K}$ values. Methane is the most volatile component, as characterized by its K-value. Hence, the leading bank contains all of the methane. Decane is the least volatile component and so it traverses the system most slowly. Again, a substantial number of grid blocks are required to overcome the effects of numerical dispersion. Examine the composition profile for methane. The hydrocarbon bank just downstream of the vapor saturation front at $\mathrm{x}_{\mathrm{D}} / \mathrm{t}_{\mathrm{D}}$ of roughly 0.9 is almost entirely methane. GEM nearly reproduces the shape of the methane bank although bank position is somewhat farther downstream than the analytical solution. As the number of grid blocks decreases in the respective simulations, resolution of this bank decreases.

In Case (2), injection of $\mathrm{CO}_{2}$ occurs under a near-miscible condition. Comparison of the analytical solutions in Figs. 8.1 and 8.2 indicates that the leading shock moves more slowly at high pressure, whereas the trailing shocks accelerate. Thus, the two-phase flow region is compressed, as indicated by Fig. 8.2. If the pressure were increased to $12.1 \mathrm{MPa}$, the system would indeed be multicontact miscible and all saturation shocks would merge resulting in piston-like displacement. Again the numerical solutions approximate the analytical solution with accuracy that decreases in proportion to the number of grid blocks. Figure 8.2 illustrates an interesting counterpoint regarding dispersion in miscible and immiscible finite difference simulations. The position of the leading vapor saturation shock is retarded by the effects of numerical dispersion. The profile for $\mathrm{CO}_{2}$ concentration in Fig. 8.2 is significantly smeared by the 100 grid block research code, labeled SU 100, and ECLIPSE 300 simulations, labeled LANL. The smearing delays the accumulation of sufficient $\mathrm{CO}_{2}$ to cause a phase transition

The challenge for any numerical reservoir simulator that incorporates multiphase flow and phase behavior is to track accurately the path that a displacement follows in composition space. Figure 8.3 illustrates this point graphically for Case (1). Such a diagram is used to illustrate the equilibrium phase behavior and/or the route through composition space that a solution follows. The 
points labeled "oil" and "gas" represent the initial oil composition and the injected gas composition, respectively. In Figure 8.3, each vertex of the pyramid indicates $100 \%$ of a particular component. The figure shows the composition path obtained from the analytical result, dashed line, as well as that predicted by the research finite-difference code, solid line. As the number of grid blocks becomes fewer, the route followed by a finite difference simulation approaches a straight line connecting the oil and gas compositions. This straight line is sometimes referred to as the dilution line. Figure 8.3 also shows quite well that the effects of dispersion as a function of grid resolution are more pronounced for solutions that are farther, in space or time, from the injection point. More thorough discussions of the relationship between phase behavior, finite-difference simulation, and dispersion are available in the literature (Walsh and Orr, 1990; Jessen et al., 2002). 

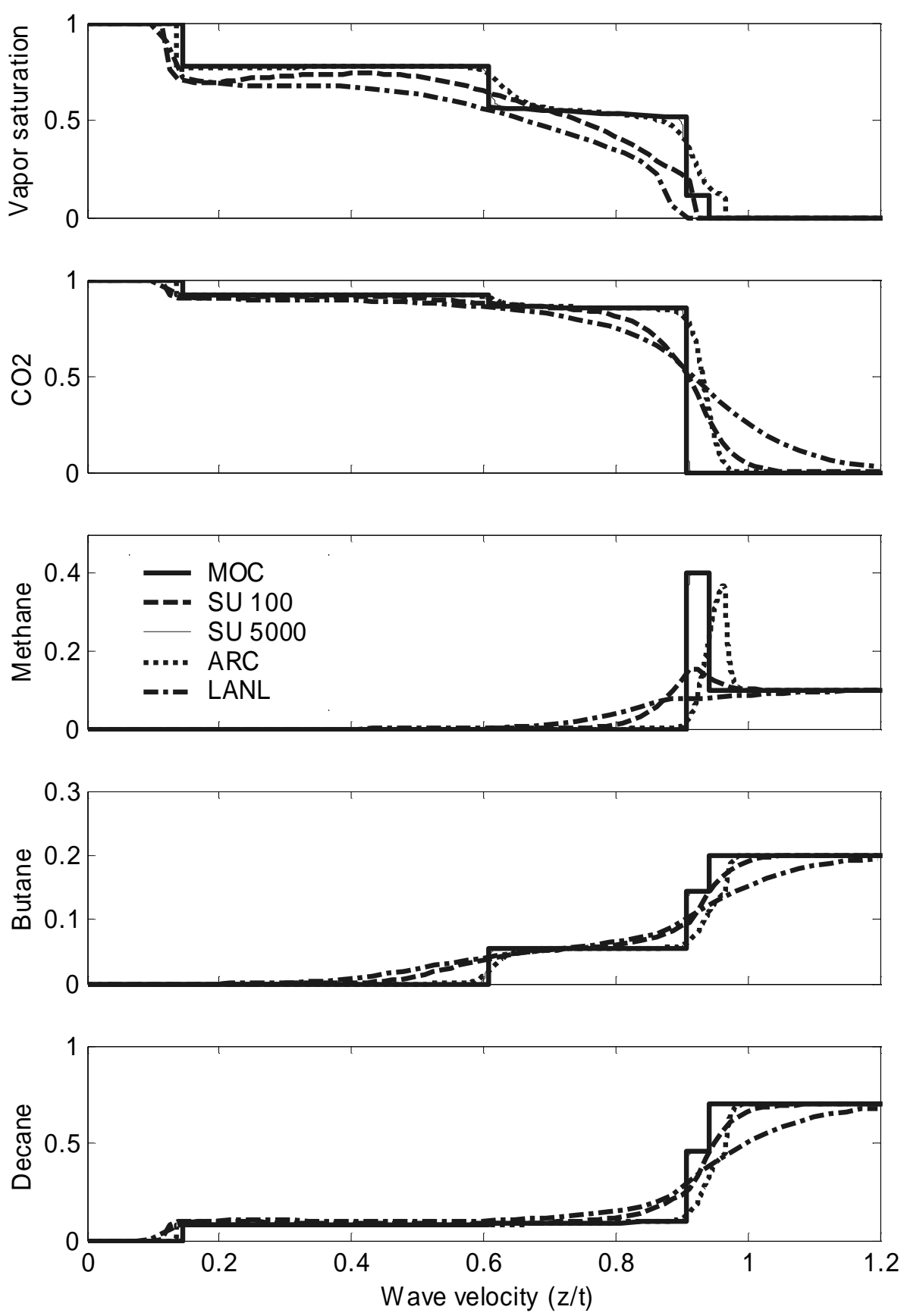

Figure 8.1 Comparison of simulation results at $11 \mathrm{MPa}$, case (1). 

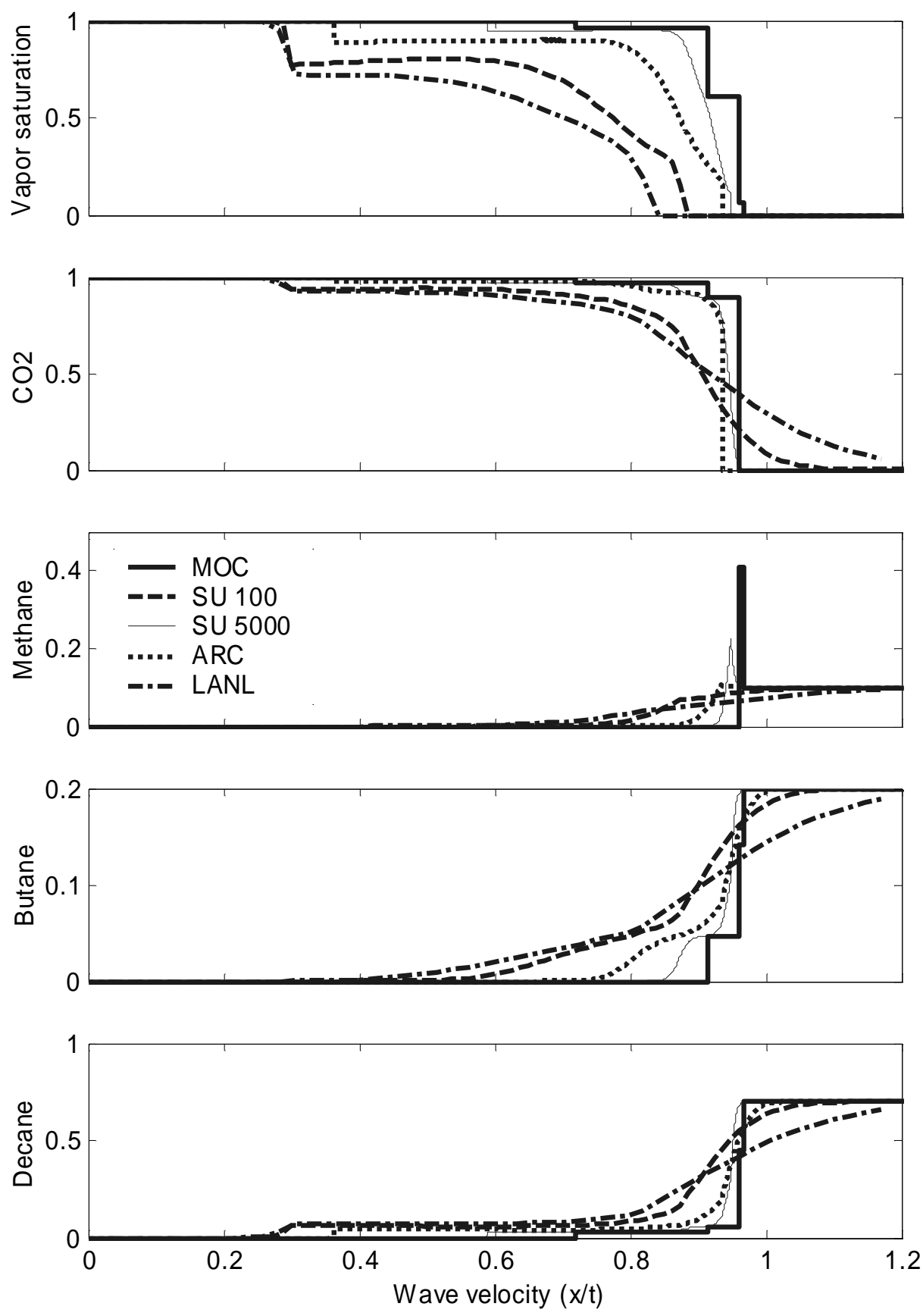

Figure 8.2 Comparison of simulation results at $12 \mathrm{MPa}$, case (2). 


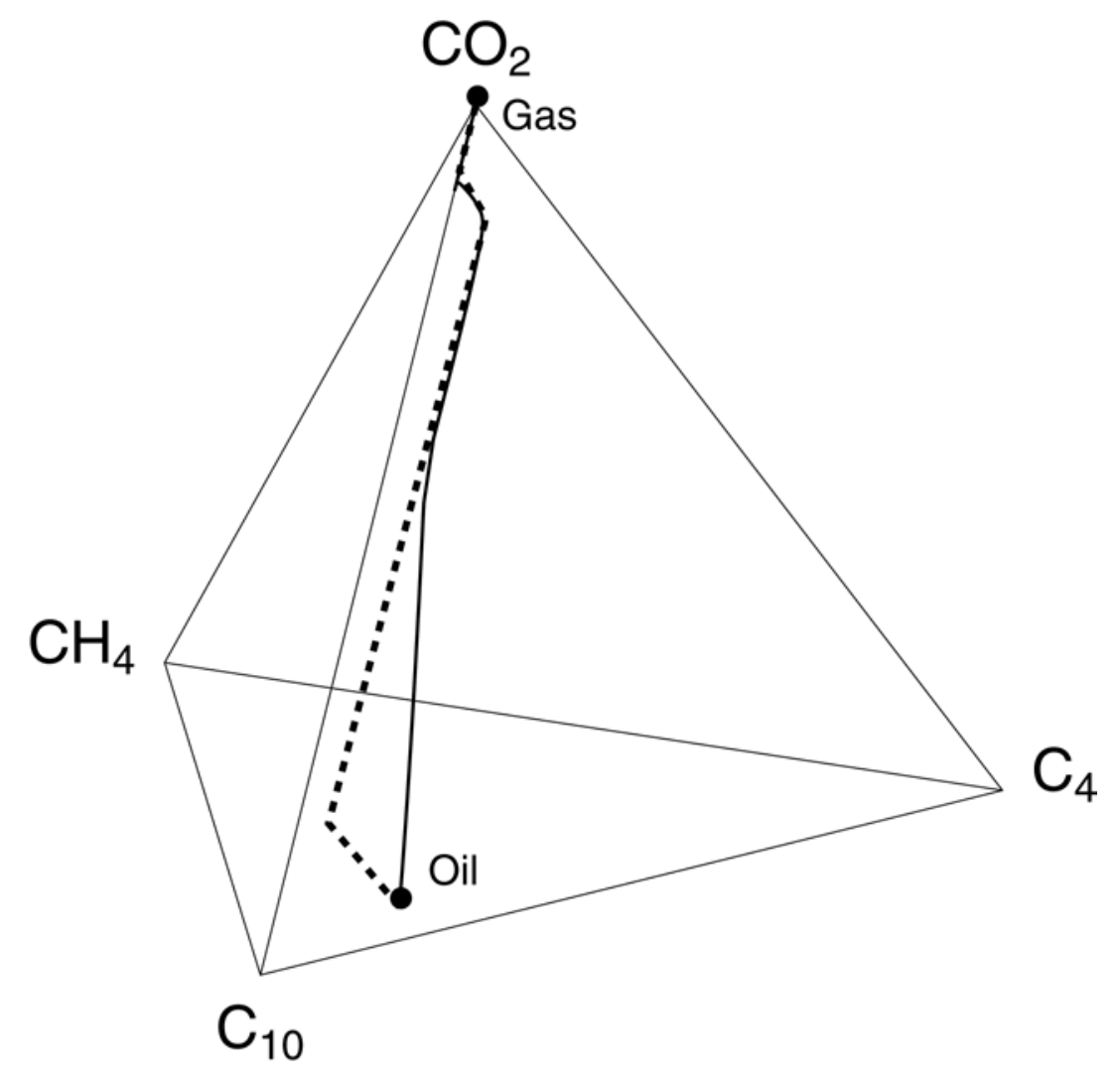

Figure 8.3 Solution route in composition space. Analytical solution (broken line) and FD 100 simulation results. 


\section{Concluding Remarks}

The study reported here has documented the capabilities of currently available numerical simulation codes to represent physical and chemical processes that would accompany $\mathrm{CO} 2$ disposal into geologic formations, including oil and gas reservoirs, and brine aquifers. Codes from ten participating groups have been exercised on a series of eight test problems that probed advective and diffusive mass transport in multiphase conditions, with partitioning of $\mathrm{CO} 2$ between gas and aqueous phases; two problems also involved solid minerals and oil phases, respectively. In the course of the study a number of bugs were found and corrected in several simulation codes. Substantial agreement was found between results predicted from different simulators, but there are also areas with only fair agreement, as well as some significant discrepancies. Most disagreements could be traced to differences in fluid property descriptions, and this clearly is an area that will require continuing efforts by code developers to assure that realistic results can be obtained. Some disagreements are due to effects from space and time discretization, while in some cases

discrepancies were noted for which no rational explanation could be found. Although code development work undoubtedly must continue, this work has shown that codes are available now that can model the complex phenomena accompanying geologic storage of $\mathrm{CO} 2$ in a robust manner, and with quantitatively similar results.

It should be noted that the test problems studied here, although prototypical for field problems, make many simplifications and approximations that should be overcome in future work. Subsurface reservoirs generally have complex heterogeneity on different scales, flows are threedimensional, and are coupled to geochemical and geomechanical effects. Non-isothermal phenomena may also come into play, and a broad range of time scales is of interest in connection with geologic sequestration. It is hoped that future code intercomparisons will address coupled processes in fully three-dimensional heterogeneous media, constrained by actual field observations.

\section{Acknowledgement}

This work was supported as part of the GeoSeq project by the National Energy Technology Laboratory (NETL) of the U.S. Department of Energy under Contract No. DE-AC03-76SF00098. We thank Andreas Bielinski, Jonathan Ennis-King, Yann Le Gallo, Kristian Jessen, David H.-S. Law, Peter Lichtner, Rajesh Pawar, Bryan Travis, Steve White and Mark White for participating in this study and submitting results. Nic Spycher (LBNL) provided the reference solubility values in Tables 2.1 and 2.2. For assistance and reviews of parts of the manuscript we thank Peter Sammon, Mohamed Hassam, Y. Wang, and J. Zhu. We are grateful to Sally Benson for her review of the manuscript and valuable suggestions. 


\section{References}

Buckley, SE. and M.C. Leverett. Mechanism of Fluid Displacement in Sands, Trans. Am. Inst. Min. Metall. Eng., Vol. 146, pp. 107 - 116, 1942.

Chapman, N., J. Andersson, P. Bogorinski, J. Carrera, J. Hadermann, D. Hodgkinson, P. Jackson, I. Neretnieks, S. Neuman, K. Skagius, T. Nicolson, C.F. Tsang and C. Voss. Developing Groundwater Flow and Transport Models for Radioactive Waste Disposal - Six Years of Experience from the INTRAVAL Project, in the proceedings of an NEA/SKI Symposium, Paris, France, pp. 45 -58, October, 1994.

CMG--Computer Modeling Group. GEM Version 01 User's Guide, Calgary, Alberta, Canada, 2001.

Doughty, C. and K. Pruess. A Similarity Solution for Two-Phase Water, Air and Heat Flow Near a Linear Heat Source in a Porous Medium, J. of Geophys. Res., 97 (B2), pp. 1821-1838, 1992.

Firoozabadi, A. and L. K. Thomas. Sixth SPE Comparative Solution Project: A Comparison of Dual-Porosity Simulators, paper SPE-18741, presented at Tenth SPE Symposium on Reservoir SimulationHouston, Texas, February 6-8, 1989.

García, J. Density of Aqueous Solutions of CO2, Lawrence Berkeley National Laboratory Report LBNL-49023, Berkeley, CA, 2001.

Gunter W.D., B. Wiwchar and E.H. Perkins. Aquifer Disposal of $\mathrm{CO}_{2}$-rich Greenhouse Gases: Extension of the Time Scale of Experiment for $\mathrm{CO}_{2}$-Sequestering Reactions by Geochemical Modeling, Mineral. and Petrol., Vol. 59, pp. 121-140, 1997.

Hitchon, B. (ed.). Aquifer Disposal of Carbon Dioxide, Geoscience Publishing, Ltd., Sherwood Park, Alberta, Canada, 1996.

Jessen, K., E.H. Stenby and F.M. Orr, Jr. Interplay of Phase Behavior and Numerical Dispersion in Finite Difference Compositional Simulation, paper SPE 75134, Proceedings of the 2002 SPE/DOE Improved Oil Recovery Conference, Tulsa, OK, April 13-17, 2002.

Jing, L., C. F. Tsang, and O. Stephansson. DECOVALEX: an International Co-operative Research Project on Mathematical Models of Coupled T-H-M Processes for Safety Analysis of Radioactive Waste Repositories, Int. J. Rock Mech. Min. Sci. \& Geomech. Abstr., Vol. 32, No. 5, pp. 389-398, 1995.

Johnson J.W., E. Oelkers and H.C. Helgeson. SUPCRT92: A Software Package for Calculating the Standard Molal Thermodynamic Properties of Minerals, Gases, Aqueous Species and Reactions from 1 to 5000 bar and 0 to $1000{ }^{\circ} \mathrm{C}$, Computers and Geosciences, Vol. 18, pp. 899 - 947, 1992.

Kongsjorden, H., O. Karstad and T.A. Torp. Saline Aquifer Storage of Carbon Dioxide in the Sleipner Project, Waste Management, Vol. 17, No. 5/6, pp. 303 - 308, 1997.

Larsson, A. The International Projects INTRACOIN, HYDRAOCOIN, and INTRAVAL, short communication in Advances in Water Resources, Vol. 15, pp. 85 - 87, 1992.

Law, D.H.S., L.G.H. van der Meer and W.D. Gunter. Numerical Simulator Comparison Study for Enhanced Coalbed Methane Recovery Processes, Part I: Pure Carbon Dioxide Injection, paper SPE-75669, presented at SPE Gas Technology Symposium, Calgary, Alberta, Canada, 30 April-2 May 2002. 
Lichtner, P.C. FLOTRAN: User's Manual, Los Alamos National Laboratory Report, LA-UR-022349, 2001.

Lindeberg, E., P. Bergmo and A. Moen. The Long-Term Fate of CO2 Injected into an Aquifer, paper G1-4, presented at Sixth International Conference on Greenhouse Gas Technologies (GHGT-6), Kyoto, Japan, October 1-4, 2002.

Monroe, W.W., M.K. Silva, L.L. Larson, and F.M. Orr, Jr. Composition Paths in Four Component Systems: Effect of Dissolved Methane on 1D CO2 Flood Performance, SPE Res. Eng., Aug, 423-432, 1990.

NIST (National Institute of Science and Technology). NIST Database 14 Mixture Property Database, version 9.08, U.S. Department of Commerce, October 1992.

Oldenburg, C.M., D. H.-S. Law, Y. Le Gallo, and S.P. White. Mixing of CO2 and CH4 in Gas Reservoirs: Code Comparison Studies, paper F1-1, presented at Sixth International Conference on Greenhouse Gas Technologies (GHGT-6), Kyoto, Japan, October 1-4, 2002.

Orr, F.M., Jr., R.T. Johns and B. Dindoruk Development of Miscibility in Four-Component CO2 Floods, SPE Res. Eng., May, pp. 135-142, 1993.

O’Sullivan, M.J. A Similarity Method for Geothermal Well Test Analysis, Water Resour. Res., Vol. 17, No. 2, pp. $390-398,1981$.

Perkins, E.H. and W.D. Gunter, W. D. A Users Manual for $\beta$ PATHARC.94: a Reaction PathMass Transfer Program, Alberta Research Council Report ENVTR 95-11, 179 p, 1995.

Plummer, L.N., T.M. Wigley and D.L. Parkhurst. The Kinetics of Calcite Dissolution in CO2 Systems at $5^{\circ} \mathrm{C}$ to $60^{\circ} \mathrm{C}$ and 0.0 to $1.0 \mathrm{~atm} \mathrm{CO} 2$, American Journal of Science, Vol. 278, pp. 179-216, 1978.

Prausnitz, J. M., R. N. Lichtenthaler, and E. G. de Azevedo. Molecular Thermodynamics of FluidPhase Equilibria, Prentice-Hall Inc., Englewood Cliffs, N. J., 1986.

Pruess, K., C. Oldenburg and G. Moridis. TOUGH2 User's Guide, Version 2.0, Lawrence Berkeley National Laboratory Report LBNL-43134, Berkeley, CA, November 1999.

Pruess, K., C.F. Tsang, D. H.-S. Law and C.M. Oldenburg. Intercomparison of Simulation Models for CO2 Disposal in Underground Storage Reservoirs, Lawrence Berkeley National Laboratory Report LBNL-47353, October 2000.

Pruess, K, C.F. Tsang, D. H.-S. Law and C.M. Oldenburg. An Intercomparison Study of Simulation Models for Geologic Sequestration of CO2, Proceedings, First National Conference on Carbon Sequestration, Washington, DC, May 14-17, 2001.

Pruess, K., A. Bielinski, J. Ennis-King, R. Fabriol, Y. Le Gallo, J. García, K. Jessen, T. Kovscek, D. H.-S. Law, P. Lichtner, C. Oldenburg, R. Pawar, J. Rutqvist, C. Steefel, B. Travis, C.F. Tsang, S. White, T. Xu. Code Intercomparison Builds Confidence in Numerical Models for Geologic Disposal of CO2, paper F1-4, presented at Sixth International Conference on Greenhouse Gas Technologies (GHGT-6), Kyoto, Japan, October 1-4, 2002. (LBNL-51200)

Pruess, K. and J. García. Multiphase Flow Dynamics During CO2 Injection into Saline Aquifers, Environmental Geology, Vol. 42, pp. 282 - 295, 2002a. 
Pruess, K. and J. García. Solutions of Test Problems for Disposal of CO2 in Saline Aquifers, Lawrence Berkeley National Laboratory Report LBNL-51812, December 2002b.

Rutqvist J., Y.-S. Wu, C.-F. Tsang, and G. Bodvarsson. A Modeling Approach for Analysis of Coupled Multiphase Fluid Flow, Heat Transfer, and Deformation in Fractured Porous Rock, Int. J. Rock mech. Min. Sci., Vol. 39, pp. 429 - 442, 2002.

Rutqvist J. and C.-F. Tsang. A Study of Caprock Hydromechanical Changes Associated with CO2 Injection into a Brine Aquifer, Environmental Geology, Vol. 42, pp. 296 - 305, 2002.

Rutqvist, J and O. Stephansson. The Role of Hydromechanical Coupling in Fractured Rock Engineering. Hydrogeology Journal, in press, 2003.

Schlumberger. Eclipse Reference Manual, v 2001A, Abingdon, United Kingdom, 2001.

Shock, E.L., H.C. Helgeson and D.A. Sverjensky. Calculation of the Thermodynamic and Transport Properties of Aqueous Species at High Pressures and Temperatures: Standard Partial Molar Properties of Inorganic Neutral Species, Geochim. Cosmochim. Acta, Vol. 53, pp. 2157 - 2183, 1989.

Soreide, I. and C.H. Whitson. Peng-Robinson Predictions fo Hydrocarbons, CO2 N2, and H2S with Pure Water and NaCl Brine, id Phase Equilibria, Vol. 77, pp. 217 - 240, 1992.

Span, R. and W. Wagner. A New Equation of State for Carbon Dioxide Covering the Fluid Region from the Triple-Point Temperature to $1100 \mathrm{~K}$ at Pressures up to $800 \mathrm{MPa}$, J. Phys. Chem. Ref. Data, Vol. 25, No. 6, pp. 1509 - 1596, 1996.

Spycher, N.F. and M.H. Reed. Fugacity Coefficients of H2, CO2, CH4, H2O and of H2O-CO2CH4 Mixtures: A Virial Equation Treatment for Moderate Pressures and Temperatures Applicable to Calculations of Hydrothermal Boiling, Geochim. Cosmochim. Acta, Vol. 52, pp. 739 - 749, 1988.

Spycher, N., K. Pruess and J. Ennis-King. $\mathrm{CO}_{2}-\mathrm{H}_{2} \mathrm{O}$ Mixtures in the Geological Sequestration of $\mathrm{CO}_{2}$. I. Assessment and Calculation of Mutual Solubilities from 12 to $100{ }^{\circ} \mathrm{C}$ and up to 600 bar, submitted to Geochim. Cosmochim. Acta, July 2002.

Stanford Geothermal Program (ed.). Proceedings of the Special Panel on Geothermal Model Intercomparison Study. Report: SGP-TR42. Also presented at: 6th Workshop on Geothermal Reservoir Engineering, Stanford University, Stanford, California, 16-18 December, 1980.

Steefel, C.I. and P. van Cappellen. A new Kinetic Approach to Modeling Water-Rock Interaction: The role of Nucleation, Precursors and Ostwald Ripening, Geochimica Cosmochimica Acta, Vol. 54, pp. 2657-2677, 1990.

Stephansson, O., L. Jing, and C.-F. Tsang (editors), Mathematical and Experimental Studies of Coupled Thermo-Hydro-Mechanical Processes in Fractured Media-DECOVALEX, Developments in Geotechnical Engineering Series, Number 79. Elsevier Science Publishers, December 1996.

Wagman, D.D., W.H. Evans, V.B. Parker, R.H. Schumm, I. Halow, S.M. Bailey, K.L. Churney and R.L. Nuttall. The NBS Tables of Chemical and Thermodynamic Properties, Jour. Phys. Chem. Ref. Data, Vol. 11, supplement no. 2, 392 p., 1982.

Walsh, B.W. and F.M Orr,. Jr. Prediction of Miscible Flood Performance: The Effect of Dispersion on Composition Paths in Ternary Systems, IN SITU 14, pp.19-47, 1990. 
White, S.P. Multiphase Non-Isothermal Transport of Systems of Reacting Chemicals, Water Resour. Res., Vol. 32, No. 7, pp. 1761-1772, 1995.

Wiebe, R. and V.L. Gaddy. The Solubility of Carbon Dioxide in Water at Various Temperatures from 12 to $40^{\circ}$ and at Pressures to 500 Atmospheres: Critical Phenomena, J. Am. Chem. Soc., Vol. 62, pp. $815-817,1940$.

Xu, T. and K. Pruess. Modeling Multiphase Non-isothermal Fluid Flow and Reactive Geochemical Transport in Variably Saturated Fractured Rocks: 1. Methodology, American Journal of Science, Vol. 301, pp. 16-33, 2001.

Xu, T., J.A. Apps and K. Pruess. Analysis of Mineral Trapping for CO2 Disposal in Deep Aquifers, Lawrence Berkeley National Laboratory Report LBNL-46992, July 2001. 


\section{Appendix: Specifications of Test Problems}

\section{APPEndix A. Test Problem 1: Mixing of Stably Stratified Gases ${ }^{\#}$}

\section{INTRODUCTION AND GENERAL DESCRIPTION}

In this problem, $\mathrm{CO} 2$ and $\mathrm{CH} 4$ gases are placed in contact one on top of the other and allowed to mix as controlled by diffusion and associated flow at 40 bars, $40{ }^{\circ} \mathrm{C}$. Mixing in the system is limited because the denser gas (CO2) is on the bottom and the lighter gas (CH4) is on the top. The diffusion and flow are assumed to be one-dimensional. A residual liquid water saturation of 0.1 exists within the pores.

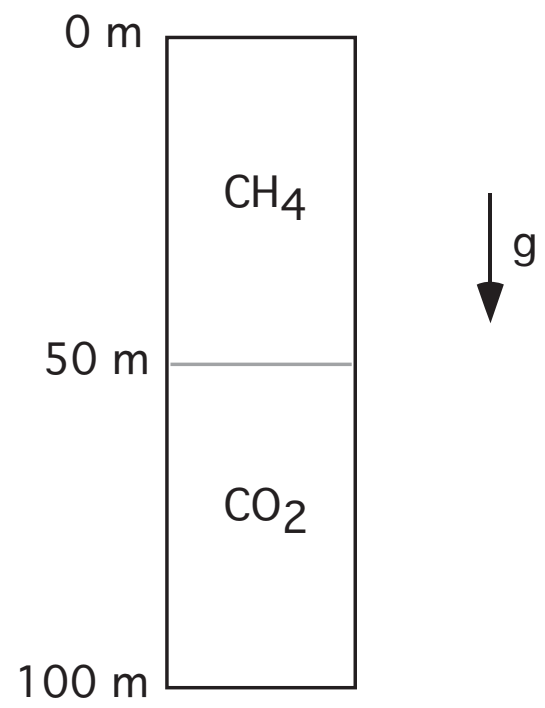

\section{LIST OF PROCESSES BEING STUDIED}

Molecular diffusion.

Density, viscosity, and solubility formulations of water, $\mathrm{CO} 2$, and $\mathrm{CH} 4$ as functions of pressure, temperature, and composition (P, T, X).

Advection in response to pressure gradients induced by equimolar diffusion of species with different molecular weights.

\section{DEFINITION OF THE PROBLEM AND INPUT DATA}

\section{Boundary conditions:}

No heat or mass flux through any boundaries (i.e., all boundaries are no-flow).

\footnotetext{
\# proposed by Curt Oldenburg; e-mail: CMOldenburg@lbl.gov
} 
Initial conditions:

$\mathrm{T}=40{ }^{\circ} \mathrm{C}$ (isothermal throughout)

$\mathrm{P}(\mathrm{Z}=0 \mathrm{~m})=40$ bars

$\mathrm{X}$ initially stratified with $\mathrm{CO} 2$ occupying the bottom half of the domain and $\mathrm{CH} 4$ occupying the top half.

\section{Input data:}

a) Porosity, tortuosity, residual liquid saturation (0.1, 1., 0.1, respectively)

b) Molecular diffusivity $\left(1 \times 10^{-7} \mathrm{~m}^{2} \mathrm{~s}^{-1}\right)$

c) Permeability and relative permeability $\left(\mathrm{k}=10^{-14} \mathrm{~m}^{2}\right.$, linear $\mathrm{k}_{\mathrm{rg}}$, liquid immobile)

d) Density, viscosity, and solubility in water of $\mathrm{CO} 2$ and $\mathrm{CH} 4$ as functions of $\mathrm{P}, \mathrm{T}$, and $\mathrm{X}$.

e) Vapor-liquid equilibrium properties of water.

\section{PROBLEM VARIATIONS}

a) Diffusion only with no gas-phase flow.

b) Low pressure scenario ( $\mathrm{P}=1 \mathrm{bar}$ ).

c) High pressure scenario $(\mathrm{P}=100 \mathrm{bar})$

d) Mixing by Dusty Gas Model instead of advective-diffusive Fickian model.

\section{DEFINITION OF RESULTS TO BE CALCULATED}

Vertical profiles at various times of :

a) $\mathrm{CO} 2$ and $\mathrm{CH} 4$ masses in liquid and gas phases per unit volume.

b) Pressure.

c) Density of the gas mixture.

\section{COMPARISON CRITERIA}

Profiles at the same times should match within $5 \%$.

\section{REFERENCES}

Severinghaus, J.P., M.L. Bender, R.F. Keeling, and W.S. Broecker, Fractionation of soil gases by diffusion of water vapor, gravitational settling, and thermal diffusion, Geochimica et Cosmochimica Acta, 60(6), 1005-1018, 1996.

Thorstenson, D.C. and D.W. Pollock, Gas transport in unsaturated zones: Multicomponent systems and the adequacy of Fick's Laws, Water Resour. Res., 25(3), 477-507, 1989. 


\section{APPEndix B. Test Problem 2: Advective-Diffusive Mixing Due to Lateral Density Gradient $^{\#}$}

\section{INTRODUCTION AND GENERAL DESCRIPTION}

In this problem, $\mathrm{CO} 2$ and $\mathrm{CH} 4$ gases are placed side-by-side in a container and allowed to mix by advection and diffusion. The strong lateral density gradient between the dense $\mathrm{CO} 2$ gas and the relatively light $\mathrm{CH} 4$ gas causes a strong flow where $\mathrm{CO} 2$ tends to move downward and $\mathrm{CH} 4$ tends to move upward to the top of the container. The flow and diffusion are assumed to be twodimensional. A residual liquid water saturation of 0.1 exists within the pores.

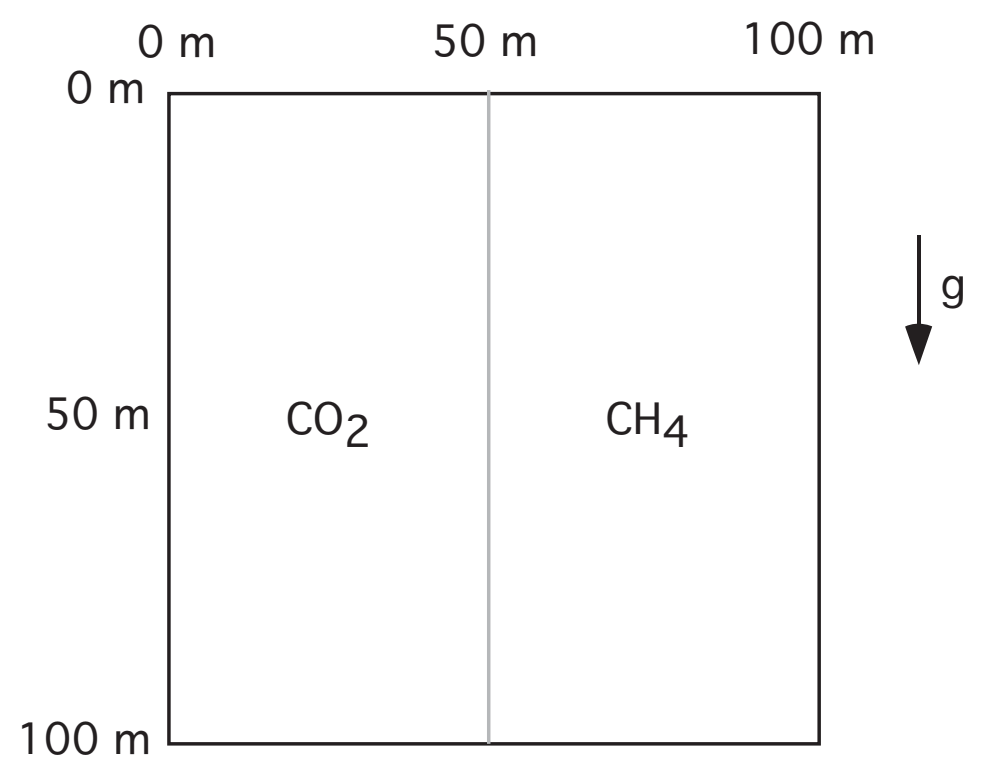

\section{LIST OF PROCESSES BEING STUDIED}

Gravity-driven advection in response to strong lateral density gradient.

Molecular diffusion.

Density, viscosity, and solubility formulations as functions of pressure, temperature, and composition (P, T, X).

Because of the strong advection, numerical dispersion will arise for most numerical methods.

\section{DEFINITION OF THE PROBLEM AND INPUT DATA}

Boundary conditions:

No heat or mass flux through any boundaries (i.e., all boundaries are no-flow).

\# proposed by Curt Oldenburg; e-mail: CMOldenburg@lbl.gov 


\section{Initial conditions:}

$\mathrm{T}=40{ }^{\circ} \mathrm{C}$ (isothermal throughout)

$\mathrm{P}(\mathrm{Z}=0 \mathrm{~m})=40$ bars

Initial composition field with $\mathrm{CO} 2$ on the left-hand half of the domain and $\mathrm{CH} 4$ on the right-hand half of the domain.

\section{Input data:}

a) Porosity, tortuosity, liquid saturation $(0.1,1 ., 0.1$, respectively)

b) Molecular diffusivity $\left(1 \times 10^{-7} \mathrm{~m}^{2} \mathrm{~s}^{-1}\right)$

c) Permeability and relative permeability $\left(\mathrm{k}=10^{-14} \mathrm{~m}^{2}\right.$, linear $\mathrm{k}_{\mathrm{rg}}$, liquid immobile)

d) Density, viscosity, and solubility in water of $\mathrm{CO} 2$ and $\mathrm{CH} 4$ as functions of $\mathrm{P}, \mathrm{T}$, and $\mathrm{X}$.

e) Vapor-liquid equilibrium properties of water.

\section{PROBLEM VARIATIONS}

a) Low pressure scenario ( $\mathrm{P}=1$ bar $)$.

b) High pressure scenario $(\mathrm{P}=100 \mathrm{bar})$.

c) Mixing by Dusty Gas Model instead of advective-diffusive Fickian model.

d) Substitute nitrogen (N2) or air for CO2.

\section{DEFINITION OF RESULTS TO BE CALCULATED}

Horizontal profiles at $\mathrm{Z}=50 \mathrm{~m}$ at various times of

a) $\mathrm{CO} 2$ and $\mathrm{CH} 4$ masses in gas and liquid phases per unit volume.

b) Density of the gas mixture.

\section{COMPARISON CRITERIA}

Profiles at the same times should match within $5 \%$.

\section{REFERENCES}

To be supplied. 


\section{APPENDIX C. Test Problem 3: Radial Flow from a CO2 Injection Well\&}

\section{INTRODUCTION AND GENERAL DESCRIPTION}

This problem addresses two-phase flow of $\mathrm{CO} 2$ and water for simplified flow geometry and medium properties. The aquifer into which injection is made is assumed infinite-acting, homogenoeus, and isotropic. Gravity and inertial effects are neglected, injection is made at a constant mass rate, and flow is assumed 1-D radial (line source). Under the conditions stated the problem has a similarity solution where dependence on radial distance $\mathrm{R}$ and time t occurs only through the similarity variable $\xi=\mathrm{R}^{2} / \mathrm{t}$ (O'Sullivan 1981; Doughty and Pruess 1992).

\section{LIST OF PROCESSES BEING STUDIED}

Two-phase flow of $\mathrm{CO} 2$ and water subject to relative permeability and capillary effects. Change of fluid density, viscosity, and $\mathrm{CO} 2$ solubility with pressure and salinity. Formation dry-out with precipitation of salt.

\section{DEFINITION OF THE PROBLEM AND INPUT DATA}

Problem parameters are summarized in Tables C.1 and C.2

\section{PROBLEM VARIATIONS}

Neglect salinity of the aqueous phase. Include non-isothermal effects. Include permeability changes due to precipitation. Inject gas that is $50 \% \mathrm{CO} 2,50 \% \mathrm{~N} 2$.

\section{DEFINITION OF RESULTS TO BE CALCULATED}

Data on $\mathrm{CO} 2$ and brine density and viscosity, and $\mathrm{CO} 2$ solubility, for the range of thermodynamic conditions encountered in the problem. Gas saturation, dissolved $\mathrm{CO} 2$ mass fraction, fraction of void space containing precipitated salt, and fluid pressure as functions of the similarity variable $\xi=$ $\mathrm{R}^{2} / \mathrm{t}$. (Use both profiles at constant time and time-series data at a specific location for plotting.)

\section{COMPARISON CRITERIA}

Results should match within $+/-5 \%$.

\section{REFERENCES}

Corey, A.T. The Interrelation Between Gas and Oil Relative Permeabilities, Producers Monthly, pp. 38 - 41, November 1954.

\footnotetext{
\& proposed by Karsten Pruess; e-mail: K_Pruess@ @lbl.gov
} 
Doughty, C. and K. Pruess. A Similarity Solution for Two-Phase Water, Air and Heat Flow Near a Linear Heat Source in a Porous Medium, J. of Geophys. Res., 97 (B2), 1821-1838, 1992.

O’Sullivan, M.J. A Similarity Method for Geothermal Well Test Analysis, Water Resour. Res., Vol. 17, No. 2, pp. $390-398,1981$.

van Genuchten, M.Th. A Closed-Form Equation for Predicting the Hydraulic Conductivity of Unsaturated Soils, Soil Sci. Soc. Am. J., Vol. 44, pp. 892 - 898, 1980.

Table C.1 Hydrogeologic parameters.

\begin{tabular}{|c|c|}
\hline $\begin{array}{l}\text { Permeability } \\
\text { Porosity } \\
\text { Pore compressibility } \\
\text { Aquifer thickness }\end{array}$ & $\begin{array}{l}\mathrm{k}=10^{-13} \mathrm{~m}^{2} \\
\phi=0.12 \\
\mathrm{c}=4.5 \times 10^{-10} \mathrm{~Pa}^{-1} \\
100 \mathrm{~m}\end{array}$ \\
\hline 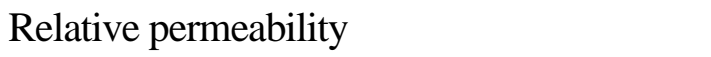 & \\
\hline $\begin{array}{l}\text { liquid: van Genuchten function (1980) } \\
\qquad \mathrm{k}_{\mathrm{rl}}=\sqrt{\mathrm{S}^{*}}\left\{1-\left(1-\left[\mathrm{S}^{*}\right]^{1 / \lambda}\right)^{\lambda}\right\}^{2} \\
\text { irreducible water saturation } \\
\text { exponent }\end{array}$ & $\begin{array}{l}\mathrm{S}^{*}=\left(\mathrm{S}_{1}-\mathrm{S}_{\mathrm{lr}}\right) /\left(1-\mathrm{S}_{\mathrm{lr}}\right) \\
\mathrm{S}_{\mathrm{lr}}=0.30 \\
\lambda=0.457\end{array}$ \\
\hline $\begin{array}{l}\text { gas: Corey curve (1954) } \\
\qquad \mathrm{k}_{\mathrm{rg}}=(1-\hat{\mathrm{S}})^{2}\left(1-\hat{\mathrm{S}}^{2}\right) \\
\text { irreducible gas saturation }\end{array}$ & $\begin{aligned} \hat{S} & =\frac{\left(S_{1}-S_{1 r}\right)}{\left(1-S_{1 r}-S_{g r}\right)} \\
S_{g r} & =0.05\end{aligned}$ \\
\hline Capillary pressure & \\
\hline $\begin{array}{l}\text { van Genuchten function }(1980) \\
\qquad \mathrm{P}_{\text {cap }}=-\mathrm{P}_{0}\left(\left[\mathrm{~S}^{*}\right]^{-1 / \lambda}-1\right){ }^{1-\lambda} \\
\text { irreducible water saturation } \\
\text { exponent } \\
\text { strength coefficient }\end{array}$ & $\begin{array}{l}S^{*}=\left(S_{1}-S_{1 r}\right) /\left(1-S_{1 r}\right) \\
S_{1 r}=0.0 \\
\lambda=0.457 \\
P_{0}=19.61 \mathrm{kPa}\end{array}$ \\
\hline
\end{tabular}

Table C.2 Initial conditions and injection specifications

\begin{tabular}{|l|l|}
\hline Pressure & $120 \mathrm{bar}$ \\
\hline Temperature & $45^{\circ} \mathrm{C}$ \\
\hline Salinity & $15 \mathrm{wt} .-\% \mathrm{NaCl}$ \\
\hline $\mathrm{CO} 2$ injection rate & $100 \mathrm{~kg} / \mathrm{s}$ \\
\hline
\end{tabular}




\section{APPEndix D. Test Problem 4: CO2 Discharge Along a Fault Zone ${ }^{\&}$}

\section{INTRODUCTION AND GENERAL DESCRIPTION}

This problem explores $\mathrm{CO} 2$ loss from storage through a leaky fault, using a highly simplified 1-D linear flow geometry. It is envisioned that an aquifer into which $\mathrm{CO} 2$ disposal is made is intersected by a vertical fault, which establishes a connection through an otherwise impermeable caprock to another aquifer $500 \mathrm{~m}$ above the storage aquifer (Fig. D.1a). This situation is idealized by assuming 1-D flow geometry and constant pressure boundary conditions as shown in Fig. D.1b (Pruess and García, 2002a).

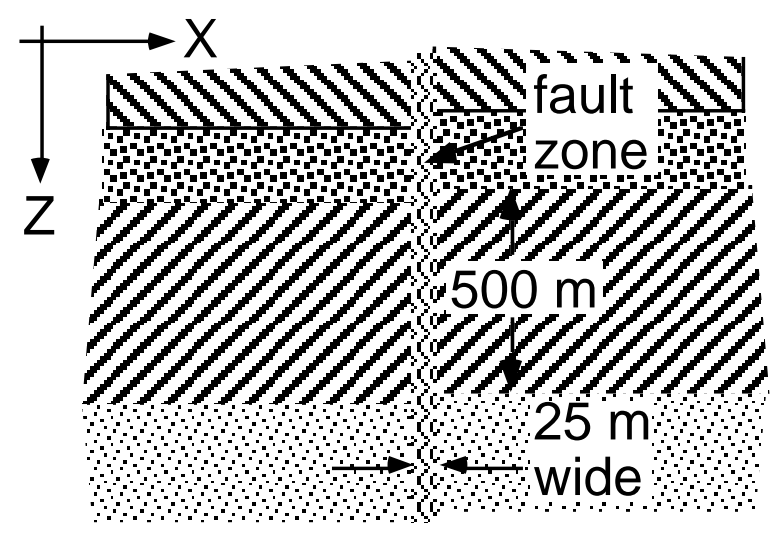

(a)

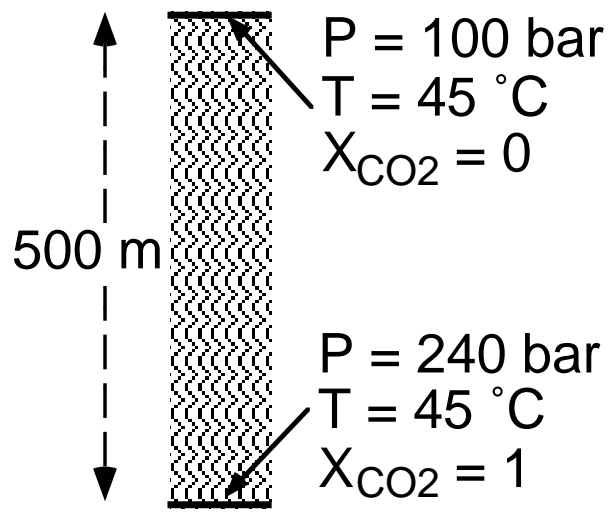

(b)

Figure D.1 Schematic of the fault zone model (a) and applied boundary conditions (b).

\section{LIST OF PROCESSES BEING STUDIED}

Immiscible displacement of water by $\mathrm{CO} 2$ subject to pressure, gravity, and capillary pressure effects.

Change of fluid density, viscosity, and $\mathrm{CO} 2$ solubility with pressure.

Formation dry-out.

\section{DEFINITION OF THE PROBLEM AND INPUT DATA}

Hydrogeologic parameters are identical to those of problem 3 (Table C.1), except that porosity is increased to $35 \%$. The fault zone is assumed to be $25 \mathrm{~m}$ wide and $500 \mathrm{~m}$ tall, with boundary conditions as given in Fig. D.1b. The reservoir fluid is assumed to be pure water (no salinity). Initial conditions are pressures in hydrostatic equilibrium relative to $\mathrm{P}=100 \mathrm{bar}$ at the top; temperature is held constant at $\mathrm{T}=45^{\circ} \mathrm{C}$ throughout.

\& proposed by Karsten Pruess; e-mail: K_Pruess@lbl.gov 


\section{PROBLEM VARIATIONS}

Include salinity of the aqueous phase and permeability changes due to precipitation. Include nonisothermal effects. Assume gas composition is $50 \% \mathrm{CO} 2,50 \% \mathrm{~N} 2$.

\section{DEFINITION OF RESULTS TO BE CALCULATED}

Data on $\mathrm{CO} 2$ and water density and viscosity, and $\mathrm{CO} 2$ solubility, for the range of thermodynamic conditions encountered in the problem. Vertical profiles of gas saturation, fluid pressure, and dissolved $\mathrm{CO} 2$ mass fraction at different times. $\mathrm{CO} 2$ inventory in gas and liquid phases after $10^{7}$ seconds. Mass flow rates of $\mathrm{CO} 2$ at the bottom and of water at the top vs. time (normalized for a 1 $\mathrm{m}$ thick section).

\section{COMPARISON CRITERIA}

Results should match to with $+/-5 \%$.

\section{REFERENCES}

Pruess, K. and J. García. Multiphase Flow Dynamics During CO2 Injection into Saline Aquifers, Environmental Geology, Vol. 42, pp. 282 - 295, 2002a. 


\section{Appendix E. Test Problem 5: Mineral Trapping in a Glauconitic Sandstone Aquifer*}

\section{INTRODUCTION AND GENERAL DESCRIPTION}

This problem addresses geochemical effects of $\mathrm{CO} 2$ injection into a glauconitic sandstone aquifer, and analyzes the impact of $\mathrm{CO} 2$ immobilization through carbonate precipitation. Batch reaction modeling of the geochemical evolution of this aquifer is performed in the presence of $\mathrm{CO} 2$ at high pressure. The problem is based on Gunter et al. (1997), who modeled water-rock reactions when $\mathrm{CO} 2$ is injected into a glauconitic sandstone aquifer in the Alberta Sedimentary Basin, Canada. Additional processes are considered such as presence of organic matter and its oxidation.

\section{LIST OF PROCESSES BEING STUDIED}

The following processes are considered: (1) equilibrium aqueous complexation, (2) redox processes, (3) the kinetics of chemical interactions between the host rock minerals and the aqueous phase (organic matter dissolution is a non-equilibrium processes), and (4) CO2 solubility dependence on pressure, temperature and salinity of the system. In addition, changes in porosity are monitored during the simulations.

\section{DEFINITION OF THE PROBLEM AND INPUT DATA}

The initial condition used in the simulation is a pure $1.0 \mathrm{M}$ solution of sodium chloride reacting with the primary minerals listed in Table E. 1 at a temperature of $54{ }^{\circ} \mathrm{C}$, a pH of 7, and an Eh of -0.1 V. Reactant phases are those minerals initially present in the aquifer formation (Table E.1). The reactant minerals dissolve progressively into the formation water, thus modifying the water composition and leading to precipitation of product phases. Two simulations are to be performed with the same initial conditions. The first simulation examines water-rock interaction under natural conditions without $\mathrm{CO} 2$ injection. The second simulation considers a $\mathrm{CO} 2$ injection pressure of 260 bar. The $\mathrm{CO} 2$ gas pressure is assumed to be maintained in equilibrium with the solution at all times. A simulation time of 100,000 years is used for both simulations.

The rate law for kinetic mineral dissolution and precipitation is taken from Lasaga (1984) and Steefel and Lasaga (1994):

$$
\mathrm{r}_{\mathrm{m}}=\mathrm{A}_{\mathrm{m} k \mathrm{~m}}\left[1-\left(\frac{\mathrm{Q}_{\mathrm{m}}}{\mathrm{K}_{\mathrm{m}}}\right)^{\mu}\right]^{\mathrm{n}}
$$

\footnotetext{
* proposed by Tianfu Xu; e-mail: Tianfu_Xu@lbl.gov
} 
where $\mathrm{m}$ is mineral index, $\mathrm{r}_{\mathrm{m}}$ is the dissolution/precipitation rate (positive values indicate dissolution, and negative values precipitation), $\mathrm{A}_{\mathrm{m}}$ is the specific reactive surface area per $\mathrm{kg}_{2} \mathrm{O}$, $\mathrm{k}_{\mathrm{m}}$ is the rate constant (moles per unit mineral surface area and unit time) which is temperature dependent, $\mathrm{K}_{\mathrm{m}}$ is the equilibrium constant for the mineral-water reaction written for the destruction of one mole of mineral $\mathrm{m}$, and $\mathrm{Q}_{\mathrm{m}}$ is the ion activity product. The parameters $\mu$ and $\mathrm{n}$ are taken equal to unity. Rate constant dependency as a function of temperature is

$$
\mathrm{k}=\mathrm{k}_{25} \exp \left[\frac{-\mathrm{E}_{\mathrm{a}}}{\mathrm{R}}\left(\frac{1}{\mathrm{~T}}-\frac{1}{298.15}\right)\right]
$$

where $\mathrm{E}_{\mathrm{a}}$ is the activation energy, $\mathrm{k}_{25}$ is the rate constant at $25^{\circ} \mathrm{C}, \mathrm{R}$ is gas constant, $\mathrm{T}$ is absolute temperature. The kinetic parameters are also given in Table E.1. Precipitation of possible secondary minerals (Table E. 1 with initial $V_{f}=0$ where $V_{f}$ is mineral volume fraction) is represented using the same kinetic rate expression as that for dissolution. The precipitation kinetic constant for a secondary mineral is assumed to be one order of magnitude greater than its corresponding dissolution rate constant. A total surface area of $10 \mathrm{~m}^{2} / \mathrm{dm}^{3}$ medium was used. The initial surface area of each primary mineral is calculated by multiplying its volume fraction with the total surface area (Table E.1). With time, the surface areas change in complex ways. We simply relate the surface areas of the primary minerals at some time to the mineral volume fraction by

$$
A=A^{0} \frac{V_{f}}{V_{f}^{0}}
$$

where $\mathrm{A}$ and $\mathrm{V}_{\mathrm{f}}$ are the reactive surface area and volume fraction of a primary mineral, respectively, and superscript zero indicates the values at time $t=0$. The reactive surface areas for secondary minerals are set to $0.25 \mathrm{~m}^{2} / \mathrm{dm}^{3}$ at all times.

\section{PROBLEM VARIATIONS}

Neglect $\mathrm{CO} 2$ solubility dependence on pressure, temperature and salinity. The reactive surface areas used for both primary and secondary minerals are uncertain and may be varied. The results also vary with thermodynamic and kinetic data.

\section{DEFINITION OF RESULTS TO BE CALCULATED}

The following variables are reported vs. time, (1) aqueous species concentrations, (2) $\mathrm{pH}$ and Eh, (3) changes of volume fraction of both primary and secondary minerals, (4) change of porosity, (5) the amounts of $\mathrm{CO} 2$ trapped in both liquid and solid phases. 
Table E.1. List of initial mineral volume fractions, potential secondary mineral phases, and their kinetic properties. All rate constants are listed for dissolution. The constants for precipitation are increased correspondingly by one order of magnitude.

\begin{tabular}{|c|c|c|c|c|c|c|}
\hline Mineral & Chemical composition & $\begin{array}{l}\text { Volume } \\
(\%)\end{array}$ & $\begin{array}{l}\text { Surface } \\
\text { area } \\
\left(\mathrm{m}^{2} / \mathrm{dm}^{3}\right. \\
\text { medium })\end{array}$ & $\begin{array}{l}\mathrm{k}_{25} \\
\left(\mathrm{moles} / \mathrm{m}^{2} \mathrm{~s}\right)\end{array}$ & $\begin{array}{l}\mathrm{E}_{\mathrm{a}} \\
(\mathrm{kJ} / \mathrm{mol})\end{array}$ & Reference \\
\hline $\begin{array}{l}\text { Primary: } \\
\text { quartz }\end{array}$ & $\mathrm{SiO}_{2}$ & 71.28 & 7.128 & $1.2589 \times 10^{-14}$ & 87.50 & Tester et al. (1994) \\
\hline K-feldspar & $\mathrm{KAlSi}_{3} \mathrm{O}_{8}$ & 1.76 & 0.176 & $1.00 \times 10^{-12}$ & 67.83 & Blum and Stillings (1995) \\
\hline kaolinite & $\mathrm{Al}_{2} \mathrm{Si}_{2} \mathrm{O}_{5}(\mathrm{OH})_{4}$ & 1.76 & $0.176 \mathrm{E} 2$ & $1.00 \times 10^{-13}$ & 62.76 & Nagy (1995) \\
\hline calcite & $\mathrm{CaCO}_{3}$ & 0.88 & 0.088 & $1.60 \times 10^{-9}$ & 41.87 & Svensson and Dreybrodt (1992) \\
\hline dolomite & $\mathrm{CaMg}\left(\mathrm{CO}_{3}\right)_{2}$ & 0.88 & 0.088 & $0.60 \times 10^{-9}$ & 41.87 & assigned based on calcite \\
\hline siderite & $\mathrm{FeCO}_{3}$ & 0.88 & 0.088 & $0.60 \times 10^{-9}$ & 41.87 & assigned based on calcite \\
\hline illite & $\mathrm{K}_{0.6} \mathrm{Mg}_{0.25} \mathrm{Al}_{1.8}\left(\mathrm{Al}_{0.5} \mathrm{Si}_{3.5} \mathrm{O}_{10}\right)(\mathrm{OH})_{2}$ & 2.64 & $0.264 \mathrm{E} 2$ & $1.00 \times 10^{-14}$ & 58.62 & Knauss and Wolery (1989) \\
\hline glauconite & $\mathrm{K}_{1.5} \mathrm{Mg}_{0.5} \mathrm{Fe}_{2.5} \mathrm{Fe}_{0.5} \mathrm{AlSi}_{7.5} \mathrm{O}_{20}(\mathrm{OH})_{2}$ & 4.4 & $0.440 \mathrm{E} 1$ & $1.00 \times 10^{-14}$ & 58.62 & set to illite \\
\hline organic & $\mathrm{CH}_{2} \mathrm{O}$ & 2.64 & 0.264 & $1.00 \times 10^{-13}$ & 0.0 & assigned based on kaolinite \\
\hline oligoclase & $\mathrm{CaNa}_{4} \mathrm{Al}_{6} \mathrm{Si}_{14} \mathrm{O}_{40}$ & 0.88 & 0.088 & $1.00 \times 10^{-12}$ & 67.83 & set to K-feldspar \\
\hline porosity & ------ & 12 & & & & \\
\hline total & ------ & 100 & & & & \\
\hline \multicolumn{4}{|l|}{ Secondary: } & & & Blum and Stillings (1995) \\
\hline smectite-Na & $\mathrm{Na}_{0.29} \mathrm{Mg}_{0.26} \mathrm{Al}_{1.77} \mathrm{Si}_{3.97} \mathrm{O}_{10}(\mathrm{OH})_{2}$ & 0.0 & $0.25 \mathrm{E} 2$ & $1.00 \times 10^{-14}$ & 58.62 & set to illite \\
\hline smectite-Ca & $\mathrm{Ca}_{0.145} \mathrm{Mg}_{0.26} \mathrm{Al}_{1.77} \mathrm{Si}_{3.97} \mathrm{O}_{10}(\mathrm{OH})_{2}$ & 0.0 & $0.25 \mathrm{E} 2$ & $1.00 \times 10^{-14}$ & 58.62 & set to illite \\
\hline
\end{tabular}

\section{COMPARISON CRITERIA}

Results should match within $+/-5 \%$.

\section{REFERENCES}

Blum, A. E., and Stillings, L. L., 1995, Feldspar dissolution kinetics, Chapter 7 of chemical weathering rates of silicate minerals, White, A.F., and Brantley, S. L. (eds), Mineral Society of America, v. 31, p. 291-351, Washington D. C.

Gunter W. D., Wiwchar, B., and Perkins, E. H., 1997, Aquifer disposal of CO2-rich greenhouse gases: extension of the time scale of experiment for $\mathrm{CO}_{2}$-sequestering reactions by geochemical modeling, Mineral. and Petrol., V. 59, p. 121-140.

Knauss, K. G., and Wolery, T. J., 1989, Muscovite dissolution kinetics as a function of pH and time at $70^{\circ} \mathrm{C} . "$ Geochimica et Cosmochimica Acta, V. 53, p. 1493-1501.

Lasaga, A. C., 1984, Chemical kinetics of water-rock interactions, Journal of Geophysical Research, v. 89, p. 4009-4025.

Nagy, K. L., Dissolution and precipitation kinetics of sheet silicates, 1995, Chemical Weathering Rates of Silicate Minerals, V. 31, p. 291-351. 
Rudnicki, J. I., and Wawersik, W. R., 1999, Report looks at sequestrating CO2 beneath earth's surface, EOS, Transactions of American Geophysical Union, v. 80, No. 50, p. 607-608.

Steefel, C. I., and Lasaga, A. C., 1994, A coupled model for transport of multiple chemical species and kinetic precipitation/dissolution reactions with applications to reactive flow in single phase hydrothermal system, American Journal of Science, v. 294, p. 529-592.

Svensson, U. and Dreybrodt, W., 1992. Dissolution kinetics of natural calcite minerals in CO2water systems approaching calcite equilibrium." Chemical Geology, v. 100, p. 129-145. Amsterdam, The Netherlands, Elsevier Science Publishers.

Tester, J. W., Worley, G. W., Robinson, B. A., Grigsby, C. O., and Feerer, J. L., 1994, Correlating quartz dissolution kinetics in pure water from 25 to $625^{\circ} \mathrm{C}$., Geochimica et Cosmochimica Acta, v. 58, p. 2407-2420. 


\section{APPENDix F. Test Problem 6: Hydromechanical Responses During CO2 Injection into an Aquifer-Caprock System\%}

\section{INTRODUCTION AND GENERAL DESCRIPTION}

This problem addresses consequences of rock deformation, including potential change in permeability and porosity, during injection of $\mathrm{CO} 2$ into a porous aquifer beneath a low permeable caprock. The problem is simplified to a one-dimensional vertical column of an aquifer-caprock system (Figure F.1). The injection is conducted at 1500 meters depth at a pre-determined constant pressure. The hydraulic boundary conditions are "no flow" except at the ground surface. As a consequence, the injected gas can only escape the aquifer through the low-permeability caprock. Because the permeability of the caprock is assumed to be stress dependent, the leakage rate will be affected by induced effective stress changes during the $\mathrm{CO} 2$ injection. The test problem is designed to induce substantial porosity and permeability change to emphasize the coupled hydromechanical effects in the code comparison.

\section{LIST OF PROCESSES BEING STUDIED}

The following processes are considered: (1) injection of $\mathrm{CO} 2$ gas into a fully water saturated aquifer with migration of gas upwards in the vertical column through a low permeability caprock; (2) mechanical stress changes and deformation in the aquifer and caprock as a consequence of changes in pore pressure during injection of $\mathrm{CO} 2$ into the aquifer; and (3) changes in porosity and permeability caused by effective stress changes in both the aquifer and caprock. These processes do not induce any significant temperature changes and the simulation could therefore be conducted in isothermal mode. However, the effects of temperature on thermophysial properties of water and $\mathrm{CO} 2$ should be taken into account.

Changes in the capillary pressure function with changes in porosity can be neglected. We also neglect effects of chemical reactions with minerals and dissolution of $\mathrm{CO} 2$ in water.

\section{DEFINITION OF THE PROBLEM AND INPUT DATA}

The calculation should be done in two phases. First the pre-injection steady state conditions of stress, fluid pressure and temperature should be established. Thereafter, the actual injection simulation should be conducted.

Initial conditions of static equilibrium should be established in a steady state pre-injection calculation as follows.

$\%$ proposed by Chin-Fu Tsang and Jonny Rutqvist; e-mail: CFTsang@lbl.gov 
a) Initial isotropic stress field increasing with depth based on the weight of the overlying rock (bulk density $=2260 \mathrm{~kg} / \mathrm{m}^{3}$ and acceleration of gravity $=9.81 \mathrm{~m} / \mathrm{s}^{2}$ )

b) Initial fully saturated rock with a hydrostatic gradient calculated assuming a liquid pressure of $\mathrm{P}_{1}=0.1 \mathrm{MPa}$ at the ground surface. Standard functions for water density (with temperature dependency) should be used.

c) An initial temperature with a thermal gradient of $30{ }^{\circ} \mathrm{C} / \mathrm{km}$ (assume fixed temperatures of 10 ${ }^{\circ} \mathrm{C}$ at the ground surface and $55^{\circ} \mathrm{C}$ at 1500 meter depth).

d) An initial porosity and permeability distribution which are dependent on the mean effective stress according to equations in Table F.1. That is, the initial porosity and permeability are decreasing with depth.

After achieving the steady state initial conditions, the injection operation should be simulated by injecting pure $\mathrm{CO} 2$ at 1500 meter depth (at the lower boundary of the model). The injection pressure should be kept constant at $30 \mathrm{MPa}$ (about $90 \%$ of the lithostatic pressure at 1500 meter depth) over a time period of 30 years.

Boundary conditions during the injection period:

a) Mechanical boundary conditions are locked for normal displacements (roller boundaries) on all boundaries except at the ground surface, which is free to move.

b) Gas pressure is kept constant (30 MPa) at the base of the model and the liquid pressure is kept constant at the ground surface $(0.1 \mathrm{MPa})$.

c) Temperature is kept constant $\left(55^{\circ} \mathrm{C}\right)$ at the base of the model and at the ground surface $(10$ $\left.{ }^{\circ} \mathrm{C}\right)$.

The problem domain includes two materials:

1) a low-permeability caprock, which extends from 1200 to $1300 \mathrm{~m}$ depth;

2) a rock mass with aquifer properties above and below the caprock.

Both materials are assumed linear elastic, with functions of porosity-stress, permeability-porosity, relative permeability and capillary pressure given in Table F.1.

\section{PROBLEM VARIATIONS}

Include additional processes such as dissolution of $\mathrm{CO} 2$ in the aqueous phase and changes of capillary pressure function with changes in porosity. Consider a two-dimensional model geometry with a vertical fault in the caprock. 


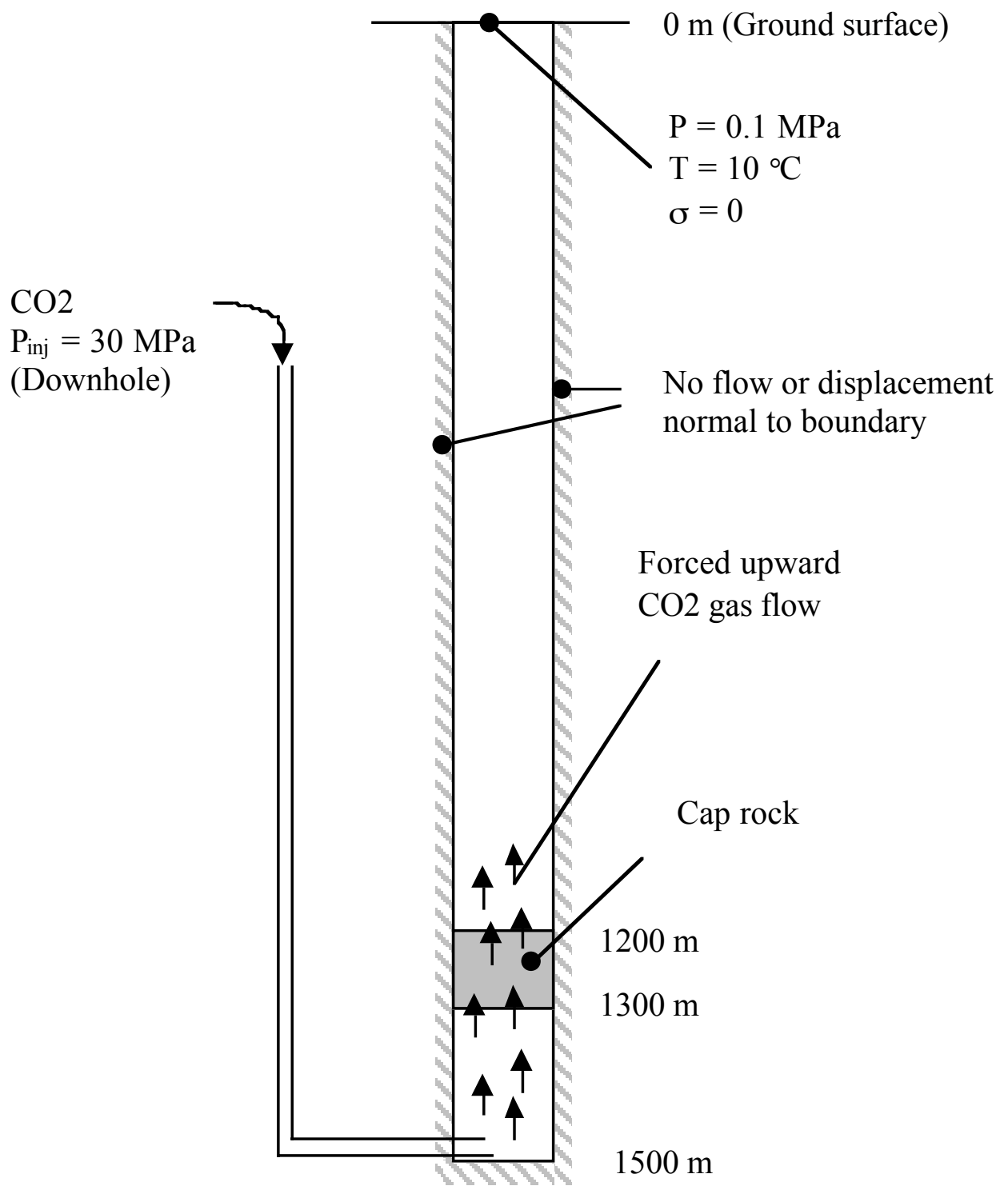

Figure F.1. Geometry of vertical column for hydromechanical test problem.

\section{DEFINITION OF RESULTS TO BE CALCULATED}

The simulation of the injection period (30 years) should be conducted with and without consideration of permeability and porosity changes.

For both simulations, provide vertical profiles at various times of:
a) Gas saturation
b) Total CO2 mass
c) Fluid pressure 
Table F.1. Rock properties.

\begin{tabular}{|c|c|c|}
\hline Rock Property & Aquifer & Caprock \\
\hline Young's modulus & $E=1.0 \mathrm{GPa}$ & $E=1.0 \mathrm{GPa}$ \\
\hline Poisson's ratio & $v=0.25$ & $v=0.25$ \\
\hline Saturated rock density & $\rho=2260 \mathrm{~kg} / \mathrm{m}^{3}$ & $\rho=2260 \mathrm{~kg} / \mathrm{m}^{3}$ \\
\hline $\begin{array}{l}\text { Porosity-stress function } \\
\text { Zero stress porosity } \\
\text { Residual porosity }\end{array}$ & $\begin{array}{l}\phi=\left(\phi_{0}-\phi_{r}\right) \exp \left(5 \cdot 10^{-8} \cdot \sigma_{M}^{\prime}\right)+\phi_{r} \\
\phi_{0}=0.1 \\
\phi_{r}=0.09\end{array}$ & $\begin{array}{l}\phi=\left(\phi_{0}-\phi_{r}\right) \exp \left(5 \cdot 10^{-8} \cdot \sigma_{M}^{\prime}\right)+\phi_{r} \\
\phi_{0}=0.01 \\
\phi_{r}=0.009\end{array}$ \\
\hline $\begin{array}{l}\text { Permeability-porosity } \\
\text { function } \\
\text { Zero stress permeability }\end{array}$ & $\begin{array}{l}k=2.284 \cdot 10^{-10} k_{0} \exp (222 \cdot \phi) \\
k_{0}=1.0 \mathrm{e}-13 \mathrm{~m}^{2}\end{array}$ & $\begin{array}{l}k=2.284 \cdot 10^{-10} k_{0} \exp (2220 \cdot \phi) \\
k_{0}=1.0 \mathrm{e}-16 \mathrm{~m}^{2}\end{array}$ \\
\hline $\begin{array}{l}\text { Corey's (1954) relative } \\
\text { permeability function }\end{array}$ & $\begin{array}{l}k_{r l}=\hat{S}^{4} \\
k_{r g}=(1-\hat{S})^{2}\left(1-\hat{S}^{2}\right) \\
\hat{S}=\frac{\left(S-S_{l r}\right)}{\left(1-S_{l r}-S_{g r}\right)}\end{array}$ & $\begin{array}{l}k_{r l}=\hat{S}^{4} \\
k_{r g}=(1-\hat{S})^{2}\left(1-\hat{S}^{2}\right) \\
\hat{S}=\frac{\left(S-S_{l r}\right)}{\left(1-S_{l r}-S_{g r}\right)}\end{array}$ \\
\hline Irreducible gas saturation & $S_{g r}=0.05$ & $S_{g r}=0.05$ \\
\hline Irreducible liq. saturation & $S_{l r}=0.3$ & $S_{l r}=0.3$ \\
\hline $\begin{array}{l}\text { van Genuchten's (1980) } \\
\text { capillary pressure function }\end{array}$ & $\begin{array}{l}P_{\text {cap }}=-P_{0}\left(\left[S^{*}\right]^{-1 / \lambda}-1\right)^{1-\lambda} \\
S^{*}=\left(S_{l}-S_{l r}\right) /\left(1-S_{l r}\right)\end{array}$ & $\begin{array}{l}P_{\text {cap }}=-P_{0}\left(\left[S^{*}\right]^{-1 / \lambda}-1\right)^{1-\lambda} \\
S^{*}=\left(S_{l}-S_{l r}\right) /\left(1-S_{l r}\right)\end{array}$ \\
\hline Irreducible liq. saturation & $S_{l r}=0.0$ & $S_{l r}=0.0$ \\
\hline Exponent & $\lambda=0.457$ & $\lambda=0.457$ \\
\hline Strength coefficient & $P_{0}=1.87 \mathrm{kPa}$ & $P_{0}=59.1 \mathrm{kPa}$ \\
\hline
\end{tabular}
d) Mean stress
e) Mean effective stress
f) Permeability
g) Porosity
h) Vertical displacement

These should be provided for the following times:

1) Initial (just before injection)

2) 1 day 

3) 1 year
4) 10 years
5) 30 years (end of injection period)
6) 100 years

The following transient monitoring data should be provided as a function of time:

1) The injection rate.

2) The rate of $\mathrm{CO} 2$ flow $\left(\mathrm{kg} / \mathrm{sm}^{2}\right)$ at the top of caprock.

\section{COMPARISON CRITERIA}

Profiles at the same time should match within 5\%.

\section{REFERENCES}

Corey, A.T. The Interrelation Between Gas and Oil Relative Permeabilities, Producers Monthly, pp. 38 - 41, November 1954.

van Genuchten, M.Th. A Closed-Form Equation for Predicting the Hydraulic Conductivity of Unsaturated Soils, Soil Sci. Soc. Am. J., Vol. 44, pp. 892 - 898, 1980. 


\section{APPENDIX G. Test Problem 7: $\mathrm{CO}_{2}$ Injection into a 2-D Layered Brine Formation\#}

\section{INTRODUCTION AND GENERAL DESCRIPTION}

This test problem is patterned after the $\mathrm{CO}_{2}$ injection project at the Sleipner Vest field in the Norwegian sector of the North Sea, and is intended to investigate the dominant physical processes associated with the injection of supercritical $\mathrm{CO}_{2}$ into a layered medium. Significant simplifications have been made, the most important of which is the assumption of isothermal conditions $\left(37^{\circ} \mathrm{C}\right.$, the ambient temperature of the formation). $\mathrm{CO}_{2}$ injection rates (1,000,000 tonnes per year), system geometry, and system permeabilities correspond approximately to those at Sleipner, although no attempt was made to represent details of the permeability structure within the host formation. Injection of the supercritical $\mathrm{CO}_{2}$, which is less dense than the saline formation waters into which it is injected, causes it to rise through the formation. Its rate of ascent, however, is limited by the presence of four relatively low permeability shales. The top and bottom of the formation is assumed to be impermeable. The only reactive chemistry considered in this problem is the dissolution of $\mathrm{CO}_{2}$ in the aqueous phase.

\section{LIST OF PROCESSES BEING STUDIED}

a) Gravity-driven advection in response to strong vertical and lateral density gradients induced by the injection of $\mathrm{CO}_{2}$ into saline formation water.

b) Density, viscosity, and solubility formulations of water and $\mathrm{CO}_{2}$ as a function of pressure and temperature $(\mathrm{P}$ and $\mathrm{T})$.

\section{DEFINITION OF THE PROBLEM AND INPUT DATA}

System Geometry:

The system is idealized as a two dimensional symmetric domain perpendicular to the horizontal injection well which has a screen length of 100 meters (Figure G.1). A one meter thick section perpendicular to the horizontal well is considered. The thickness of the formation at the injection site is 184 meters. The injection point is 940 meters below the sea floor, while the ocean depth at the site is 80 meters. The formation is assumed to consist of four lower permeability shale units 3 meters thick which are distributed within the high permeability sand. Each shale unit is separated by 30 meters. The well is 30 meters below the lowest shale unit, while the bottom of the aquifer is another 22 meters below the well.

\footnotetext{
\# proposed by Carl Steefel; e-mail: steefel1@1lnl.gov
} 


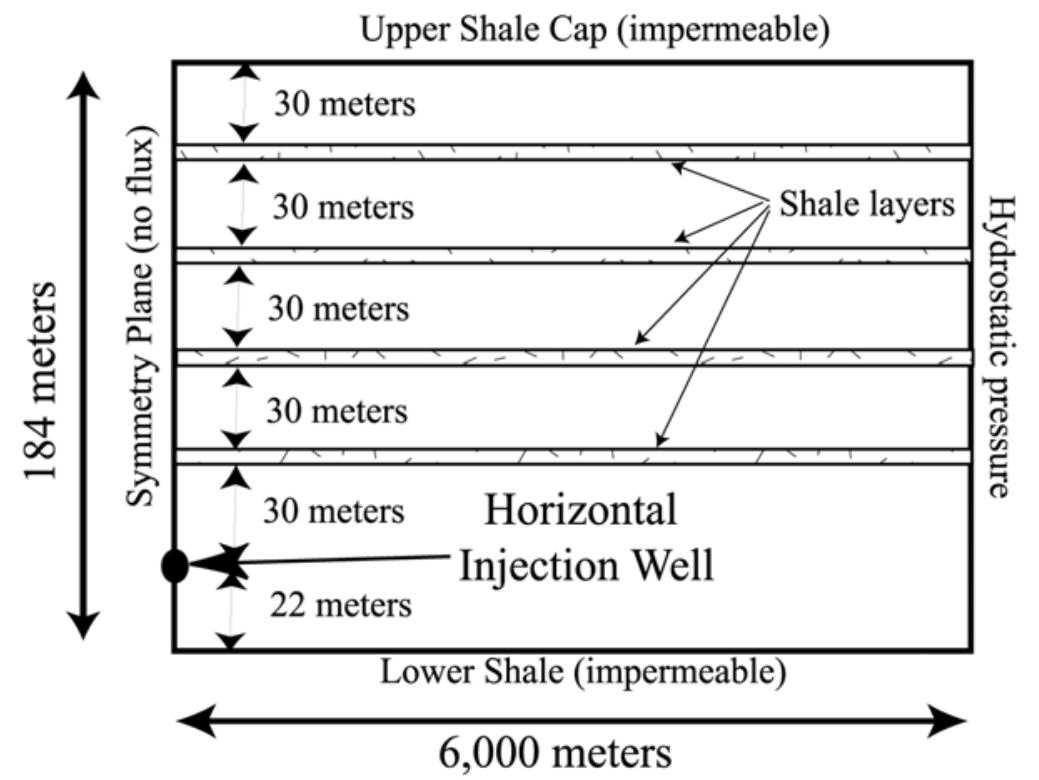

Figure G.1 Schematic representation of geometry for $\mathrm{CO} 2$ injection in Utsira Formation.

\section{Boundary conditions:}

No heat or mass flux is allowed across any of the boundaries except the vertical boundary 6,000 meters from the injection well. This boundary is fixed at hydrostatic pressure, thus allowing flow into and out of the domain so as to avoid overpressuring the formation. The 6,000 meter boundary is chosen, however, to be far enough from the injection well that the $\mathrm{CO}_{2}$ does not reach this boundary after 2 years of injection.

Initial conditions (Table G.1):

a) $\mathrm{T}=37{ }^{\circ} \mathrm{C}$ (isothermal throughout)

b) $\mathrm{P}=$ hydrostatic (approximately 110 bars at injection point, approximately 90 bars at top of formation).

c) $\mathrm{CO}_{2}$ in the aqueous phase in equilibrium with a $\mathrm{P}_{\mathrm{CO} 2}$ of 0.5 bars, a typical value for sedimentary formation waters at the temperature we are considering.

Table G.1 Initial conditions and injection specifications

\begin{tabular}{|l|l|}
\hline Pressure at well & $110 \mathrm{bar}$ \\
\hline Temperature & $37^{\circ} \mathrm{C}$ \\
\hline Salinity & $3.2 \mathrm{wt} .-\% \mathrm{NaCl}$ \\
\hline $\mathrm{CO} 2$ injection rate & $0.1585 \mathrm{~kg} / \mathrm{s}$ in half space \\
\hline
\end{tabular}


Injection specifications (Table G.1):

a) Temperature $=37^{\circ} \mathrm{C}$

b) Injection rate: $31.7 \mathrm{~kg} / \mathrm{s}$ over entire screen length (100 meters), corresponding to $0.317 \mathrm{~kg} / \mathrm{s}$ for the 1 meter thick section considered. Because of symmetry, injection rate in half space is therefore $0.1585 \mathrm{~kg} / \mathrm{s}$.

c) Height of well cell: 1 meter.

d) Injection time scale: 2 years

Input data (Table G.2):

a) Capillary pressure and relative permeability described with van Genuchten parameters (both liquid and gas mobile). Porosity is $35 \%$ for sands, $10.25 \%$ for shales.

b) Fully saturated permeability ( $\mathrm{k}=3 \times 10^{-12} \mathrm{~m}^{2}$ in sand layers, $10^{-14} \mathrm{~m}^{2}$ in shales $)$

c) Density, viscosity, and solubility in water of $\mathrm{CO}_{2}$ as functions of $\mathrm{P}$ and $\mathrm{T}$ (Span and Wagner, 1996).

d) Vapor-liquid equilibrium properties of water.

\section{PROBLEM VARIATIONS}

Include non-isothermal effects by making the $\mathrm{CO}_{2}$ injection temperature equal to $65{ }^{\circ} \mathrm{C}$.

\section{RESULTS TO BE CALCULATED}

Liquid and gas saturations as a function of space and time. $\mathrm{CO}_{2}$ concentration in the aqueous phase as a function of space. Gas and liquid fluxes.

\section{COMPARISON CRITERIA}

Results should match within $+/-5 \%$. 
Table G.2 Hydrogeologic parameters

\begin{tabular}{|c|c|}
\hline $\begin{array}{l}\text { Permeability } \\
\text { Porosity } \\
\text { Aquifer thickness }\end{array}$ & $\begin{array}{l}\text { Sands: } 3 \times 10^{-12} \mathrm{~m}^{2} \text {; Shales: } 10^{-14} \mathrm{~m}^{2} \\
\text { Sands: } \phi=0.35 ; \text { Shales: } \phi=0.1025 \\
184 \mathrm{~m}\end{array}$ \\
\hline Relative permeability & \\
\hline $\begin{array}{l}\text { liquid: van Genuchten function (1980) } \\
k_{r l}=\sqrt{S^{*}}\left\{1-\left(1-\left[S^{*}\right]^{1 / \lambda}\right)^{\lambda}\right\}^{2} \\
\text { irreducible water saturation } \\
\text { exponent }\end{array}$ & $\begin{array}{l}S^{*}=\left(S_{l}-S_{l r}\right) /\left(1-S_{l r}\right) \\
S_{1 \mathrm{r}}=0.20 \\
\lambda=0.400\end{array}$ \\
\hline $\begin{array}{l}\text { gas: van Genuchten function (1980) } \\
k_{r g}=\sqrt{S_{g}^{*}}\left\{1-\left(1-\left[S_{g}^{*}\right]^{1 / \lambda}\right)^{\lambda}\right\}^{2} \\
\text { irreducible gas saturation } \\
\text { exponent }\end{array}$ & $\begin{array}{l}S_{g}^{*}=\left(S_{g}-S_{g r}\right) /\left(1-S_{g r}\right) \\
S_{g r}=0.05 \\
\lambda=0.400\end{array}$ \\
\hline Capillary pressure & \\
\hline $\begin{array}{l}\text { van Genuchten function }(1980) \\
P_{\text {cap }}=-P_{0}\left(\left[S^{*}\right]^{-1 / \lambda}-1\right)^{1-\lambda} \\
\text { irreducible water saturation } \\
\text { exponent } \\
\text { strength coefficient }\end{array}$ & $\begin{array}{l}S^{*}=\left(S_{l}-S_{l r}\right) /\left(1-S_{l r}\right) \\
\mathrm{S}_{\mathrm{lr}}=0.20 \\
\lambda=0.400 \\
\text { Sand: } \mathrm{P}_{0}=3.58 \mathrm{kPa} ; \text { Shale: } \mathrm{P}_{0}=62.0 \mathrm{kPa}\end{array}$ \\
\hline
\end{tabular}

\section{REFERENCES}

van Genuchten, M.Th. A Closed-Form Equation for Predicting the Hydraulic Conductivity of Unsaturated Soils, Soil Sci. Soc. Am. J., Vol. 44, pp. 892 - 898, 1980.

Span, R. and W. Wagner. A New Equation of State for Carbon Dioxide Covering the Fluid Region from the Triple-Point Temperature to $100 \mathrm{~K}$ at Pressures up to $800 \mathrm{MPa}$, J. Phys. Chem. Ref. Data, Vol. 25, No. 6, pp. 1509 - 1596, 1996. 


\section{APPendix H. Test Problem 8: CO2-Oil Displacement and Phase Behavior ${ }^{2}$}

\section{INTRODUCTION AND GENERAL DESCRIPTION}

This problem probes our ability to predict accurately the interplay of $\mathrm{CO}_{2}$-oil phase behavior and multiphase flow. $\mathrm{CO}_{2}$ is injected into an oil-containing medium under two different conditions leading to miscible and immiscible displacement. This initial problem is posed in a one-dimensional geometry so that direct comparison can be made to available analytical solutions that have been derived for the $\mathrm{CO}_{2}$-oil flow problem (Monroe et al. 1990, Orr et al. 1993). These solutions do not include the effects of capillary and hydrodynamic dispersion, but the effect of volume change on mixing will be computed.

\section{LIST OF PROCESSES BEING STUDIED}

Multiphase flow of $\mathrm{CO}_{2}$ and oil subject to relative permeability and phase behavior effects.

Development of miscibility in $\mathrm{CO}_{2}$-oil systems.

Numerical formulations for density, viscosity, and $\mathrm{CO}_{2}$ solubility in oil.

Degree of numerical dispersion in numerical solutions.

\section{DEFINITION OF THE PROBLEM AND INPUT DATA}

- Oil composition: $10 \% \mathrm{CH}_{4}, 20 \% \mathrm{C}_{4}$, and $70 \% \mathrm{C}_{10}$.

- Injected gas composition: $100 \% \mathrm{CO}_{2}$

- Injection P: case (a) $\mathrm{P}=11.0 \mathrm{MPa}$ and case (b) $\mathrm{P}=12.0 \mathrm{MPa}$.

- Injection condition: constant volumetric rate

- Temperature: $\mathrm{T}=71.1^{\circ} \mathrm{C}$ and isothermal throughout.

- Geometry: one dimensional.

- Permeability and porosity: comparisons will be made in nondimensional form and so need not be specified.

- Relative permeability: $\mathrm{k}_{\mathrm{rg}}=\left(\frac{\mathrm{S}_{\mathrm{g}}}{1-\mathrm{S}_{\mathrm{or}}}\right)^{2} ; \mathrm{k}_{\mathrm{ro}}=\left(\frac{1-\mathrm{S}_{\mathrm{g}}-\mathrm{S}_{\mathrm{or}}}{1-\mathrm{S}_{\mathrm{or}}}\right)^{2}$ where $\mathrm{S}_{\mathrm{or}}=0.2$

- Phase behavior: Reference results will be computed from the Peng-Robinson equation of state (Peng and Robinson, 1976) with the critical properties, volume corrections, and interaction coefficients tabulated by Orr et al. (1993). For comparison purposes, any phase behavior package can be employed.

2 proposed by Tony Kovscek; email: kovscek@ pangea.stanford.edu 


\section{PROBLEM VARIATIONS}

Extend to more than 4 components to examine degree of chromatographic separation of various components. Include other combustion gases and $\mathrm{N}_{2}$ in the injection gas. Examine the accuracy of prediction of the minimum miscibility pressure.

\section{DEFINITION OF RESULTS TO BE CALCULATED}

Saturation and composition profiles along the one-dimensional medium. For consistency the abscissa should be $\mathrm{x}_{\mathrm{D}} / \mathrm{t}_{\mathrm{D}}$ where the dimensionless distance, $\mathrm{x}_{\mathrm{D}}$, is defined as $\mathrm{x} / \mathrm{L}$, the dimensionless time, $t_{\mathrm{D}}$, is $\mathrm{q}_{\mathrm{inj}} \mathrm{t} / \mathrm{fAL}$, and $\mathrm{A}$ is the cross-sectional area of the medium.

\section{COMPARISON CRITERIA}

Profiles should reproduce the location of saturation and composition shocks within $\pm 5 \%$.

\section{REFERENCES}

Monroe, W.W., M.K. Silva, L.L. Larson, and F. M. Orr, Jr., 1990, Composition Paths in Four Component Systems: Effect of Dissolved Methane on $1 \mathrm{D} \mathrm{CO}_{2}$ Flood Performance, SPE Res. Eng., Aug, 423-432.

Orr, F, M, Jr., R. T. Johns, and B. Dindoruk, 1993, Development of Miscibility in Four-Component $\mathrm{CO}_{2}$ Floods, SPE Res. Eng., May, 135-142.

Peng, D. Y. and D. B. Robinson, 1976, A New Two Constant Equation of State, Ind. Eng. Chem. Fund., 15, 59-64. 